\title{
Atmospheric Relative Concentrations in Building Wakes
}

Manuscript Completed: April 1995

Date Published: May 1995

\section{Prepared by}

J. V. Ramsdell, Jr., C. A. Simonen, S. B. Smyth

J. Y. Lee, NRC Technical Monitor

Pacific Northwest Laboratory

Richland, WA 99352

\section{Prepared for}

Division of Radiation Safety and Safeguards

Office of Nuclear Regulatory Research

U.S. Nuclear Regulatory Commission

Washington, DC 20555-0001

NRC Job Code L2648 


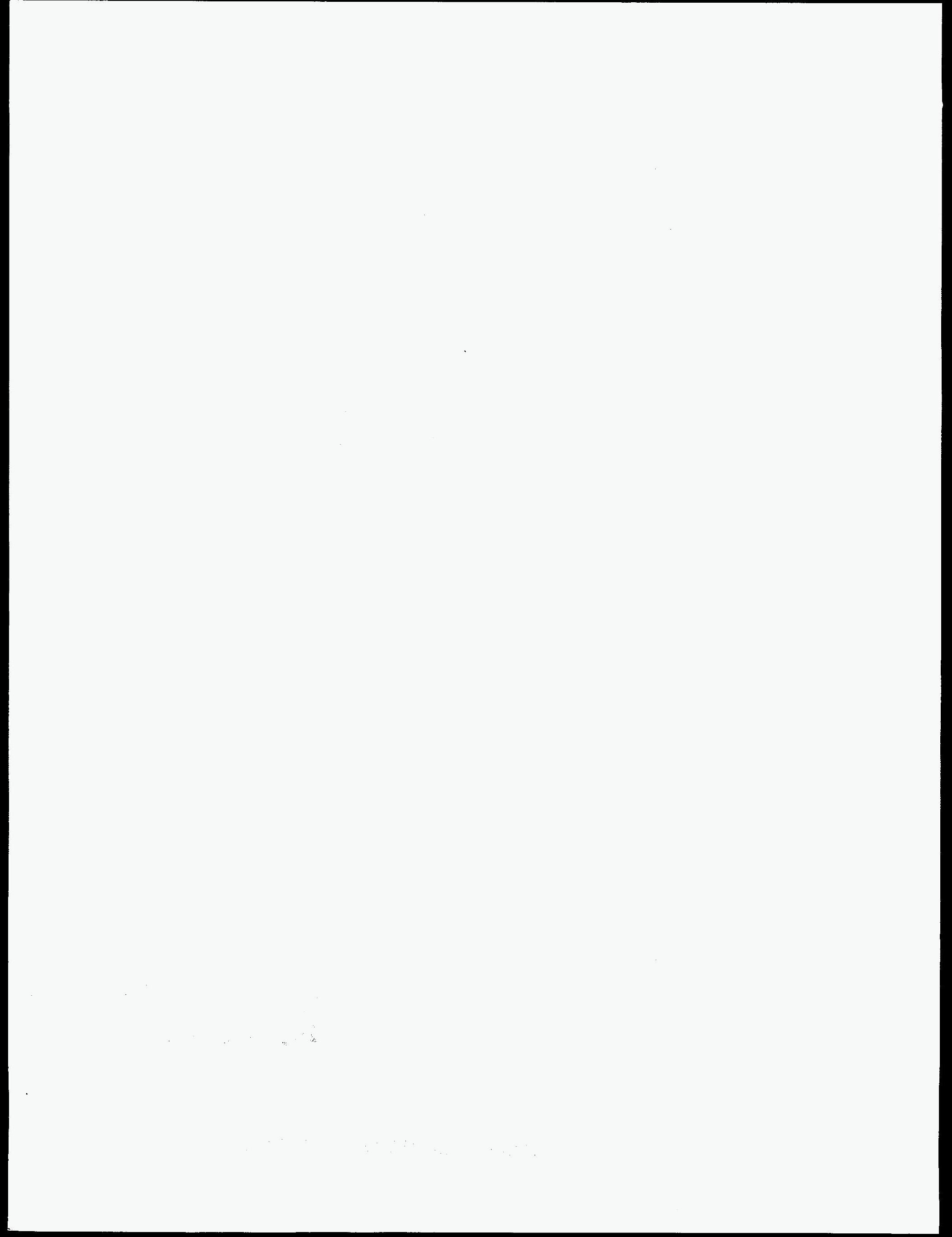




\section{DISCLAIMER}

This report was prepared as an account of work sponsored by an agency of the United States Government. Neither the United States Government nor any agency thereof, nor any of their employees, make any warranty, express or implied, or assumes any legal liability or responsibility for the accuracy, completeness, or usefulness of any information, apparatus, product, or process disclosed, or represents that its use would not infringe privately owned rights. Reference herein to any specific commercial product, process, or service by trade name, trademark, manufacturer, or otherwise does not necessarily constitute or imply its endorsement, recommendation, or favoring by the United States Government or any agency thereof. The views and opinions of authors expressed herein do not necessarily state or reflect those of the United States Government or any agency thereof. 


\section{DISCLAIMER}

Portions of this document may be illegible in electronic image products. Images are produced from the best available original document. 


\begin{abstract}
This report documents the ARCON95 computer code developed for the U.S. Nuclear Regulatory Commission Office of Nuclear Regulatory Research for use in control room habitability assessments. The document includes a user's guide to the code, a description of the technical basis for the code, and a programmer's guide to the code. The ARCON95 code uses hourly meteorological data and recently developed methods for estimating dispersion in the vicinity of buildings to calculate relative concentrations at control room air intakes that would be exceeded no more five percent of the time. These concentrations are calculated for averaging periods ranging from one hour to 30 days in duration. Relative concentrations calculated by ARCON95 are significantly lower than concentrations calculated using the currently accepted procedure when winds are less than two meters per second. For higher wind speeds, ARCON95 calculates about the same concentrations as the current procedure.
\end{abstract}





\section{Contents}

Abstract $\ldots \ldots \ldots \ldots \ldots \ldots \ldots \ldots \ldots \ldots \ldots \ldots \ldots \ldots \ldots \ldots \ldots \ldots \ldots$

Acknowledgements $\ldots \ldots \ldots \ldots \ldots \ldots \ldots \ldots \ldots \ldots \ldots \ldots$ viii

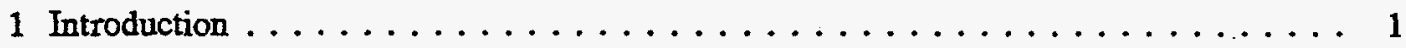

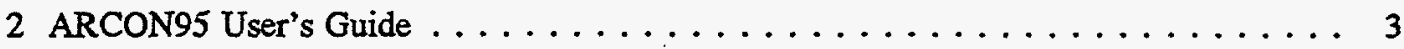

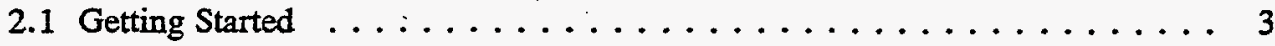

2.1.1 Hardware Requirements $\ldots \ldots \ldots \ldots \ldots \ldots \ldots \ldots$

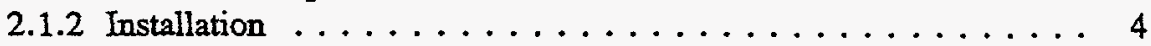

2.2 Running ARCON95 ... . . . . . . . . . . . . 5

2.2.1 The User Interface . . . . . . . . . . . . 6

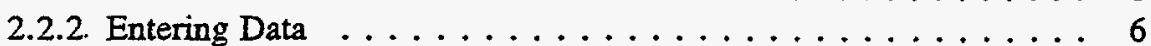

2.2 .3 Exiting ARCON95 $\ldots \ldots \ldots \ldots \ldots \ldots \ldots \ldots$

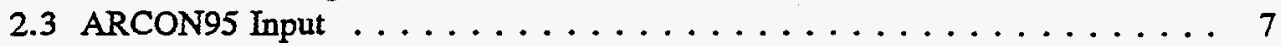

2.3.1 Input Data File Name . . . . . . . . . . . 8

2.3.2 Scenario Description . . . . . . . . . . . . . 10

2.3.3 Meteorological Data . . . . . . . . . . . . . 12

2.3 .4 Receptor Data . . . . . . . . . . . . . . . 15

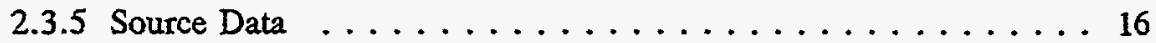

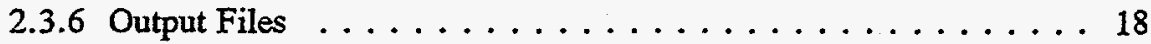

2.3 .7 Default Data . . . . . . . . . . . . . . . 19

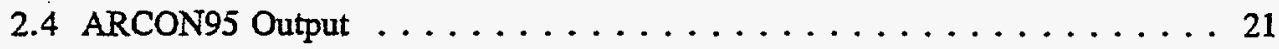

2.4 .1 Header . . . . . . . . . . . . . . . . 21

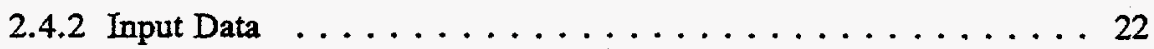

2.4 .3 ARCON95 Results . . . . . . . . . . . 23

2.5 Examples ......................... 25

2.5.1 Example 1 - Ground-Level Release . . . . . . . . . 25

2.5.2 Example 2 - Uncapped Vent Release . . . . . . . . 25

2.5.3 Example 3 -- Capped Vent Release . . . . . . . . . . 29

2.5.4 Example 4 -. Stack Release . . . . . . . . . . . . 29

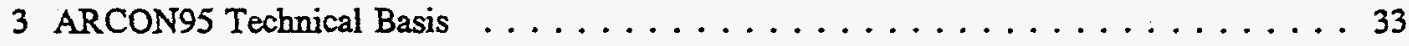

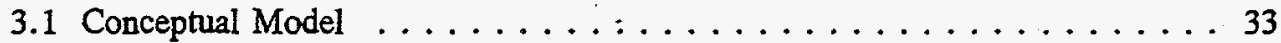

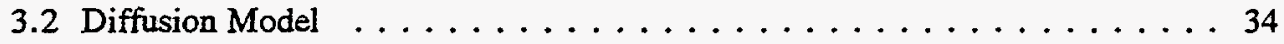

3.3 Calm Winds . . . . . . . . . . . . . . . . . 39

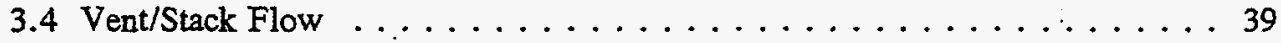

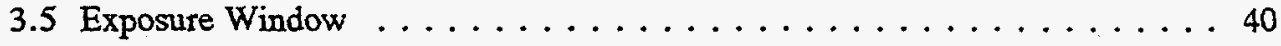

3.6 Averaging Methods . . . . . . . . . . . . . . . 40

3.7 Relative Concentrations for Standard Intervals . . . . . . . . . . 40

3.8 Missing Data $\ldots \ldots \ldots \ldots \ldots \ldots \ldots \ldots \ldots \ldots \ldots \ldots \ldots \ldots \ldots \ldots$

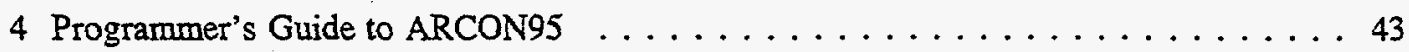

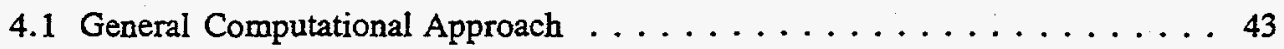

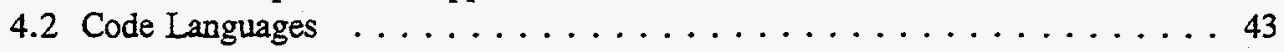

4.3 Coding Standards . . . . . . . . . . . . . . . 43 


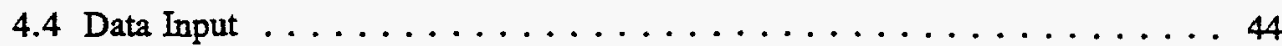

4.4 .1 Run Specification File . . . . . . . . . . . . . . 45

4.4.2 Meteorological Data Files ................45

4.5 Model Output . . . . . . . . . . . . . . . . 46

4.6 Program Description . . . . . . . . . . . . . . . . . 47

4.6 .1 ARCON95 . . . . . . . . . . . . . . . 48

4.6 .2 Subroutine CURVEFIX . . . . . . . . . . . 50

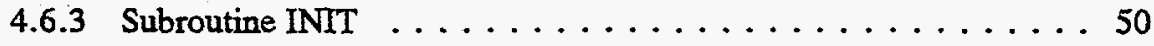

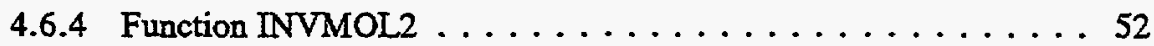

4.6.5 Subroutine METREAD $\ldots \ldots \ldots \ldots \ldots \ldots \ldots \ldots \ldots \ldots$

4.6 .6 Subroutine NSIGMA . . . . . . . . . . . 52

4.6 .7 Subroutine PROC . . . . . . . . . . . . 53

4.6 .8 Subroutine RECORD $\ldots \ldots \ldots \ldots \ldots \ldots \ldots \ldots \ldots$

4.6 .9 Subroutine SCENREAD $\ldots \ldots \ldots \ldots \ldots \ldots \ldots \ldots \ldots$

4.6 .10 Subroutine SHIFT $\ldots \ldots \ldots \ldots \ldots \ldots \ldots \ldots$

4.6 .11 Subroutine SUMMARY $\ldots \ldots \ldots \ldots \ldots \ldots \ldots$

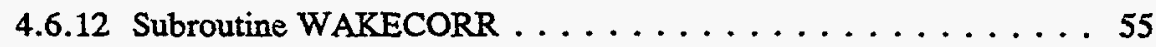

4.6.13 Subroutine WINDYXOQ $\ldots \ldots \ldots \ldots \ldots \ldots \ldots$

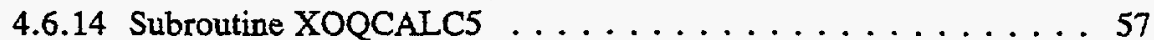

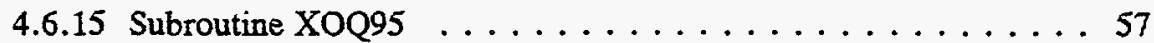

4.7 Quality Assurance $\ldots \ldots \ldots \ldots \ldots \ldots \ldots \ldots$. . . . . . . . . . . . . . .

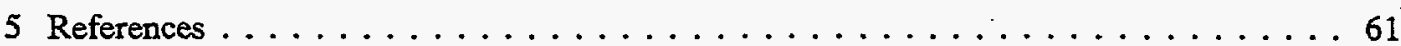

Appendix A ARCON95 FORTRAN Computer Code $\ldots \ldots \ldots \ldots \ldots \ldots \ldots \ldots$

A.1 ARCON95 ..................... 65

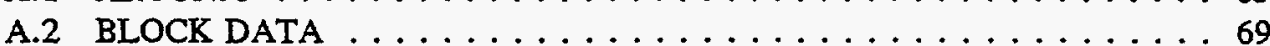

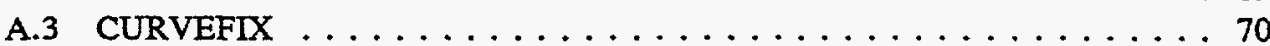

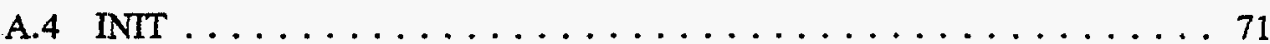

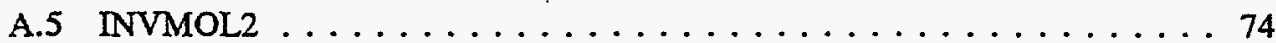

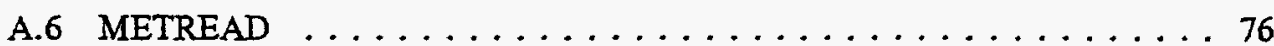

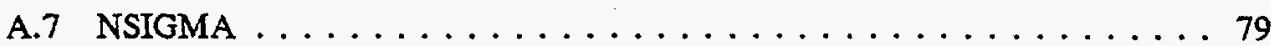

A.8 $\quad$ PROC $\ldots \ldots \ldots \ldots \ldots \ldots \ldots \ldots \ldots \ldots \ldots \ldots \ldots \ldots \ldots \ldots$

A.9 RECORD . . . . . . . . . . . . . . . . 83

A.10 SCENREAD . . . . . . . . . . . . . . . 86

A.11 SHIFT . . . . . . . . . . . . . . . . . 89

A.12 SUMMARY . . . . . . . . . . . . . . . 90

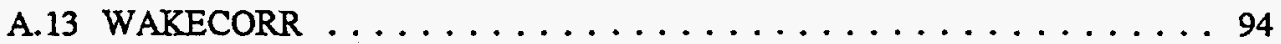

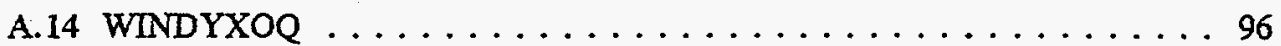

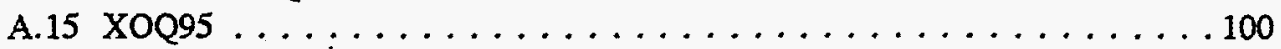

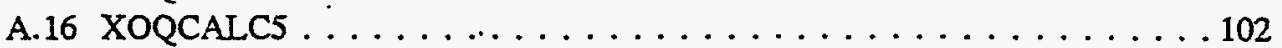

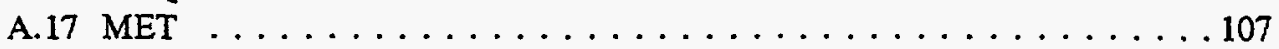

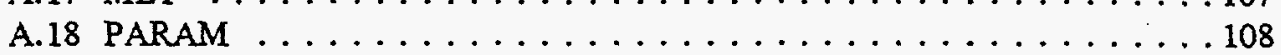

A.19 SCENARIO . . . . . . . . . . . . . . . . . 108

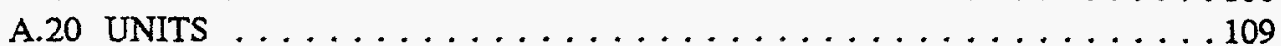

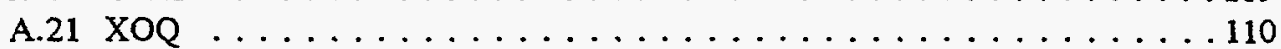

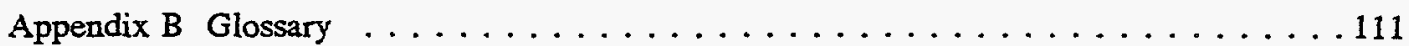




\section{Acknowledgements}

This report is the culmination of work on diffusion in vicinity of buildings that began in the mid 1980s. The work has been conducted as part of several projects. The contributions of the NRC staff, NRC Technical Monitors, and NRC Project Managers have been significant. They have asked pointed questions, made suggestions, and insisted that the work remain focussed on the control room habitability assessments. I would like to thank the NRC staff members, past and present who have contributed to this work. These individuals include the current Technical Monitor, Jay Lee, and Project Manager, A. K. Roecklein. Project Managers and Technical Monitors on earlier projects included Charles Ferrell, Jim Fairobent, and Irv Spickler. Other NRC staff members who have assisted in the work include Jack Hayes and Barry Zalcman.

I would like to thank other individuals have had significant roles in development of this code. These individuals include Ray Hosker, Atmospheric Transport and Diffusion Division of NOAA's Air Resources Laboratory; Jerry Sagendorf, Air Resources Laboratory; Bill Petersen and Alan Huber U.S. Environmental Protection Agency; David Wilson, Department of Mechanical Engineering, University of Alberta; and Frank Gifford, who reviewed the development and evaluation of the mathematical models that are implemented in ARCON95. In addition, I would like to thank Doug Akers at the Idaho National Engineering Laboratory, who tested several versions of the code. 
Introduction

\section{Introduction}

General Design Criterion 19 of 10 CFR 50, Appendix A sets forth the requirements for control rooms at nuclear power plants. This criterion states that "Adequate radiation protection shall be provided to permit access and occupancy of the control room under accident conditions without personnel receiving radiation exposures in excess of 5 rem...." The code described in this manual, Atmospheric Relative CONcentrations in Building Wakes (ARCON), is a tool for use by the U.S. Nuclear Regulatory Commission (NRC) staff in their review of licensee submittals related to control room habitability.

ARCON implements a model for calculating concentrations in the vicinity of buildings developed by the Pacific Northwest Laboratory (PNL) a previous contract with NRC. A preliminary version of the code was tested by NRC staff and contractors. The present version of the code is called ARCON95 to distinguish it from the test version. This manual deals specifically with the ARCON95 code.

Following this introduction, the ARCON95 code documentation is divided into three parts. The first part of the documentation is a user's guide to the ARCON95 code. It contains the information needed to install and run the code. The user's guide includes four example problems that illustrate application of the code and highlight some results that might not be expected. The second part describes the technical basis for the code. The technical basis information is presented to provide the background material needed to properly interpret and apply the ARCON95 results. The third part is a programmer's guide to the portion of the code that performs the data manipulation and calculation. This information is provided for use by anyone who may be called upon to modify the code. 

User's Guide

\section{ARCON95 User's Guide}

This user's guide to the ARCON95 code consists of four sections. The first section will assist you in getting started. It describes the hardware requirements for and installation of the code. The second section describes how to run the code. It covers the user interface and entering data. The third section describes the input required by ARCON95. It provides a description of each.item and gives acceptable limits for the items. The fourth section contains four example problems and lists partial ARCON95 output for each problem.

\subsection{Getting Started}

This section of the user's guide covers the installation of the ARCON95 code on your computer. The code is supplied on a single disk. If you have the required hardware and sufficient disk space, installation of the code will be a simple matter.

\subsubsection{Hardware Requirements}

ARCON95 runs on personal computers using the $80 \times 86$ processor (IBM compatible computer) with a math coprocessor. To ensure that the program will run correctly, the computer must have the following

- a high density floppy disk drive (either 3.5 or 5.25 inch disks) and a hard disk

- 640 kilobytes of memory

- a VGA color monitor

- a mouse.

Running ARCON95 requires more than 470 kilobytes of free memory. If ARCON95 will not ran, check to see if there is sufficient available memory. An error message will be displayed on the monitor. However, the message may flash by so rapidly that it isn't readable. If the program creates a run specification file containing the input data but doesn't read the meteorological data or create output files, insufficient memory is likely to be the problem.

A VGA color monitor is needed by the programs used for data input. They require a monitor that can display 50 lines of text. If the ARCON95 is run on a computer with a monochrome monitor, the colors used in the input programs may make it difficult to distinguish some of the controls used in the programs.

A mouse is recommended. It facilitates moving through the program and selecting program options. However, ARCON95 can be run on computers without a mouse. If a mouse is not available, options can be selected using the TAB key or by pressing the key associated with the highlighted letter in the desired option.

If neither a color monitor or a mouse are available, ARCON95 may be run by bypassing the shell programs used for data input. An ASCII text editor can be used to create the user input file that controls ARCON95. This file is called the run specification file. ARCON95 may then be run by typing "ARCONF" followed by a space and then the name of the run 
specification file. The contents and format of the run specification file are described in Section 4.4.1.

\subsubsection{Installation}

The ARCON95 code consists of five files:

- ARCON95.BAT

- ARCONVB.EXE

- ARCONVB2.EXE

- ARCONF.EXE

- ARCHELP.TXT.

These files must be placed in the subdirectory from which the program is to be run. Other files used and generated by the program may be placed in other subdirectories, if desired. ARCON95 supports path names of up to 40 characters for meteorological data and output files. Problems in program execution may arise if the program is embedded too deeply in a directory structure.

An installation program is included with the ARCON95 code. This program will create an ARCON95 directory and copy the program files from the installation disk to the ARCON95 directory. To run the installation program, place the ARCON95 installation disk in your computer disk drive and make the drive containing the installation disk the active drive by typing the drive letter followed by a colon at the prompt.

The installation program is started by typing A95_INST followed by the path to the directory to where the program is to be installed on the command line. The installation command has the general form

A95_INST Name1 Name2 Name3 Name4.

where A95_INST is the name of the installation program and names Name1 through Name4 define the path to the installation directory. There must be spaces between the installation program name and the directory names.

The command line entry to install ARCON95 from a disk in the B: drive to directory C: \ARCON95\CODE would appear as

$$
\text { B:1>A95_INST C: } \backslash \text { ARCON95 CODE }
$$

The first name in the path must contain both the drive designation and the backslash. The remaining names do not require the backslash. It will be provided by the program. The installation program supports a path that includes four subdirectory levels. You must specify at least one name; it is not necessary to specify more than one.

When the installation program begins, it will create the directories listed on the command line, working from left to right across the command line. If a directory exists, its existence will be 
noted and the program will move to the next level. This process will continue until the final subdirectory in the path is reached. The program will then copy all files on the installation disk to the subdirectory.

Additional subdirectories may be created to hold the meteorological data files used by ARCON95 and to receive the output files generated by ARCON95. You will have to create these directories manually

No customization is required after files have been copied to the appropriate subdirectories; the program may be run by typing "ARCON95" at the DOS prompt. However, if you normally run your computer console in a 43- or 50-line mode, you may wish to customize the ARCON95.BAT file. The mode commands in ARCON95.BAT change the console to the 50line mode prior to running ARCON95, and then change the console to the 25-line mode when ARCON95 is complete. If you normally run in the 50-line mode, both of the mode commands in ARCON95.BAT may be deleted. If you normally run in the 43-line mode, the second mode command should be changed from

mode con lines $=25$

to

mode con lines $=43$.

Any text editor that produces ASCII files, for example the editor invoked by the DOS EDIT command, may be used to make this change.

\subsection{Running ARCON95}

ARCON95 runs from a Visual Basic shell under the DOS operating system. The shell provides a graphical user interface for data entry and initiates execution of the computational program. When computations are complete, the shell permits revision of input for a new set of computations. This section describes the procedures for running ARCON95 within the Visual Basic shell.

To start ARCON95, set the default directory to the subdirectory where the ARCON95 program files are installed. For example, if ARCON95 is installed on the C: drive in a subdirectory named ARCON95, type cd ARCON95 at the C:1> prompt. You should see

$$
\text { C: } 1>\text { cd ARCON95 }
$$

When you press $<$ ENTER $>$, the prompt will change to

\section{C: \ARCON95>}

to indicate that you are in the ARCON95 directory. ARCON95 may then be run by typing ARCON95 and pressing <ENTER>. This will start ARCON95. 


\subsubsection{The User Interface}

This section presents general information about interacting with the computer to run ARCON95. The Visual Basic shell program consists of a series of screens that provide information about ARCON95 and accept input required for the calculations. Online help is available during data entry if you are using a mouse. Help is obtained by clicking on the word Help in the menu bar at the top of the screen.

\subsubsection{Entering Data}

ARCON95 is designed to be run with a mouse. In general, the instructions that follow will assume that you are using a mouse. However, there are keyboard substitutes for the mouse actions required to run the program. ARCON95 uses several methods to obtain input. These methods are

- command buttons

- text boxes

- choice lists

Command buttons initiate some sort of action. To activate a command button, place the mouse cursor on the button and click with the left button on the mouse. If you are not using a mouse, you activate a command button by using the $\langle\mathrm{TAB}>$ key to highlight the button and then pressing <ENTER>. You can tell when a command button becomes active because its appearance will change.

Command buttons are labelled. The labels include OK, CONTINUE, and YES and NO. These labels are self explanatory. There are five additional buttons that have meanings that are less obvious. The CANCEL button causes the program to return to the previous input screen without saving any of the data that you have entered or modified. The File Search button appears when you are asked to enter the name of an input data file. If you click on the File Search button when it appears you will be presented with two windows. One of the windows allows you to change directories, and the other lists names of files. Use of these windows will be described later. The DONE button appears on data entry forms. It is used to save the data you have entered when you are finished entering data. The last two buttons VALUES and RUN are found at the bottom of the main data entry screen. After all data have been entered, the VALUES button is used to have ARCON95 check to see that all required data have been entered and are within range. After the values have been checked, the RUN button is used to initiate calculations.

Text boxes are used for entering either text or numerical information. The information is entered from the keyboard. You make a text box active by clicking on the box, or using the $\langle\mathrm{TAB}\rangle$ key. When you move from a text box after entering data, ARCON95 will check the entry to ensure that it is proper. If an improper entry is detected, a message box will appear and you will be returned to the text box where the error is.

Choice lists are used to obtain information when the number of options is small. A choice list is used to specify the wind speed units and another choice list is used to enter the release type. 
After you activate the choice list, you can move within the list using either the mouse or the up and down arrow keys.

There is a menu bar at the top of data input screens. You must have a mouse to use the menu bar. The menu bar lists three options - Input, Help, and Quit. You use the menu bar by clicking on a listed item to you can gain access to the item. The Input option provides access to data input forms after data have been entered and saved. It also provides access to several model parameters that have default values that are not likely to need changing in routine application of ARCON95. The Help option activates ARCON95 Help. If you bave questions about entering specific data items, you may be able to find an answer in Help without leaving the program or without having to find this manual. The final option on the menu bar is Quit. Quit is used to exit the Visual Basic shell program without running ARCON95 or saving any data. You leave the program by clicking on Quit.

\subsubsection{Exiting ARCON95}

The method used to exit ARCON95 depends on where you are in the program. If you are at the title or disclaimer screen, you exit the program by using the CANCEL button. Between the disclaimer screen and the scenario input screen, use the CANCEL button to return to the title screen. While you are in the scenario input screen, you exit the program by clicking on Quit in the menu bar. Finally, if you have just completed running the program, use the NO button when asked if you wish to run another scenario. When you exit ARCON95 in any of these ways, your screen will return to its initial operating mode.

If you wish to exit ARCON95 while the computational part of the code is running, you may use CONTROL-C to stop the code. If you use this method of exiting the program, your screen will be in the 50-line mode. To return your screen to the 25 -line mode, type

mode con lines $=25$

at the DOS prompt and then press <ENTER $>$.

\subsection{ARCON95 Input}

When you start ARCON95 the first screen you will see is a title screen. The title screen contains the program name and buttons that offer two choices: CONTINUE or CANCEL. Place the cursor on CONTINUE and click the left mouse button if you wish to start the program, or click on CANCEL to exit from the code and return to the DOS command line.

NOTE: If you are not using a mouse, you may use the highlighted letters in the option buttons: CONTINUE and CANCEL. By typing ALT-o (pressing the ALT button and letter o key at the same time), you will be doing the same thing as clicking the mouse on Continue. You may abort the program using the same method but substituting the letter n for o (i.e., ALT-n).

If you elect to continue, you will see a legal disclaimer. Again, you must decide to continue the program or return to the abort the program. Clicking on $\mathrm{OK}$ or pressing the <ENTER> 
key will allow the program to continue. The $\underline{\mathrm{OK}}$ button default is set to continue. Clicking on CANCEL causes program execution to stop and returns you to the DOS command line.

\subsubsection{Input Data File Name}

The first data input screen follows the disclaimer. The screen has two sets of options. The first set of options allows you to choose to recall and revise an existing input file or enter data in an entirely new file prior to running ARCON95. You select either Input New Data or Open an Existing Input File. You make your selection by placing the cursor between the appropriate parentheses and clicking the left button of the mouse. The second set of options is represented by the CONTINUE and CANCEL buttons. If you place the cursor on CANCEL and click with the left mouse button, you will return to the title screen. You may exit ARCON95 from there. Figure 1 shows this screen. If you haven't run ARCON95 before or you are starting a new analysis, you should select Input New Data before clicking on CONTINUE.

ARCON95 uses a file to transfer data entered by users to the code used for computations. This file is called the run specification file. When you click on CONTINUE after selecting Input New Data, ARCON95 displays the form used for entering the name of the run specification file name. This form is shown in Figure 2. It consists of a text box labelled "File Name:". This box suggests a file name with an .RSF extension. You enter a file name by moving the cursor to the asterisk, deleting it, and typing the name of your choice. File names are limited to eight characters. In addition, the combined length of the file name and the path to the file must be 40 characters or fewer. The boxes below the text box used for entering the run specification file name contain information about existing run specification files. The box on the left shows the names of files in the current directory with .RSF extensions, and the right-hand box shows path to the current directory. Use these boxes to ensure that you don't unintentionally overwrite an existing file, or to select an existing file that has most of the input that you need. However, be warned that if you select an existing file

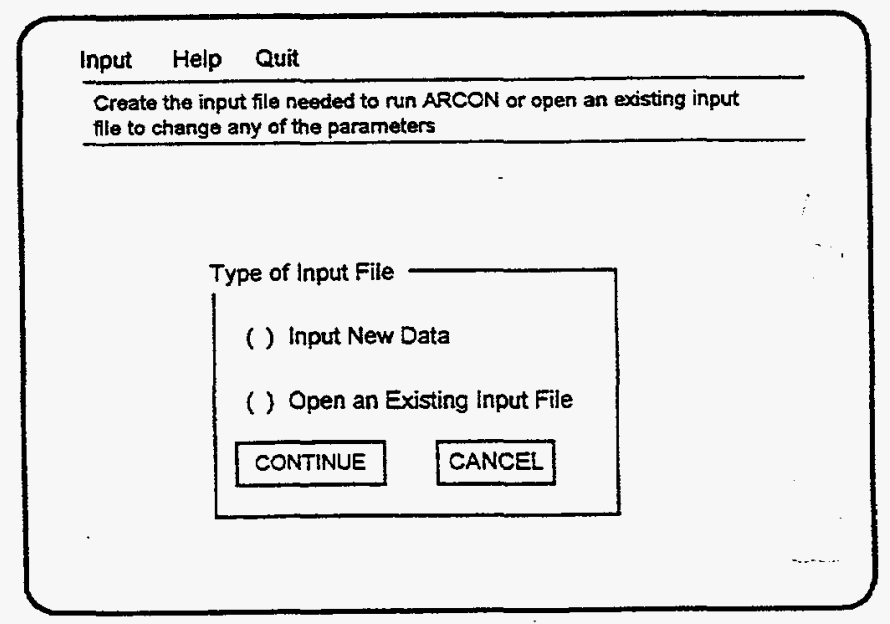

Figure 1 Input file selection screen 


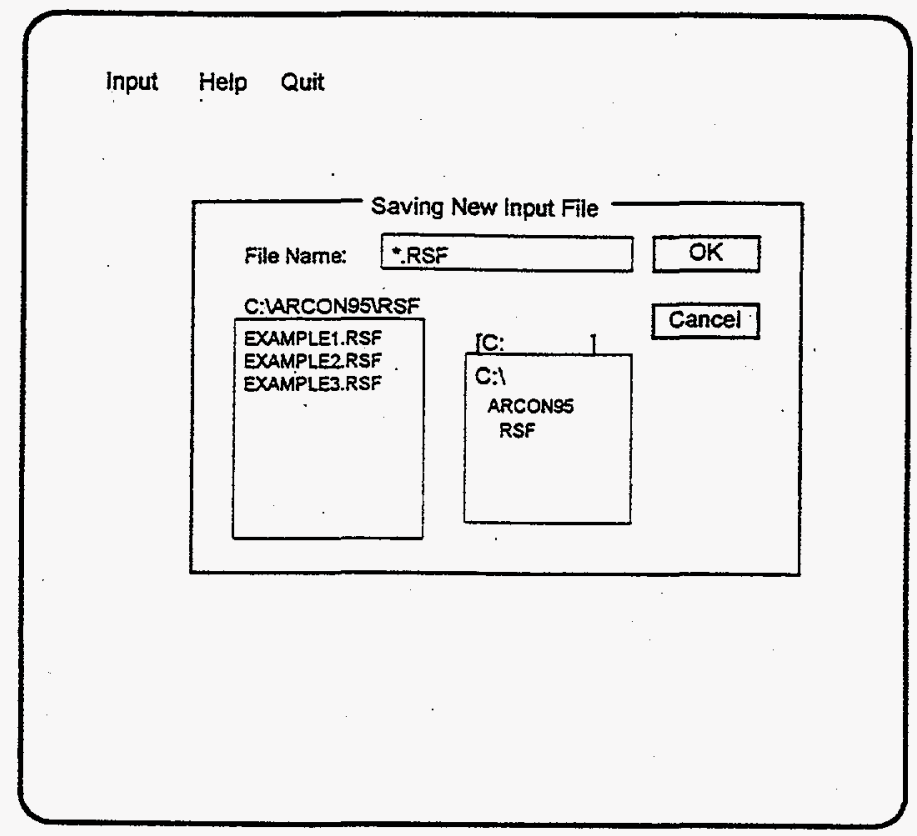

Figure 2 Run specification file name entry screen

and don't change the path or file name, the original file will be overwritten when you save your new scenario. When you have entered the file name and the appropriate path, click on the OK button to proceed to the scenario entry screen.

If you click on the CANCEL button, ARCON95 returns to the previous form where you may change your selection.

When you click on CONTINUE after selecting Open an Existing Input File, ARCON95 displays the form used for entering the name of a run specification file to be updated. This form appears to be identical to the form used for entering the name of a new run specification file except for the title displayed at the top of the form. However, the essential difference between the forms is in the responses to a click on the $\underline{O K}$ button. When you elect to modify an existing file, clicking on the OK button moves you to the forms used for entering the scenario, but an additional form overlays the scenario entry forms. This form is used to enter the name of the file to be used when saving the revised run specification file. The name of the file being revised is the default name for the revised file. If you use this name the original file will be overwritten. After you enter the new file name, you continue with data entry by clicking on the $\underline{\mathrm{OK}}$ button. 


\subsubsection{Scenario Description}

Six forms are used for entering the data for the run specification file. However, typical users will generally only enter or change values in five of the forms. Four of the data entry forms are shown in separate boxes on the Scenario Input Screen when it first appears. These boxes are labelled

- Meteorological Input

- Receptor Input

- Source Input

- Output Files.

Figure 3 shows the Scenario Input Screen without the detailed structure of the four data entry forms. You will note the menu bar at the top of the screen, the four data entry forms that cover the majority of the screen, and a box at the bottom of the screen that contains two buttons. You will also note that each of the four data entry forms has a DONE button. When you complete entering data in each form, click on the DONE button to save your entries for inclusion in the run specification file. If you don't click on the DONE button, your entries will not be saved. After you click on the DONE button the data entry form will disappear. Figure 4 shows the screen as it will appear after all data entry is complete. At this time you should click on the VALUES button to have ARCON95 check your data entries to ensure that all required data have been entered and that the data are within the acceptable range. If all required data have not been entered a warning message will appear. When you understand the message, click on $\underline{\mathrm{OK}}$.

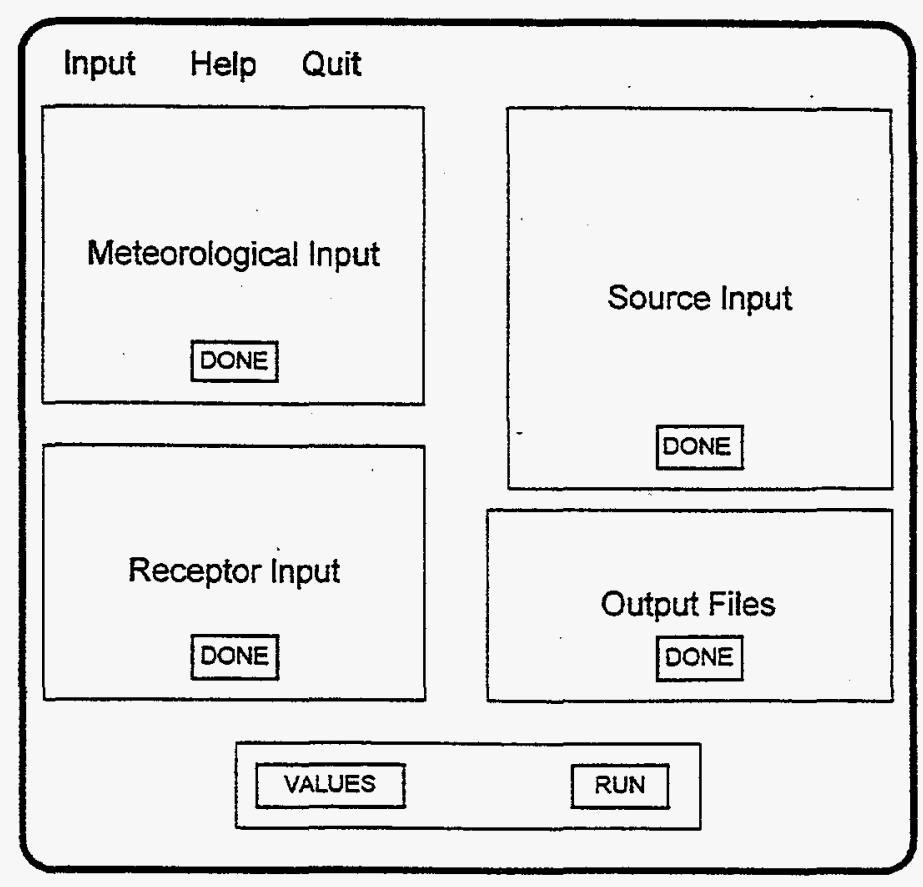

Figure 3 Scenario input screen layout 
Figure 4 Completed scenario input screen without data entry forms

If you get the warning message that indicates you must enter additional data, or if you would like to change data after clicking a DONE button, you may reopen one or more data entry forms by clicking on Input on the menu bar. Clicking on the menu bar will display a list of the six data input forms. This list is shown in Figure 5. Click on the form used for entering the data that you wish to change and the form will reappear. The Met File Name(s) data entry form is used for selecting meteorological data files. It appears after you enter the number of meteorological files in the meteorological data entry form. The Default data entry form is

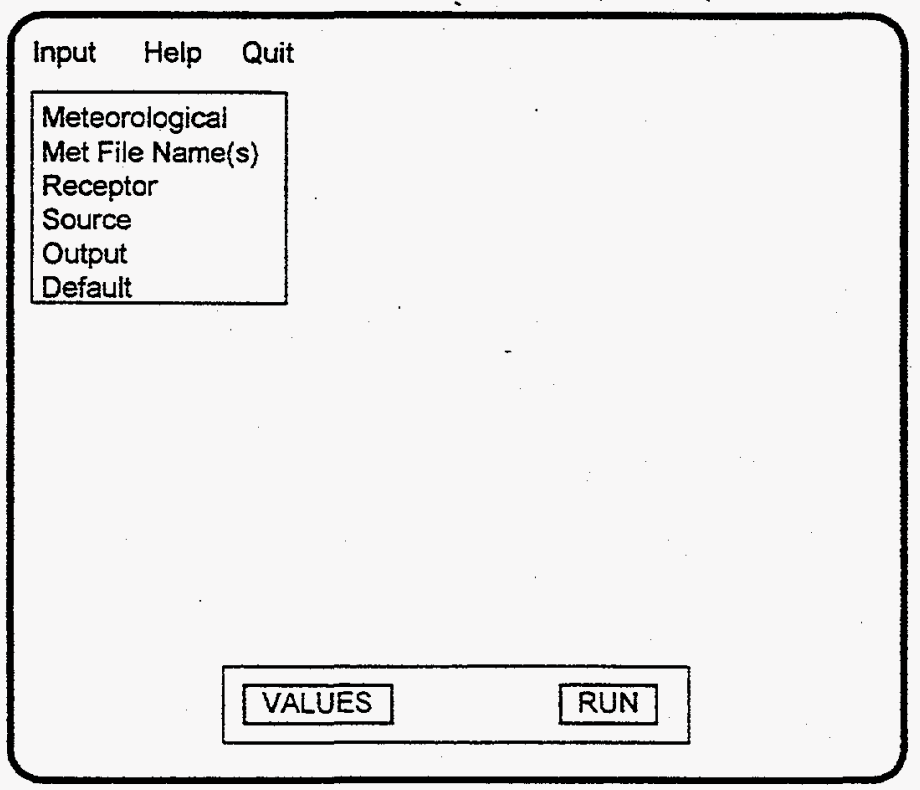

Figure 5 Input menu 
used to change model parameters that normally don't need to be modified. It only appears when requested from the Input menu. You should not alter the parameters on the Default form unless you are familiar with the technical bases for the models used in ARCON95. You may enter data in the forms in any order. However, you must enter data in every form, and the data must be within limits before ARCON95 will begin its calculations. If you enter data that is not within reason, ARCON95 will display an error message, and the text box where the value/letters were entered will be highlighted. You should correct the entry before continuing.

When you start with an existing data file, the DONE buttons will be enabled when you reach the scenario input screen signifying that a run may be started with the data as they are. If you change one or more entries, you must click on the DONE button to update data in the file. If you do not click on the DONE button, the new file will retain the data from the original file.

If you are entering data for a new file, you must click on the VALUES button to ensure that all data are entered correctly before you can start the calculations. This provides another check on the validity of the values by confirming that all the input boxes have a value. After clicking on VALUES, you will be informed on the status of the data entry. If all required information is present and within range, the RUN button will be activated. You are only required to click on the VALUES button when creating a new file, but you may use it anytime to see if all required data have been entered.

After all the data are correct, ARCON95 computations are started by clicking on the RUN button.

\subsubsection{Meteorological Data}

The Meteorological Input form is located in the upper left of the ARCON95 Scenario Input Screen. This form is shown in Figure 6. Four pieces of information are entered in this form. The first three pieces are entered in text boxes. The entry in each box should be a number. The fourth entry is made using by selecting the appropriate wind speed units from an option list.

Meteorological data are input to ARCON95 using meteorological data files. At least one meteorological data file is required, but the program will accept meteorological data as many 10 files. The meteorological data file entry form will appear after you enter the number of meteorological data files. This form is shown in Figure 7. It has a text box for entering the file name. If you are modifying an existing run specification file, the meteorological files used in the previous scenario will be used as default file names. If these files are correct, click on the DONE button. Otherwise if you know the file names you may enter the names of new files in the boxes and click on the DONE button. 
Meteorological Input

Number of Met Data Files

1

Lower Measurement Height

10.0

Upper Measurement Height

Wind Speed $\begin{aligned} & \text { ( ) } \mathrm{mph} \\ & (\text { ) } \mathrm{m} / \mathrm{s} \\ & (\text { ) knots }\end{aligned}$

DONE

Figure 6 Meteorological input form

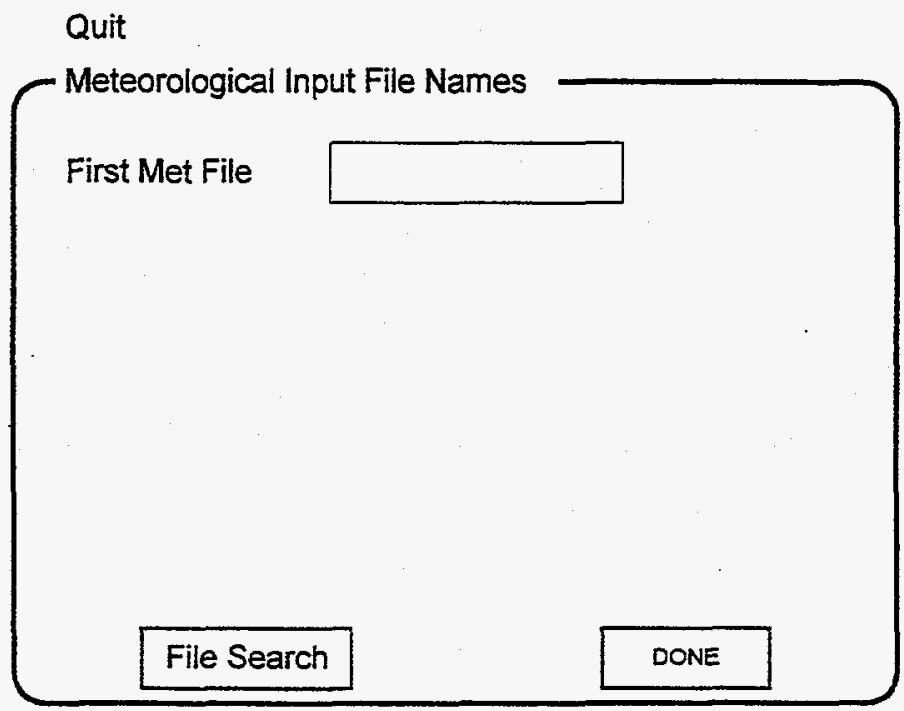

Figure 7 Meteorological input file names form

If you don't know the name of the meteorological data files, click on the File Search button. When you click on the File Search button, a form will appear that is similar to the form used for entering the run specification file name. This form, shown in Figure 8, is overlaid on the 


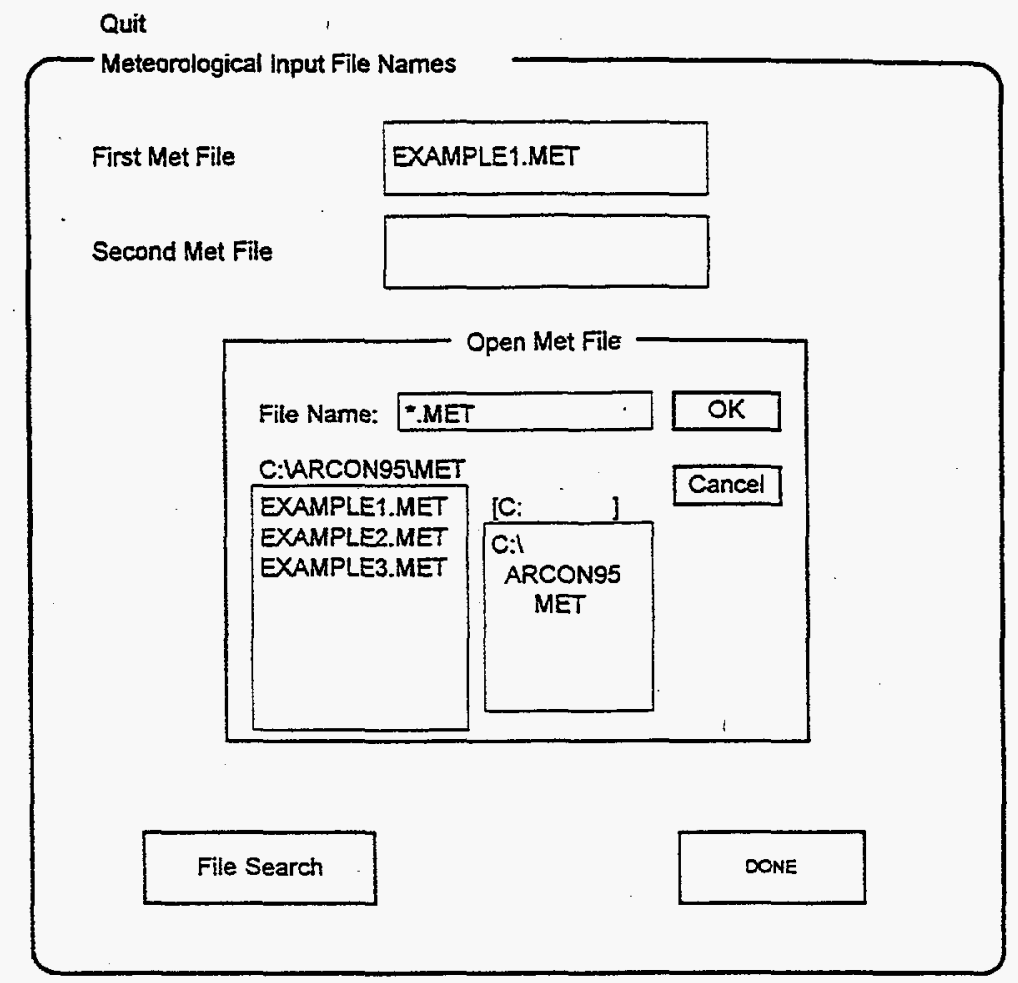

Figure 8 Meteorological input files form for two files

meteorological data file entry form. You can select a file from the list in the left hand box by clicking on the file name and then on the OK button. If the file doesn't exist in the current directory, you can use the right-hand box to change directories.

File names should be entered so that the meteorological data are in chronological order. ARCON95 assumes that the data form a continuous time series. If the data in the files are not a continuous time series, the $X / Q$ values calculated for averaging periods that are longer than one hour will be meaningless.

If you enter names manually, the file and path name combined is limited to 40 characters. File Search works in the same manner as the directory search described earlier for input file names. After you finish entering file names, click on the DONE button to return to the previous form to complete the scenario description.

You must enter a name for each meteorological file to exit from the meteorological file data entry screen in a normal manner. If you can't find a meteorological file and wish to quit ARCON95 to continue the search or create a meteorological data file, you may do so by clicking on Quit on the menu bar at the top of the screen. If you want to return to the Scenario Input Screen without quitting ARCON95, you may enter any name. 
The meteorological data files require one record per hour. Each record must include the day of the year, the hour of the day, the stability, and the wind direction and wind speed at the lower measurement level. The record may also include a five-character location identifier, and a wind direction and speed for the upper level. Section 4.4.1 provides a complete description of the meteorological data file structure.

The second and third text boxes on the Meteorological Input form are used to enter wind speed measurement heights. Enter the heights in meters. The height of the lower-level measurement may not be greater than $100 \mathrm{~m}$, and the height of the upper-level measurement may not be greater than $300 \mathrm{~m}$. If wind data are available for only a single measurement height, enter the height in the text box for the lower level.

\subsubsection{Receptor Data}

The Receptor Input Form is used to enter data related to the receptor. In control room habitability assessments the receptor is the control room air intake. The Receptor Input form, shown in Figure 9, is located in the lower left-hand corner of the Scenario Input Screen. All entries on this form are numerical values.

The distance from the source to the receptor refers to the horizontal distance between the release point and the air intake. This distance may not exceed $10,000 \mathrm{~m}$.

The intake height is the height of the intake above grade. It may not exceed $100 \mathrm{~m}$.

Elevation difference is the difference in plant grade between the positions of the intake and release. This difference will normally be zero. Enter zero if the release point and intake are on the same structure or the heights of the release point and intake are measured from the

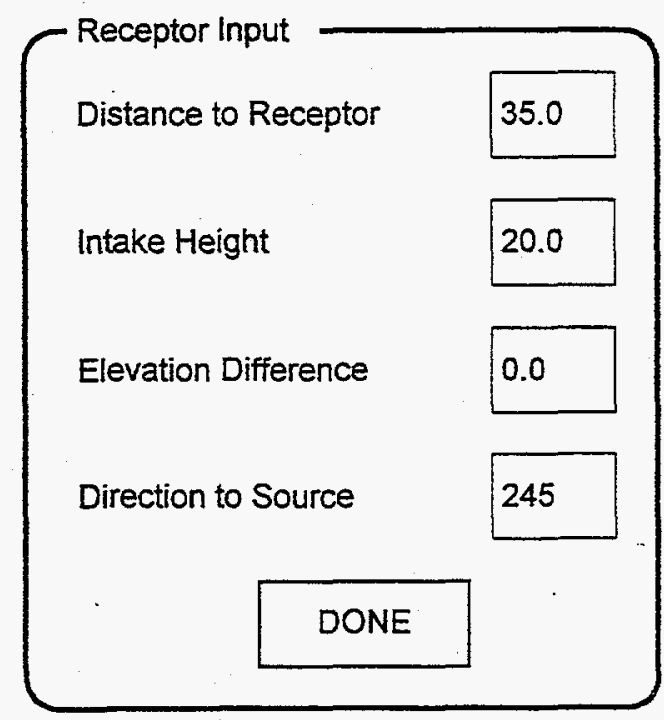

Figure 9 Receptor input form 
same reference plane. If the release point and intake are widely separated, there may be a difference in the height of the reference plane. In this case the difference in elevation should be entered. Enter the difference as a positive value if the grade elevation at the release point is higher than at the intake. If the grade elevation at the intake is higher, enter a negative value. ARCON95 will accept elevation differences from $-1,000 \mathrm{~m}$ to $+1,000 \mathrm{~m}$.

The direction from the intake to the source is the last item entered in the Receptor Input form. This direction is used to determine when the wind carries effluents from the release point to the intake. Assuming that the wind directions in the meteorological data file follow the standard convention of recording the direction from which the wind blows, you will enter the proper direction if you imagine that you are standing at the intake facing the release point. If you are looking north, enter north $\left(360^{\circ}\right)$. If you are looking southwest, enter southwest $\left(225^{\circ}\right)$, etc. ARCON95 will transform the wind direction to the transport direction for you.

The distance from the receptor to the air intake, the height of the air intake, and the difference in grade elevation between the positions of the intake and the release point must be entered in meters. The direction to the source is entered in degrees. The data may be entered in the text boxes in any order.

\subsubsection{Source Data}

Information describing the release point is entered in the Source Input form. This form, shown in Figure 10, is located in the upper right-hand corner of the Scenario Input Screen. The option list at the top of the form is used to enter a general description of release. ARCON95 uses this description in determining if your input is sufficient and if the values are within acceptable limits. It also uses this description in selection of the equations used for calculating X/Q. The text boxes below the choice list are used to enter a more detailed description of the release.

If you select a ground-level release in the choice list at the top of the Source Input form, you may enter zeros in all of the text boxes. ARCON95 will assume a ground-level release height and will not use the vertical velocity or stack radius, even if entered. However, you are likely to want to enter a building area. You must enter a building are if you want to estimate concentrations at an air intake that is in the wake of a structure using the high wind speed, building-wake corrections to the diffusion coefficients.

A release height is required if you select a vent or elevated release. It can be any value between 1 and $300 \mathrm{~m}$. ARCON95 does not compute plume rise. Therefore, if you wish to include plume rise in your calculation, you must combine plume rise with the actual stack height to get an effective stack height and enter the effective stack height in the text box in place of the actual height.

If you select either a ground-level or vent release and wish to include wake diffusion in your calculations, you must enter a building area. Building area controls the distance down wind that building-wake effects will be felt. The larger the area, the farther downwind they will be felt. However, a building area is not required. If you don't enter an area, intake concentrations will be calculated assuming normal dispersion. The range of acceptable values for building area is 0 to $10,000 \mathrm{~m}^{2}$. 


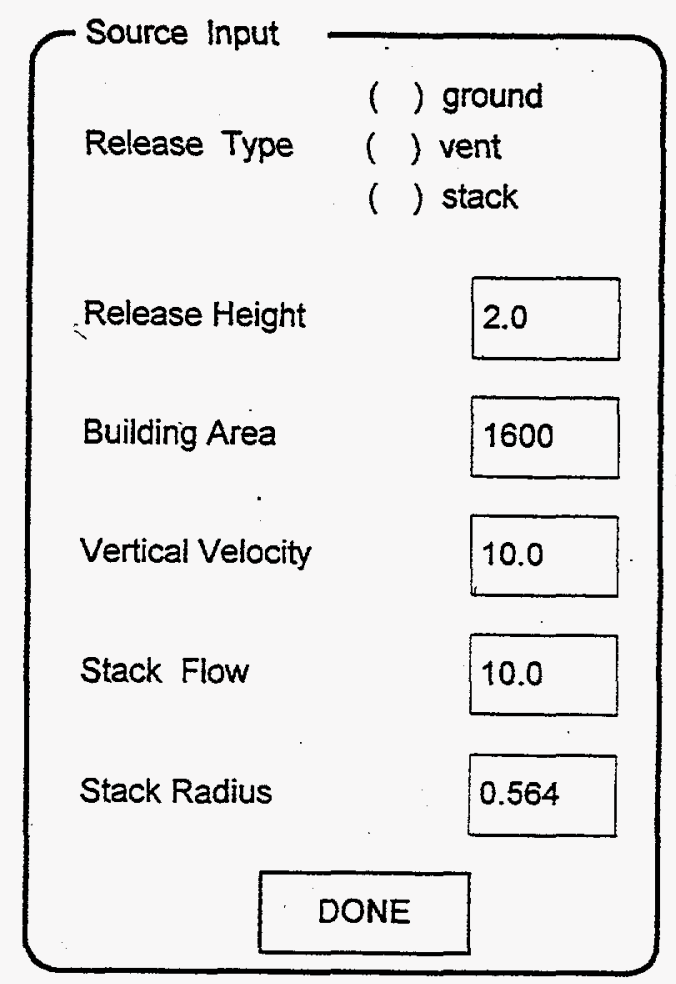

Figure 10 Source input form.

The vertical velocity is used in both vent- and elevated-release calculations. In vent release calculations, the vertical velocity of the vent exhaust is compared with the release height wind speed to determine how much of the exhaust enters the building wake. When the ratio of vertical velocity to the wind speed exceeds 5 , the exhaust rises above the wake; when the ratio is less than 1, the exhaust is completely trapped in the wake, and at intermediate ratios, part of the exhaust enters the wake. In elevated-release calculations, the vertical velocity is used to determine if the stack height should be reduced to account for downwash. Downwash is included in the calculation whenever the ratio of the vertical velocity to the release height wind speed is less than 1.5. ARCON95 accepts vertical velocities ranging from 0 to $50 \mathrm{~m} / \mathrm{s}$. A vertical velocity of zero should be entered if the vent is capped.

The stack flow is used in model calculations whenever entered. Its function is to ensure that effluent concentrations in the atmosphere are always less than the concentration at the release point. The closer together the release point and receptor are and the larger the flow, the more important it is to include the flow in the calculations. ARCON95 accepts flows ranging from 0 to $100 \mathrm{~m}^{3} / \mathrm{s}$.

The last entry in the Source Input form is for the stack radius. Stack radius is used only in elevated release calculations. It determines the maximum stack height reduction during downwash conditions. ARCON95 will accept stack radius entries from 0 to $10 \mathrm{~m}$. 
In reality, the stack or vent exit velocity, stack flow, and stack radius are related. However, the stack or vent exit velocity is not necessarily directed in the vertical. Vents are frequently capped or horizontal. Therefore, ARCON95 does not check to make sure that these three entries are consistent. You must do that.

\subsubsection{Output Files}

The Output Files form shown in Figure 11 is the fourth form on the Scenario Input Screen. It is located in the lower right-hand corner of the screen. This form is used to specify the names of two files to receive the normal ARCON95 output.

The name of the file to receive the primary output is entered in the Output File text box. When the run is complete, this file will contain heading information related to the ARCON95 code, the date and time that the code was run (if the date and time in the computer's clock are correct), a listing of the input to the code, and the output from the code. The output from the code includes the number of hours of data processed by the code, the number of hours of missing data, the range of predicted concentrations for hourly concentrations, the 95 th percentile concentration estimates.

The CFD File Name box is used to enter a name for the file to receive the cumulative frequency distributions of the concentrations calculated for ten averaging intervals. This file is designed to be imported into a spreadsheet for further data analysis and display. These distributions may be used to determine median concentrations, and concentrations at representative of other percentiles. You must enter a name for the primary output file; but entering the CFD file name is optional. ARCON95 will allow you to run the code if you don't enter a CFD file name. However, you will be required to enter a name for the file when ARCON95's calculations are complete.

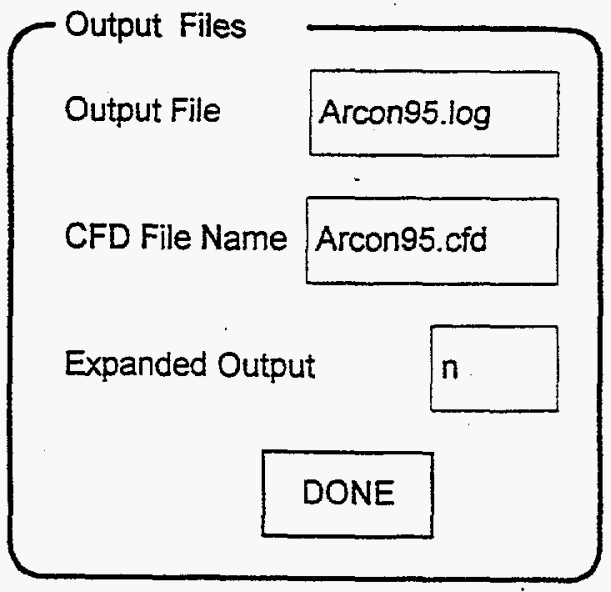

Figure 11 Output files form 
User's Guide

If you click in an Output File text box and then click in another area of the input form, ARCON95 will enter a default name. The default file names are Arcon95.LOG for the primary output file and Arcon95.CFD for the cumulative distribution file.

ARCON95 will not overwrite an existing primary output file or a CFD file. If you enter the name of an existing file for either of these files, ARCON95 will abort. An error message will be displayed on your screen, but it may not remain long enough to read.

The last entry in the Output Files form is a control that enables ARCON95's expanded output option. The Expanded Output option is included primarily to give advanced modelers access to intermediate information for use in code verification. In general, you can ignore this text box and accept the default value, $n$. If you wish to look at the expanded output, change the $n$ (no) to a y (yes). ARCON95 will only accept lower-case letters. When you request expanded output you will be asked for a file name as soon as the computational program begins. This file is referred to as the QA file.

The QA file contents include diffusion coefficients and wind speed correction factors used by the code, a copy of the meteorological data file, the centerline and sector-average $X / Q$ values calculated for each hour, and frequency distributions of the average concentrations.

Consequently when ARCON95 is run with the expanded output option and a large meteorological data set, the result will be a large (several hundred kilobytes) QA file.

Figure 12 shows a Scenario Input Screen as it might appear following data entry prior to clicking on any DONE buttons.

\subsubsection{Default Data}

The remaining data input form is called the Default Values form. It is used to change a default values for parameters used in the dispersion model. It is also used to modify the averaging intervals for $X / Q$. It is generally not necessary to change these parameters; therefore, the form is not displayed routinely.

The Default Values form, shown in Figure 13, is accessed by clicking on Default on the Input menu. The Input menu will be displayed if you click on the word Input in the menu bar at the top of the screen. The parameters included on the form are the surface roughness length, the width of the wind direction window, the minimum wind speed, sector-averaging width constant, number of hours for each averaging interval, and the minimum number of hours for a valid average. All of these parameters are defined and discussed in Section 3. If you aren't comfortable with the information in Section 3, you probably shouldn't be changing default values. 


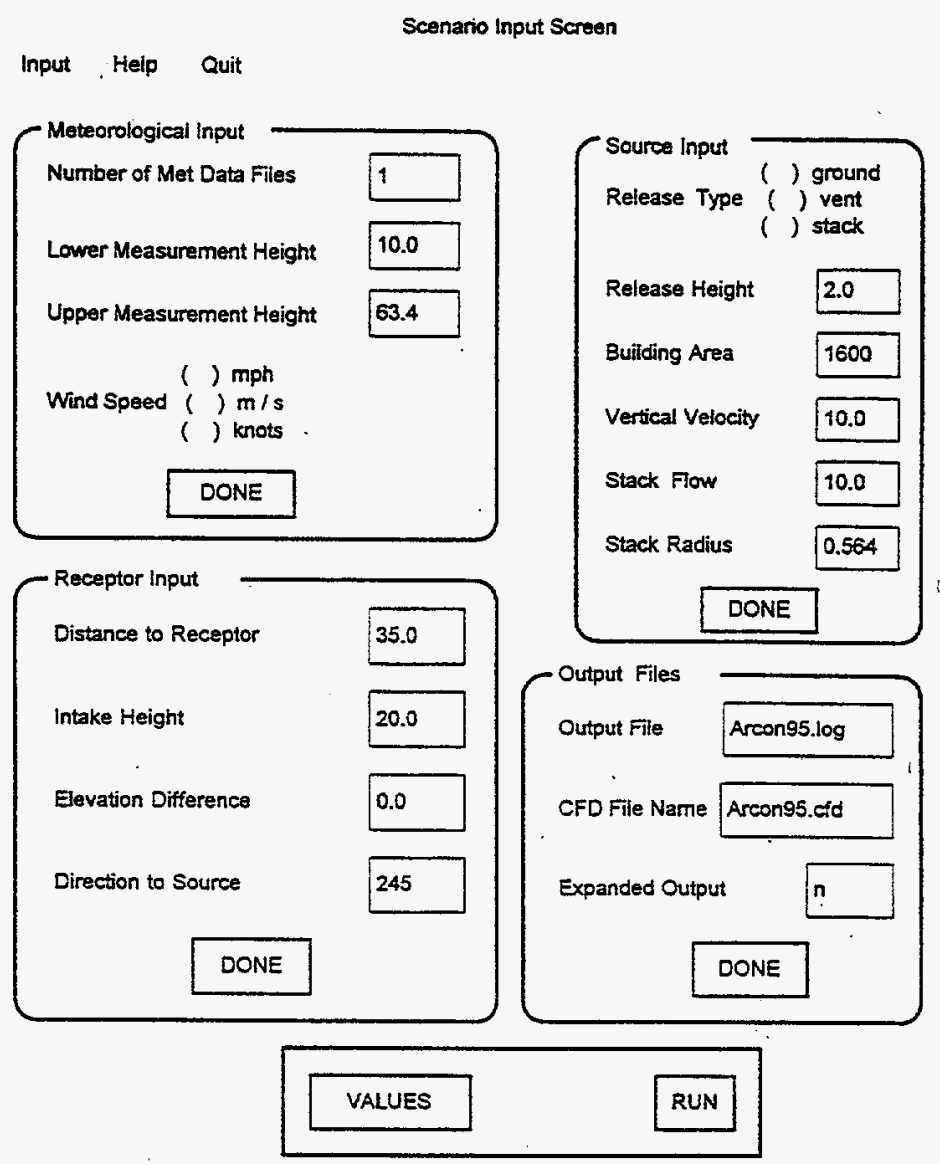

Figure 12 Completed scenario input form

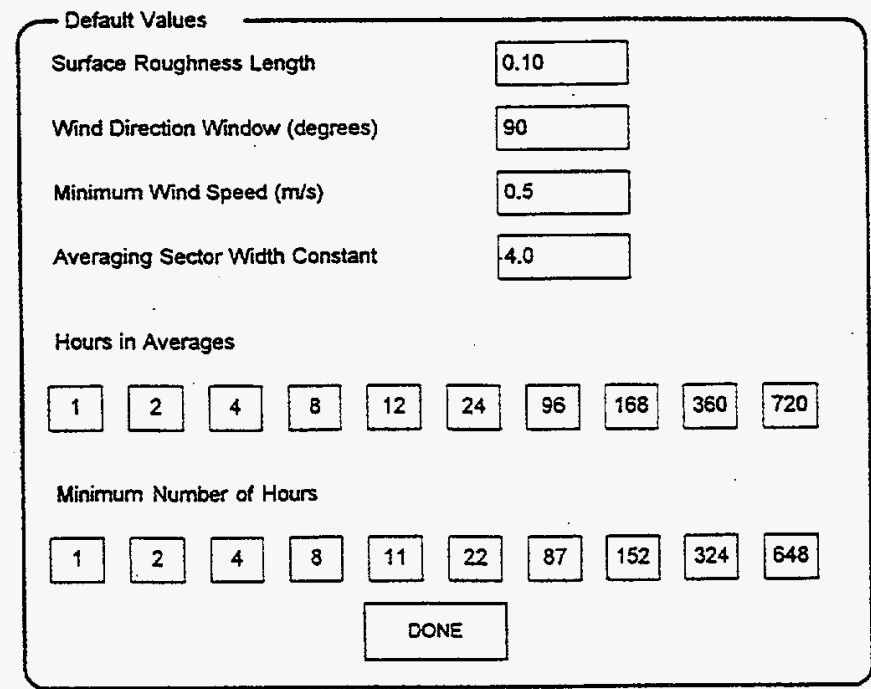

Figure 13 Default values form 
User's Guide

\subsection{ARCON95 Output}

In the Output Files form of the Scenario Input Screen you entered a name for a file to be used for the primary output from ARCON95. This section describes the primary output file.

The primary output file from ARCON95 is an ASCII text file. It may be viewed, edited, annotated, and/or printed using a text editor or word processor. Some of the lines of text in the file exceed 80 characters in length. As a result, the best results will be obtained if you use a text editor or word processing program that allows you to control the font size and number of characters on a line. The files can be printed on 8.5 - by 11 - inch paper using 0.5 -inch margins with 16.67 characters per inch.

The contents of ARCON95's primary file are divided into three sections. The first section is a header. The second section lists the input to the code, and the third section summarizes the results of the calculations. These sections are discussed below.

\subsubsection{Header}

The header in the ARCON95 primary output file provides information about the code. Figure 14 shows a file header. The first three items in the header identify the code. They are the code name, the organization sponsoring code development, and the date and time that the code was compiled. The time of code compilation establishes what version of the code was used for the calculations. The next two items list people who can be contacted about the code and gives the reference for the code documentation. The names and phone numbers listed in the header were current when this guide was written. These items are followed by a disclaimer. The disclaimer was provided by the NRC for inclusion in software developed for the agency. The

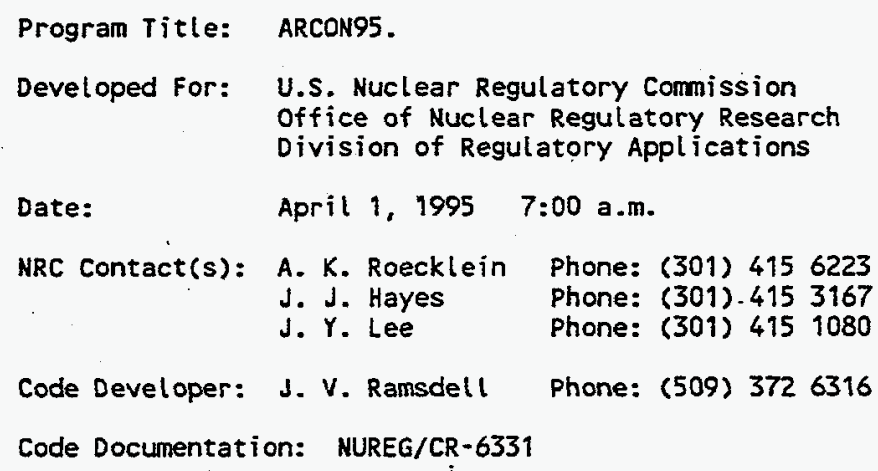

The program was prepared for an agency of the United States Government. Neither the United States Goverment nor any agency thereof, nor any of their employees, makes any warranty, expressed or implied, or assumes any legal liability or responsibilities for any third party's use, or the results of such use, of any portion of this program or represents that its use by such third party would not infringe privately owned rights.

PROGRAM RUN 4/ 1/1995 at 07:46:01

Figure 14 ARCON95 primary output file header 
final line of the header gives the date and time that the program was run. This time may be used to identify the results of the most recent model run if ARCON95 is run several times with the same input and output file names.

\subsubsection{Input Data}

The second section of the ARCON95 primary output file is a listing of the user input. Figure 15 shows the Input Data section of a primary output file. This listing contains all of the information in the run specification file. It also shows the range of wind directions that are assumed to carry effluents from the release point to the intake. This range is calculated from the direction of the source from the intake and the wind direction sector width.

The example shown in Figure 15 is for an ARCON95 run that did not include expanded output. When the expanded output option is selected, the last line of the input section contains the QA output file name.

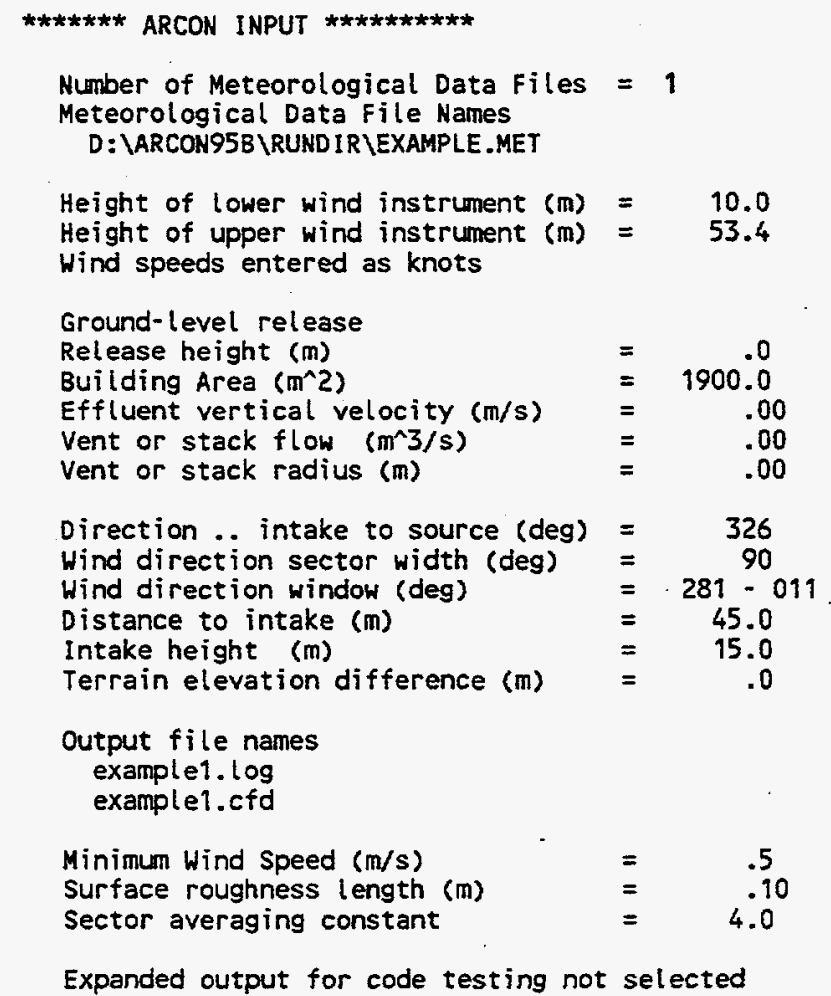

Figure 15 Input data section of an ARCON95 primary output file 
User's Guide

\subsubsection{ARCON95 Results}

The final section of the primary output file contains the results of the ARCON95 calculations. Figure 16 shows the results section of a primary output file.

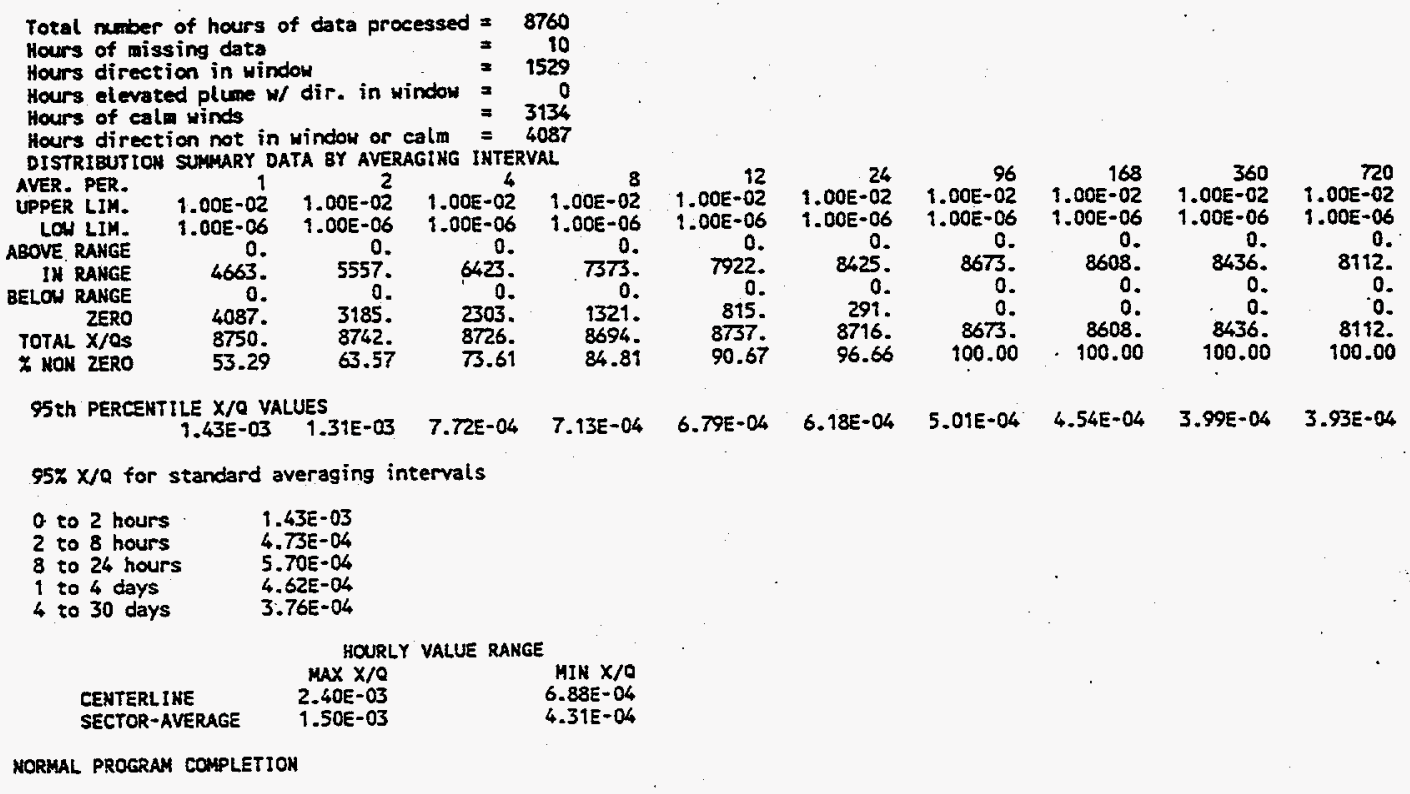

Figure 16 Results section of ARCON95 primary output file

The first six lines of the results section summarize the meteorological data. The first line shows the number of hours of data processed. A normal year has 8760 hours; leap years have 8784. The second line shows the number of hours that ARCON95 was unable to calculate a $\mathrm{X} / \mathrm{Q}$. Fewer than 10 percent of the hours processed should have missing data if the meteorological data have been obtained with a well-maintained system. The third line shows the number of hours with a wind direction in the window that carries effluent from the release point to intake. The size of this number depends on the orientation of the line between the release point and the intake with respect to the prevailing wind direction. If the prevailing wind direction tends to carry material from the release point to the intake, the number of hours in the window can approach 50 percent of the total hours. If the wind rarely blows from the release point to the intake, the number of hour in the window could be 10 percent or less. The fourth line gives the number of hours of elevated plumes during the time that the wind is calm or the wind direction is in the window. This number should be zero unless you have specified a vent release with an uncapped vent or a stack release. The fifth line is the number of hours of calm winds (wind speed less than the minimum wind speed set in the Default Values form). The final line is the number of hours for which $\mathrm{X} / \mathrm{Q}$ was assumed to be zero because the wind direction was not in the window and the wind was not calm. 
The next ten lines contain a summary of the intermediate result of the calculations by averaging period (in hours). ARCON95 calculates X/Qs and creates a X/Q frequency distribution using $X / Q$ bins. The lines labelled Upper Lim. and Lower Lim. define the range of $X / Q$ bins use to compile the $X / Q$ frequency distribution for each averaging period. The range should cover four orders of magnitude. Ranges for the 1- and 2-hour averaging periods will be the same, as will the ranges for the 4- through 720-hour periods. However, the ranges for these two groups of averaging periods may not be the same, as shown in Figure 16.

The distribution of $\mathrm{X} / \mathrm{Q}$ s calculated for each averaging period is summarized in the five lines following the line giving the lower limit for the X/Q bins. The first of these lines gives the number of $X / Q$ s that were greater than the upper limit of the bins. This number should be zero unless you have processed more than 10,000 hours of data. When you process more than 10,000 hours of data, the bin limits are set based on the first $10,000 \mathrm{X} / \mathrm{Qs}$ calculated. As a result, if you process more than 10,000 hours of data and the highest X/Qs don't occur in the first 10,000, there could be a small number of $X / Q s$ above the range of bins. The next line gives the number of $X / Q$ s within the range of bins, and the following line gives the number of $\mathrm{X} / \mathrm{Qs}$ below the range. If you are running a vent- or stack-release scenario, you may find some $\mathrm{X} / \mathrm{Qs}$ that are listed as below the range. These $\mathrm{X} / \mathrm{Qs}$ are within an order of magnitude of the lower limit. Values that are more than an order of magnitude lower than the lower limit are counted as zero because they are not a factor in determining the 95 th percentile $X / Q s$. The zero line gives the number of $X / Q$ s that were more than an order of magnitude below the lower limit of the bins. The total $X / Q$ line gives the basis for calculating the 95 th percentile $\mathrm{X} / \mathrm{Q}$.

The line labelled 95th Percentile X/Q Values gives the 95th percentile values for averaging periods beginning at the start of release. Thus, the 2-hour average is for the 0 - to 2-hour time period. Similarly, the 8-hour value is for the 0 - to 8 -hour time period, and the 96 -hour value is for the 0- to 96-hour time period. In general, these values should decrease as the duration of the averaging period increases. However, it is possible to have the 95 th percentile value increase as the averaging interval increases. This unexpected behavior is most likely to occur with elevated or uncapped vent releases.

Control room habitability assessments generally involve the use of different $\mathrm{X} / \mathrm{Qs}$ as the postulated accident progresses. The X/Qs for various intervals during the accident can be calculated directly from the 95th percentile values. Section 3.7 discusses the calculation of the values for time periods that don't begin at the beginning of the release. Values for five standard averaging intervals are given following the 95 th percentile values. The $X / Q$ value for the 0 - to 2 -hour averaging period is usually the 1-hour value. However, if the 95 th percentile 2 -hour average $X / Q$ is larger than the 1 -hour value, the 2 -hour value is used.

The standard X/Q values don't necessarily decrease as the duration of the averaging period increases. Notice that the 2- to 8-hour X/Q in Figure 16 is lower than the 8- to 24-hour X/Q. This mathematical result is correct, but it is an artifact of changing from a centerline model for the 0- to 2-hour X/Q calculations to a sector-average model for the 2- to 8-hour X/Q calculations. Use of the reported value ensures that the total exposure calculated at the end of 8 hours will be the 95 th percentile value. 
The last part of the results section of the log file lists the maximum and minimum 1-hour X/Q values calculated by the centerline and sector-average models. These values may be used to check the range of $X / Q$ bins.

The line NORMAL PROGRAM COMPLETION should be the last line of the log file. If it isn't, the program has ended in an error mode and the results should not be used.

\subsection{Examples}

The following four examples demonstrate the use of ARCON95 to assess the consequences of ground-level, vent, and elevated releases. The meteorological data for the examples are in a file named EXAMPLE.MET. This file will be used in each of the examples. However, each example makes a different set of assumptions about the meteorological measurement system used in collection of the data.

Each example includes a scenario description that provides all of the information required to run ARCON95 and sufficient output for you to check the results of your calculations. The header sections of the log files and the lower portions of the cumulative frequency distribution files have been deleted.

\subsubsection{Example 1 -- Ground-Level Release}

The first example is a ground-level release scenario. The release point is at the base of building with a cross-sectional area of $1,900 \mathrm{~m}^{2}$. The direction from the intake to the release to the release point is $326^{\circ}$, and the distance between the intake and release point is $45 \mathrm{~m}$. The intake is located $15 \mathrm{~m}$ above the ground. Use the meteorological file, with the understanding that the wind speeds are in knots (nautical miles per hour) and that the wind sensors are located at the 10- and 53.4-m levels of the meteorological tower. Name the output files EXAMPLE1.LOG and EXAMPLE1.CFD.

The log file for Example 1, minus the heading, is shown in Figure 17. Figure 18 shows a portion of the cumulative distribution file for the example. After comparing the results in your $\log$ file with those in Figure 17, look at the cumulative distribution in Figure 18. Notice that the cumulative frequency of 1 -hour $X / Q$ s increases from 0 to the maximum 4663 in a $X / Q$ range of less than an order of magnitude. The range of $X / Q s$ increases as the averaging period increases up to about 96 hours (4 days). When the length of the averaging period increases beyond 4 days, the range of values decreases until it is only about a factor of 2 for a 30-day average.

\subsubsection{Example 2 -- Uncapped Vent Release}

The second example is an uncapped roof-top vent release. The direction from the air intake to the vent is $083^{\circ}$, and the distance is $18 \mathrm{~m}$. The vent has a radius of $1 \mathrm{~m}$, under accident conditions it has a nominal flow of $15.7 \mathrm{~m}^{3} / \mathrm{s}$, and it is uncapped. The plant drawings indicate that the heights of the air intake and vent are 25 and $29 \mathrm{~m}$ above the plant reference elevation, respectively, and that the cross-sectional area of the building on which the vent is located is $1730 \mathrm{~m}^{2}$. Hourly meteorological data are available in a file named EXAMPLE.MET. The 


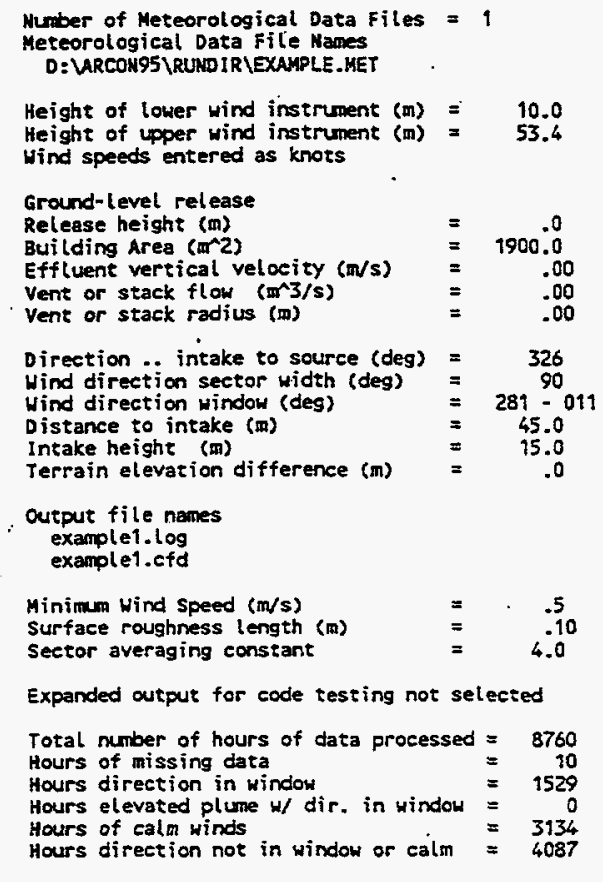

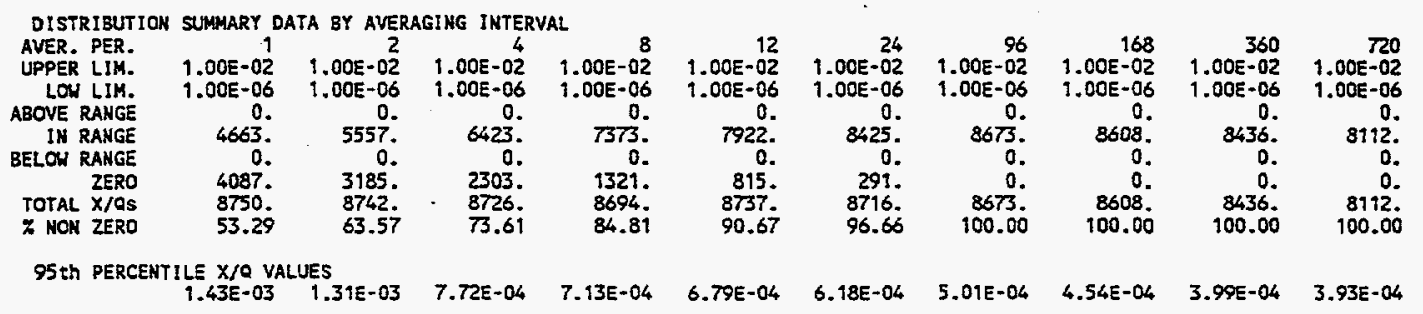
95\% $x / 0$ for standard averaging intervals

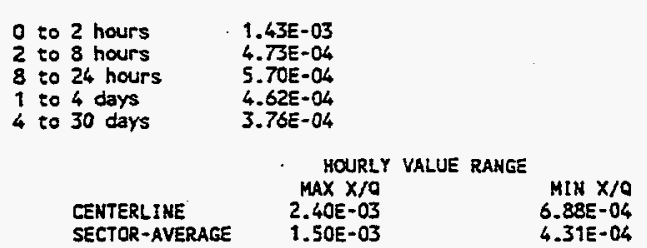

NORMAL PROGRAM COMPLETION

Figure 17 ARCON95 results for example 1 
User's Guide

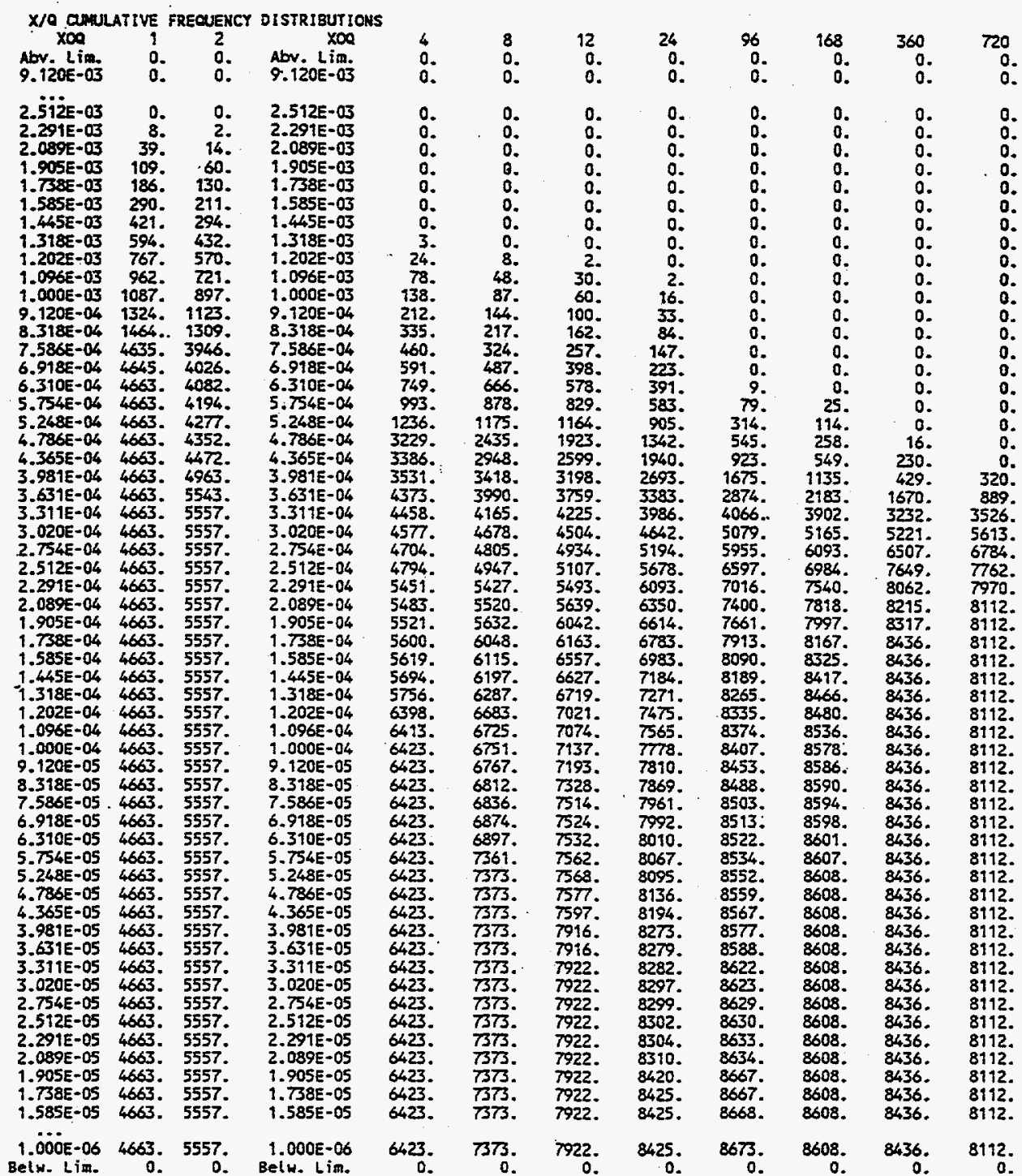

Figure 18 ARCON95 cumulative frequency distribution file for example 1 
wind data were measured at 10 and $92.1 \mathrm{~m}$, and the wind speeds are reported in meters per second. Name the primary ARCON95 output file EXAMPLE2.LOG, and the cumulative frequency distribution file EXAMPLE2.CFD. When you run the program you should get the output shown in Figure 19 in the EXAMPLE2.LOG file. If you didn't, did you forget to calculate and enter the vertical velocity. The vertical velocity is the flow divided by the vent area of $3.14 \mathrm{~m}^{2}$, assuming a round vent.

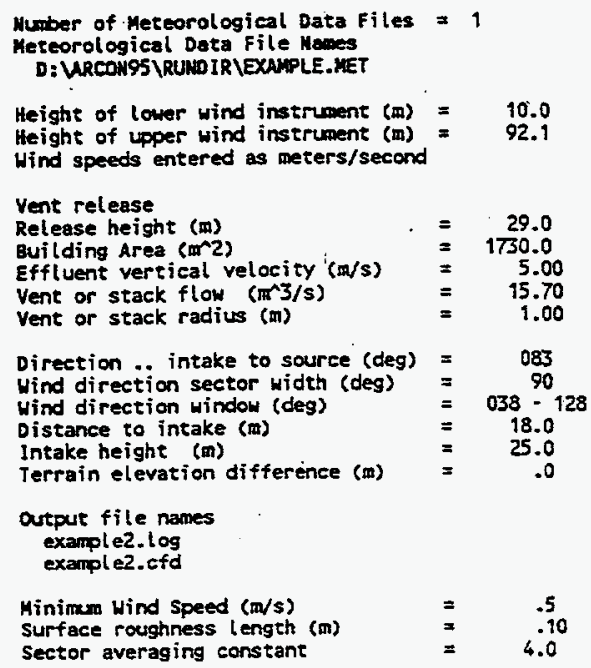

69.62

95x $\times / 0$ for standard averaging intervals

$\begin{array}{ll}0 \text { to } 2 \text { hours } & 1.94 E-03 \\ 2 \text { to } 8 \text { hours } & 9.09 E-04 \\ 8 \text { to } 24 \text { hours } & 8.12 E-04 \\ 1 \text { to } 4 \text { days } & 5.55 E-04 \\ 4 \text { to } 30 \text { days } & 2.77 E-04\end{array}$

$$
\begin{array}{lcr}
\text { HOLRLY VALUE RANGE } \\
\text { MAX X/9 } \\
\text { CENTERLINE } & 9.59 E-03 & \text { MIN X/O } \\
\text { SECTOR-AVERAGE } & 6.37 E-03 & 2.98 E-31 \\
& & 6.91 E-32
\end{array}
$$

NORMAL PROGRAM COMPLETION

Figure 19 ARCON95 results for example 2 
As you look at the results in Figure 19 notice that there are a number of $X / Q$ values that are below the lower limit of the $X / Q$ bins. These values occur during light winds when the vertical velocity of the vent release is sufficiently large that release is treated as if it were from a stack.

\subsubsection{Example 3 -- Capped Vent Release}

Repeat the problem in Example 2, except assume that the vent is capped. What changes as result of the change in assumptions? How much difference do you think the change in assumptions makes in the 95 th percentile $X / Q s$ ? You can check yourself by comparing the input and results sections of the log file shown in Figures 20 with the comparable file shown in Figures 19.

You should have set the vertical velocity to zero to represent the capped vent. Did you? - Did you change the names of the output files before you tried to rerun the problem?

As you look at the results in the log file, compare the number of X/Qs for 1-hour averages in Figures 19 and 20. There are no X/Qs within an order of magnitude of the bottom of the range of bins when the vent is capped. The number of $X / Q s$ in the range of bins in Example 3 is larger than the number in and below the range in Example 2. The differences are the result of setting the vertical velocity of the effluent to zero in Example 3. When this is done, ARCON95 treats the vent release as a ground-level release.

Next notice that the 95th percentile X/Qs in Example 3 are about a factor of 5 larger than those in Example 2. This difference in values illustrates the importance of checking on whether a vent is capped or not. Vents on the sides of structures that bave horizontal flow should be treated the same as capped vents.

\subsubsection{Example 4 -- Stack Release}

The third example is a stack release. In this example, a $65-\mathrm{m}$ stack is located $210 \mathrm{~m}$ from the intake at a bearing of $284^{\circ}$. The diameter of the stack exit is $2 \mathrm{~m}$, and the nominal flow is $31.4 \mathrm{~m} / \mathrm{s}$. The air intake is $25 \mathrm{~m}$ above grade. Assume that there is no change in grade between the locations of the intake and stack. Use the meteorological data file, assuming that the wind speeds in the file are now given in miles per hour and the wind measurement heights are 10 and $63.9 \mathrm{~m}$. Name the output files EXAMPLE4.LOG and EXAMPLE4.CFD.

In addition to demonstrating that the $X / Q$ s calculated for this type of scenario are significantly lower than for ground or vent releases, this example shows one set of conditions under which the 95 th percentile, 2-hour average $X / Q$ can exceed the 1-hour average. The results in Figure 21 show that the 95 th percentile 1 -hour $X / Q$ is $2.08 \times 10^{-7} \mathrm{~s} / \mathrm{m}^{3}$ and that the 2-hour value is $1.53 \times 10^{-5} \mathrm{~s} / \mathrm{m}^{3}$. The total X/Qs line in Figure 21 shows that $8750 \mathrm{X} / \mathrm{Qs}$ were considered in calculating the 95 th percentile 1 -hour average $X / Q$, and 8742 were considered in calculating the 2-hour value. In both cases the 95 th percentile $X / Q$ is exceeded by about 437 values.

To verify the result that 1 -hour value is lower than the 2 -hour value is correct, look at the cumulative frequency distributions in Figure 22 which contains an excerpt from the output file EXAMPLE4.CFD. The maximum 1-hour X/Qs exceed the maximum 2-hour values as 


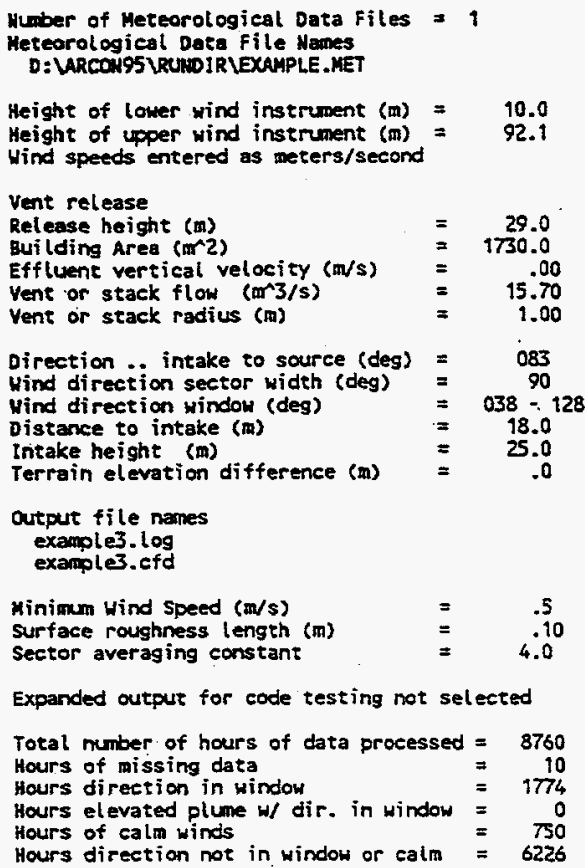

Figure 20 ARCON95 results for example 3

expected. But, the tail of the distribution is long and there is a small group of values in the tail. Reducing the highest values by 50 percent gives values that are still in the upper 5 th percentile of the X/Q distribution. As a result the 95 th percentile 2-hour average X/Q occurs at about $2.5 \times 10^{-5} \mathrm{~s}^{3} \mathrm{~m}^{3}$, while the corresponding 1 -hour average at about $2.1 \times 10^{-7}$. Thus, it is apparent that the result is correct. 


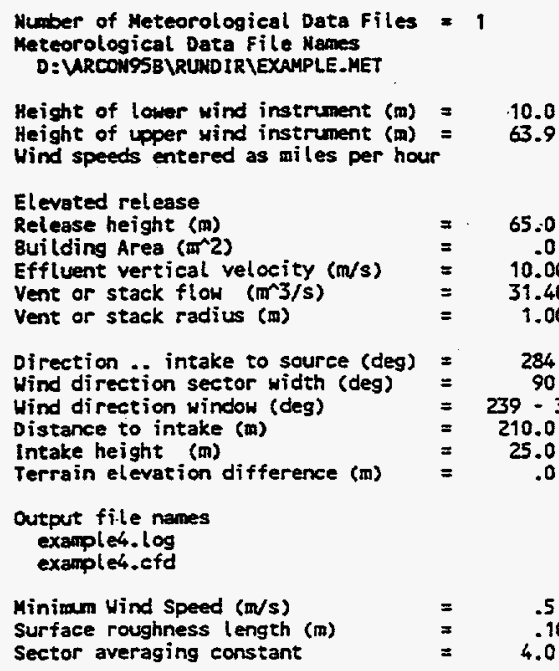

Minimm Wind Speed ( $\mathrm{m} / \mathrm{s}$ ) Surface roughness length (m) Sector averaging constant

Expanded output for code testing not selected

Total number of hours of data processed $=8760$ Hours of missing dat

Hours direction in window

Hours elevated plume of dir in window $=3118$

Hours direction not in window or calm $=506$

DISTRIBUTIOH SUMHARY DATA BY AVERAGING INTERVAL

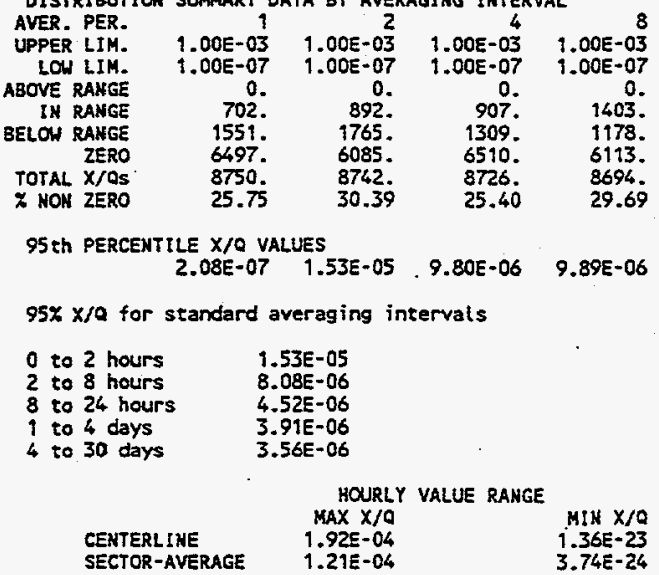

NORMAL PROGRAM COMPLETION

Figure 21 ARCON95 results for example 4 


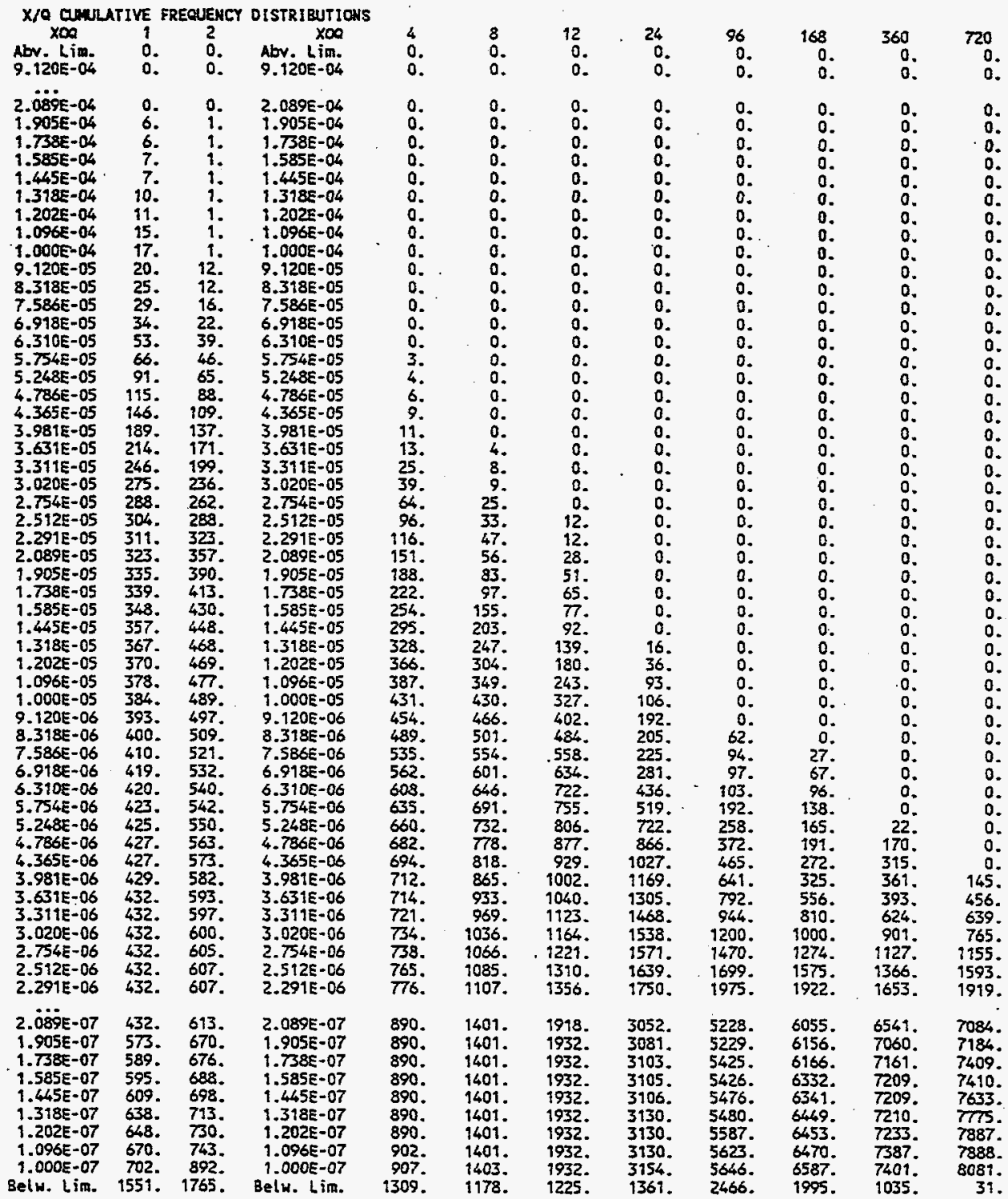

Figure 22 ARCON95 cumulative frequency distribution for example 4 
Technical Basis

\section{ARCON95 Technical Basis}

The first part of this document is a User's Guide to the ARCON95 code. It provides basic information related to installation and operation of the ARCON95 code. This part of the documentation covers the technical basis for the code. It provides the information needed to understand and apply the results of the ARCON95 calculations. The last part of the document deals with the details of the computer code. It is intended for those who need to know about the organization of the code and the individual code modules.

\subsection{Conceptual Model}

The basic diffusion model implemented in the ARCON95 code is a straight-line Gaussian model that assumes the release rate is constant for the entire period of release. This assumption is made to permit evaluation of potential effects of accidental releases without having to specify a complete release sequence.

ARCON95 permits evaluation of ground-level, vent, and elevated releases. Building wake effects are considered in evaluation of relative concentrations from ground-level releases. Vent releases are treated as a mixed ground-level and elevated release. The proportions of the mixture is determined by the ratio between the effluent vertical velocity and the release-height wind speed using the procedure included in the NRC XOQDOQ code (Sagendorf et al. 1982). Elevated releases are treated in the usual manner with correction for downwash and differences in terrain elevation between the stack and the control room intake.

Diffusion coefficients used in ARCON95 have three components. The first component is the diffusion coefficient used in other NRC models, for example XOQDOQ (Sagendorf, et al. 1982) and PAVAN (Bander 1982). The other two components are corrections to account for enhanced dispersion under low wind speed conditions and in building wakes. Derivations of the low wind speed and building wake corrections are described by Ramsdell and Fosmire (1995).

Parameter values for the correction factors are based on analysis of diffusion data collected in various building wake diffusion experiments. The experiments were conducted under a wide range of meteorological conditions. However, a large number of experiments were conducted during low wind speeds, when wake effects are minimal. The wake correction model included in ARCON95 treats diffusion under these conditions much better than previous models. Thus, the diffusion coefficients in ARCON95 account for both low-wind speed meander and wake effects.

ARCON95 calculates relative concentrations using hourly meteorological data. It then combines the hourly averages to estimate concentrations for periods ranging in duration from 2 hours to 30 days. Wind direction is considered as the averages are formed. As a result, the averages account for persistence in both diffusion conditions and wind direction. Cumulative frequency distributions are prepared from the average relative concentrations. Relative concentrations that are exceeded no more than five percent of the time (95th percentile relative concentrations) are determined from the cumulative frequency distributions for each averaging 
period. Finally, the relative concentrations for five standard averaging periods used in control room habitability assessments are calculated from the 95 th percentile relative concentrations.

The following sections describe the model processes and components included in ARCON95. They also describe how the averages are formed, and how missing data are treated.

\subsection{Diffusion Model}

The ARCON95 code implements a straight-line Gaussian diffusion model. The basic model for a ground-level releases is

$$
\frac{X}{Q^{\prime}}=\frac{1}{\pi \sigma_{y} \sigma_{z} U} \exp \left[-0.5\left(y / \sigma_{y}\right)^{2}\right]
$$

$$
\begin{aligned}
& \text { where } \mathrm{X} / \mathrm{Q}^{\prime}=\text { relative concentration (concentration divided by release rate) } \\
& \\
& \qquad \begin{aligned}
\sigma_{\mathrm{y}}, \sigma_{\mathrm{z}}= & \text { diffusion coefficients }(\mathrm{m}) \\
\mathrm{U} & =\text { wind speed }(\mathrm{m} / \mathrm{s}) \\
\mathrm{y}= & \text { distance from the center of the plume }(\mathrm{m}) .
\end{aligned}
\end{aligned}
$$

This equation assumes that the release is continuous, constant, and of sufficient duration to establish a representative mean concentration. It also assumes that the material being released is reflected by the ground. Diffusion coefficients are typically determined from atmospheric stability and distance from the release point using empirical relationships. A diffusion coefficient parameterization from the NRC PAVAN (Sagendorf et al. 1982) and XOQDOQ (Bander 1982) codes is used for $\sigma_{\mathrm{y}}$ and $\sigma_{\mathrm{z}}$.

To estimate diffusion in building wakes, composite wake diffusion coefficients, $\Sigma_{y}$ and $\Sigma_{z}$, replace $\sigma_{\mathrm{y}}$ and $\sigma_{\mathrm{z}}$. The composite wake diffusion coefficients are defined by

$$
\begin{aligned}
& \Sigma_{y}=\left(\sigma_{y}^{2}+\Delta \sigma_{y 1}^{2}+\Delta \sigma_{y 2}^{2}\right)^{1 / 2} \\
& \Sigma_{z}=\left(\sigma_{z}^{2}+\Delta \sigma_{z 1}^{2}+\Delta \sigma_{z D}^{2}\right)^{1 / 2}
\end{aligned}
$$

where $\sigma_{\mathrm{y}}$ and $\sigma_{\mathrm{z}}$ are the normal diffusion coefficients, $\Delta \sigma_{\mathrm{y} 1}$ and $\Delta \sigma_{\mathrm{z} 1}$ are the low wind speed corrections, and $\Delta \sigma_{\mathrm{y} 2}$ and $\Delta \sigma_{\mathrm{z} 2}$ are the building wake corrections. These corrections are described and evaluated in Ramsdell and Fosmire (1995). The form of the low wind speed corrections is

$$
\begin{aligned}
& \Delta \sigma_{\mathrm{y} 1}^{2}=9.13 \times 10^{-3}\left\{1-\left[1+\frac{\mathrm{x}}{1000 \mathrm{U}} \exp \left(\frac{-\mathrm{x}}{1000 \mathrm{U}}\right)\right]\right\} \\
& \Delta \sigma_{\mathrm{z} 1}^{2}=6.67 \times 10^{2}\left\{1-\left[1+\frac{\mathrm{x}}{100 \mathrm{U}} \exp \left(\frac{-\mathrm{x}}{100 \mathrm{U}}\right)\right]\right\}
\end{aligned}
$$

where $\mathrm{X}$ is the distance from the release point to the receptor, in meters, and $\mathrm{U}$ is the wind speed in meters per second. It is appropriate to use the slant range distance for $\mathrm{x}$ because 
these corrections are made only when the release is assumed to be at ground level and the receptor is assumed to be on the axis of the plume. The diffusion coefficients corrections that account for enhanced diffusion in the wake have a similar form. These corrections are

$$
\begin{aligned}
& \Delta \sigma_{\gamma_{2}}^{2}=5.24 \times 10^{-2} \mathrm{U}^{2} \mathrm{~A}\left\{1-\left[1+\frac{\mathrm{x}}{10 \sqrt{\mathrm{A}}} \exp \left(\frac{-\mathrm{x}}{10 \sqrt{\mathrm{A}}}\right)\right]\right\} \\
& \Delta \sigma_{2}^{2}=1.17 \times 10^{-2} \mathrm{U}^{2} \mathrm{~A}\left\{1-\left[1+\frac{\mathrm{x}}{10 \sqrt{\mathrm{A}}} \exp \left(\frac{-\mathrm{x}}{10 \sqrt{\mathrm{A}}}\right)\right]\right\}
\end{aligned}
$$

where $A$ is the cross-sectional area of the building.

An upper limit is placed on $\Sigma_{\mathrm{y}}$ as a conservative measure. This limit is the standard deviation associated with a concentration uniformly distributed across a sector with width equal to the circumference of a circle with radius equal to the distance between the a source and receptor. This value is

$$
\begin{aligned}
\Sigma_{y \max } & =\frac{2 \pi x}{\sqrt{12}} \\
& \approx 1.81 \mathrm{x} .
\end{aligned}
$$

The model described by Equations (1) through (5) is a replacement for the dispersion model in the control room habitability assessment procedure developed by Murphy and Campe (1974). Earlier building wake diffusion model studies conducted for the NRC (Ramsdell 1988, 1990) showed that the Murphy-Campe model did not predict the variations of the concentrations in the vicinity of buildings particularly well. The studies also showed that one of the primary reasons that the Murphy-Campe model did not predict concentration well was that it overpredicted concentrations during low wind speed conditions. The model described above overcomes the problems associated the Murphy-Campe model.

Figure 23 compares the relative concentration predictions of the two models as a function of wind speed for conditions that existed during diffusion experiments at seven reactor sites. The experiments are discussed in detail elsewhere (Ramsdell 1988, 1990). Figure 23 clearly shows that the primary differences in model predictions occur under low wind speed conditions. As a result, it is reasonable to assume that use of ARCON95 in place of the Murphy-Campe model would have the greatest effect at reactor sites with low average wind speeds. At those sites the effect of changing models would be a general reduction in the relative concentrations used to evaluate control room concentrations resulting from postulated reactor accidents.

Figure 24 compares the ratio of relative concentration predictions of the Murphy-Campe model to relative concentration predictions by the model in ARCON95 with relative concentrations observed in the field experiments. Ratios greater than one indicate that the Murphy-Campe model predicts higher concentrations than ARCON95, while ratios less than one indicate that ARCON95 predicts the higher concentrations. Data in the figure show that ARCON95 predicts some concentrations up to a factor of 2 higher than those predicted by the MurphyCampe model. In contrast, there are numerous instances where ARCON95 predicts concentrations that are more than a factor of 10 lower than the Murphy-Campe model 


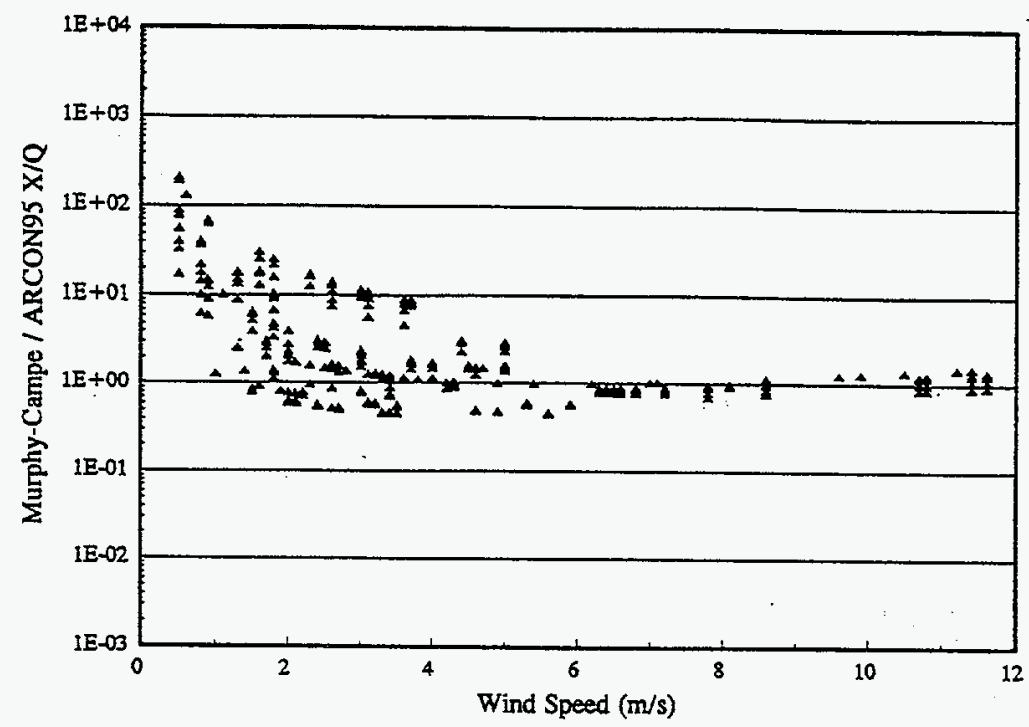

Figure 23 Murphy-Campe / ARCON95 concentration ratios by wind speed

predictions. The figure also shows that the tendency for ARCON95 to predict lower concentrations than the Murphy-Campe model is rather uniform across the full range of observed concentrations.

Equations (1) through (5) are appropriate for estimating relative concentrations for 1-hour periods. A sector-average relative concentration model is frequently used to estimate concentrations for periods longer than an hour. The sector-average plume model is derived by

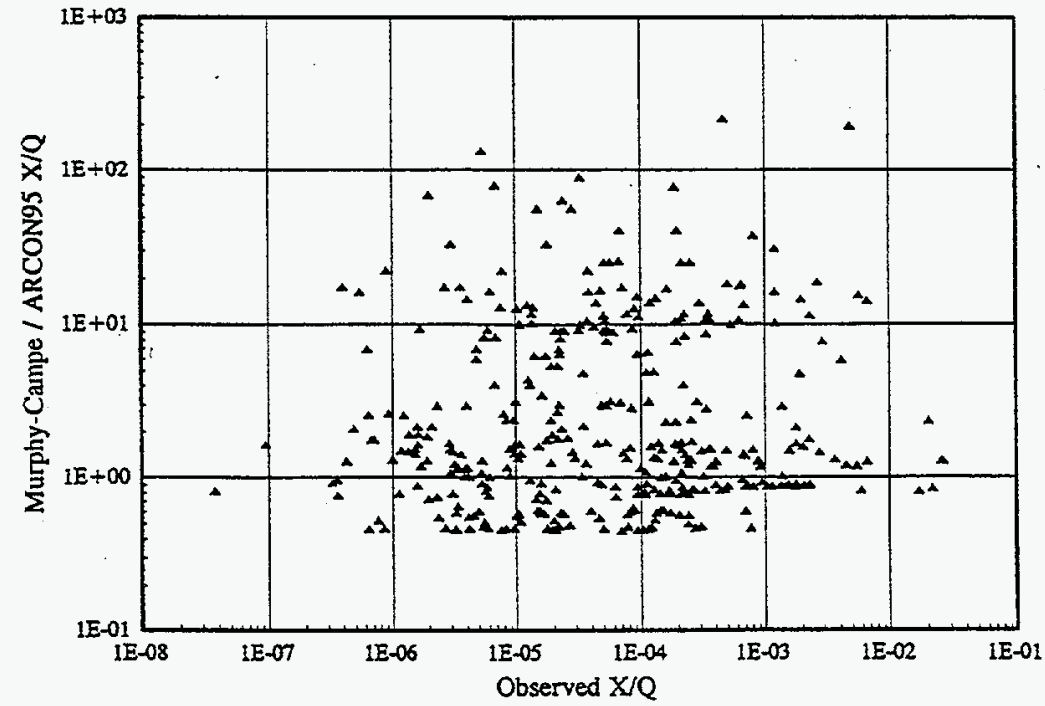

Figure 24 Murphy-Campe / ARCON95 concentration ratios by observed concentration 
integrating the concentration across the normal plume model to obtain a crosswind integrated concentration, $\mathrm{CIC}$, which is

$$
\begin{aligned}
\frac{C I C}{Q^{\prime}} & =\int_{-\infty}^{\infty} \frac{1}{\pi \Sigma_{y} \Sigma_{z} U} \exp \left[-0.5\left(\frac{y-y_{0}}{\Sigma_{y}^{2}}\right)\right] d y \\
& =\frac{2}{\sqrt{2 \pi} \Sigma_{z} U} .
\end{aligned}
$$

The relative concentration is then calculated by dividing CIC/Q' by the width of the sector, $\mathrm{W}_{\mathrm{S}}$

$$
\begin{aligned}
\frac{\mathrm{X}_{\mathrm{sa}}}{\mathrm{Q}^{\prime}} & =\frac{2}{\sqrt{2 \pi} \mathrm{W}_{\mathrm{z}} \Sigma_{\mathrm{z}} \mathrm{U}} \\
& \approx \frac{0.80}{\mathrm{~W}_{3} \Sigma_{\mathrm{z}} \mathrm{U}} .
\end{aligned}
$$

In most cases, the sector width is defined as the width of a $22.5^{\circ}$ sector, which is a function of the distance downwind. This procedure works well except for small distances in unstable atmospheric conditions. In unstable atmospheric conditions the procedure gives sector average concentrations that are greater than the centerline concentration at small distances. This problem can be avoided by redefining the definition of the sector width. For the ARCON95 code, the sector width is the larger of $\alpha \Sigma_{y}$, where $\alpha$ is a numerical constant with a value of 4 , and $\pi \mathrm{x} / 8$, where $\mathrm{x}$ is the distance between source and receptor. The value of $\alpha$ is entered via the run specification file to permit use of values other than 4. The value of $\alpha$ is set in the Default Values form in the Visual Basic shell. Values in the range between 4 and 6 are reasonable. The default value of 4 was selected to be conservative. Approximately $95 \%$ of the material in a Gaussian plume is within $\pm 2 \Sigma_{y}$ of the plume axis.

To be consistent with the centerline model, and to be conservative, the sector width is be limited to a maximum value. This maximum value is the circumference of a circle with radius equal to the distance between the source and receptor, i.e.

$$
\mathrm{W}_{\mathrm{smax}}=2 \pi \mathrm{x} \text {. }
$$

For elevated releases, the relative concentration is given by

$$
\frac{\mathrm{X}}{\mathrm{Q}^{\prime}}=\frac{1}{\pi \sigma_{y} \sigma_{z} U} \exp \left[-0.5\left(\frac{\mathrm{y}}{\sigma_{y}}\right)^{2}\right] \exp \left[-0.5\left(\frac{\mathrm{h}_{e}-\mathrm{h}_{\mathrm{i}}}{\sigma_{z}}\right)^{2}\right]
$$

where $h_{e}$ is the effect stack beight and $h_{j}$ is the height of the intake. Wake corrections are not made to diffusion coefficients used in calculating concentrations in elevated plumes. Effective stack height is determined from the actual stack height $\left(\mathrm{h}_{\mathrm{s}}\right)$, the difference in terrain elevation between the stack and intake locations $\left(t_{s}-t_{i}\right)$, and stack downwash $\left(\Delta h_{d}\right)$ by 


$$
h_{c}=h_{s}+\left(t_{s}-t_{1}\right)+\Delta h_{d}
$$

where the stack downwash is computed as

$$
\Delta h_{d}=4 r_{s}\left[\frac{w_{o}}{U\left(h_{g}\right)}-1.5\right]
$$

and $r_{s}$ is the radius of the stack, $w_{0}$ is the vertical velocity of the effluent, and $U\left(h_{s}\right)$ is the wind speed at stack height. A release is considered elevated if the actual stack height is more than 2.5 times the height of structures in the immediate vicinity of the stack. Plume rise is not considered in calculating effective stack height in ARCON95. If consideration of plume rise is desired, the plume rise must be calculated manually and added to the release height before the release height is entered.

The sector-average model is used to calculate relative concentrations for elevated releases for averaging periods longer than 2 hours. The sector-average plume model for elevated releases may be derived in the same manner as the sector-average plume for ground-level releases. It is

$$
\frac{X_{s a}}{Q^{\prime}}=\frac{2}{\sqrt{2 \pi} W_{s} \sigma_{z} U} \exp \left[-0.5\left(\frac{h_{e}-h_{i}}{\sigma_{z}}\right)^{2}\right]
$$

ARCON95 treats vent releases in addition to ground-level and elevated releases. A vent release is a release that takes place through roof-top vent with an uncapped vertical opening. The treatment of these releases depends on the vertical velocity of the effluent and the wind speed at roof height. If the vertical velocity is more than 5 times the wind speed, the release is treated as an elevated release with a stack height equal to the height of the vent. If the vertical velocity is less than the wind speed, the release is treated as a ground-level release. Finally, if the vertical velocity is less than 5 times the wind speed but greater than the wind speed, the release is treated as a mixed-mode release based on the discussion in Regulatory Guide 1.111 (NRC 1977) and the implementation in XOQDOQ (Sagendorf et al. 1982).

The relative concentration for a mixed-mode release is a weighted average of the relative concentrations for elevated and ground-level releases. The weights for the mixed-mode release are determined as follows. An entrainment coefficient, $E_{t}$, is determined for those hours when $\mathrm{w}_{0} / \mathrm{U}$ is between one and five: 


$$
\begin{array}{ll}
E_{t}=2.58-1.58\left(\frac{W_{0}}{U}\right) & \text { for } 1<\frac{W_{0}}{U} \leq 1.5 \\
E_{t}=0.3-0.06\left(\frac{W_{o}}{U}\right) & \text { for } 1.5<\frac{w_{0}}{U}<5
\end{array}
$$

The weight given to the concentration from the ground-level plume is $E_{t}$, and the weight given to the elevated plume is $1-E_{t}$.

\subsection{Calm Winds}

ARCON95 treats calm wind diffusion explicitly. The common derivation of the Gaussian plume model involves assumptions that eliminate the portion of the solution of the diffusion equation that describes diffusion when the wind speed approaches zero. An alternative, equally reasonable, derivation has been published by Frenkiel (1953). The basic assumptions in the derivation are that air motions do not cease even when the mean wind velocity approaches zero and that the diffusion coefficients are proportional to standard deviations of the wind fluctuations and the time following release. Frenkiel's model is described by Kao (1984).

Concentrations calculated by Frenkiel's model have a local minimum at $U=0$. The concentration increases until it reaches a maximum at $U \approx 1 \mathrm{~m} / \mathrm{s}$, and then it decreases as the $U$ continues to increase. At high wind speeds, the concentration decreases proportional to $1 / U$ as in the usual formulation of the Gaussian plume model. The exact wind speed at which the maximum occurs is a function of distance between source and receptor. It occurs at lower speeds for small distances.

The diffusion model described by Equation (1) has approximately the same behavior at low wind speeds as the Frenkiel model when the low wind speed corrections given by Equation (3) are applied to the normal diffusion coefficients. Therefore, ARCON95 uses Equation (1) with the low wind speed correction for calm wind conditions. Winds are defined as calm when the wind speed falls below the minimum speed set in the Default Values form. This minimum speed is used for calculations when the winds speed are calm. This assumption yields concentrations that are within a few percent of the maximum for all distances.

Wind direction is not considered during calm winds. In all cases of calm winds the receptor is assumed to be directly downwind of the release point. This assumption should be conservative because it substitutes non-zero values of X/Q for values that would normally be zero if wind direction were considered.

Building wake is not a significant factor at low wind speeds.

\subsection{Vent/Stack Flow}

The diffusion equations presented in Sections 3.2 and 3.3 assume point sources. Use of these equations to calculate concentrations at receptors near short stacks and vents can result in 
physically unreal concentration estimates. The concentrations calculated at the receptors can be higher than the concentrations in the stack or vent. ARCON95 limits the concentrations at receptors by allowing the user to specify the volumetric flow through the stack. Given an initial concentration estimate calculated using the equations previously described, relative concentrations corrected for stack flow, are calculated as

$$
\left(\mathrm{X} / \mathrm{Q}^{\prime}\right)^{*}=\frac{1}{\frac{1}{\mathrm{X} / \mathrm{Q}^{\prime}}+\mathrm{F}}
$$

where $\left(X / Q^{\prime}\right)^{*}$ is the corrected relative concentration and $F$ is the flow.

\subsection{Exposure Window}

In computing average relative concentrations at the intake, ARCON95 assumes that material travels directly from the release point to the intake if the wind direction is within a window specified by the user. The wind direction window is based on the direction from the intake to release point and the angular width of the window. The direction from the intake to the release point is specified as part of the normal user input. The width of the window is taken from the Default Values form. It may be changed if necessary. The default width of the window is $90^{\circ}\left( \pm 45^{\circ}\right.$ from line between the release point and the intake). The actual window width is $1^{\circ}$ wider than specified if the specified width is an even number and $1^{\circ}$ narrower if it is odd.

\subsection{Averaging Methods}

Average relative concentrations used to determine the X/Q' cumulative frequency distributions are computed as overlapping mean values. The centerline model is used to compute 1- and 2hour X/Q' averages, and the sector-average model is used for averages exceeding 2 hours.

\subsection{Relative Concentrations for Standard Intervals}

Standard Review Plan 6.4 (USNRC 1981) and various regulatory guides related to estimation of consequences of radionuclide releases following an accident require relative concentration estimates for various periods following the start of release. ARCON95 calculates concentrations for the following standard periods: 0 to 2 hours, 2 to 8 hours, 8 to 24 hours, 1 to 4 days, and 4 to 30 days. These values are calculated from the 95 th percentile average relative concentrations as follows. The larger of the 1- and 2-hour average relative concentration is used for the 0 -to 2 -hour period. Average relative concentrations for the 2- to 8-hour period are calculated as 


$$
\overline{X / Q^{\prime}}=\frac{8 \times X / Q^{\prime}(8 \mathrm{hr})-2 \times X / Q^{\prime}(2 \mathrm{hr})}{6 \mathrm{hr}}
$$

where $X / Q^{\prime}(8 \mathrm{hr})$ and $X / Q^{\prime}(2 \mathrm{hr})$ are 95th percentile average values for 8 and 2 hours, respectively. The 6 hours in the denominator is the length of the averaging period. Relative concentrations for the remaining standard periods are calculated in the same manner.

\subsection{Missing Data}

ARCON95 uses time series of hourly meteorological data to properly account for the effects on wind direction persistence in reducing average relative concentrations for periods longer than 2 hours in duration. As a result, ARCON95 treats missing data by deleting hours with missing data from the calculation of the average relative concentrations used in determining the cumulative frequency distributions. Missing data tolerance criteria are used to determine when the number of hours of missing data make a specific average relative concentration unacceptable. The criterion for averages of 8 hours or less is zero missing data. For longer duration averages, up to $10 \%$ missing data are accepted. Averages are not calculated for periods in which the number of hours of missing data exceed the tolerance criteria. The missing data tolerance criteria are set in the run specification file. These criteria may be changed in the Default Value form.

The primary ARCON95 output contains a meteorological data summary and a summary of the relative concentrations by averaging intervals. These summary tables permit calculation of the number of averages not computed because of missing data.

Relative atmospheric concentrations (X/Q') that are exceeded no more than $5 \%$ of the time during a year are determined from complementary cumulative frequency distributions of the averages for each averaging period. The basis for determining these values is the possible number of averages for the period minus the number of averages not available due to missing data. For example, assuming data for one year are being processed, there are 8760 possible hourly X/Q' values. The 95 th percentile relative concentration is that concentration exceeded by 438 values. However, if $10 \%$ of the data were missing, the 95 th percentile relative concentration would be that concentration that is exceeded by 394 values. 


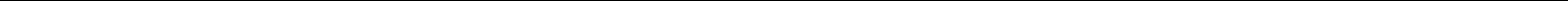




\section{Programmer's Guide to ARCON95}

The first two parts of this document have dealt with the ARCON95 from the user's perspective. They have provided the information needed to install and run the ARCON95 program and to understand and apply the results for the program. This part of the document deals specifically with the ARCON95 computer code. It is intend for individuals who may be called upon to revise the code or place the code in a different shell.

\subsection{General Computational Approach}

ARCON95 is implemented as a modular code. It includes three executable programs. Two of the programs are written in Visual Basic. They provide the shell program used for data input and permit ARCON95 to run one scenario after another without the user having to restart the program. The third program is written in FORTRAN. It performs ARCON95's computational tasks. This part of the document deals with the FORTRAN code.

The ARCON95 FORTRAN code consists of a main program to control the program execution and 14 subroutines and functions to handle the data and perform the model calculations. Each program unit is coded using a structured approach.

\section{4:2 Code Languages}

The computational portion of ARCON95 is written in standard ANSI FORTRAN-77 programming language, with some extensions designed to enhance code maintenance and promote structured programming style. Specific extensions used include long variable names, IMPLICIT NONE, INCLUDE and SELECT CASE statements, the DO WHILE and END DO statements.

The user interface is written in Visual Basic to provide a user-friendly shell. A second Visual Basic program links the FORTRAN-77 code and the shell to reduce computer memory requirements.

\subsection{Coding Standards}

The following coding standards are followed in all ARCON95 FORTRAN program units.

The code for each program unit includes two blocks:

- definition block - the definition block includes the program unit name, history, description, and relationship to other units and include files. It may also contain references, algorithm descriptions, and variable definitions.

- code block - code and comments. 
The code block in each FORTRAN program units begins with the statement IMPLICIT NONE. The type and dimensions of all variables are defined in type statements.

The primary method of passing variables between major program units is named common blocks. Common blocks contain related information, and the block name indicates the general nature of the information. The common blocks are defined in code segments contained in INCLUDE files. The INCLUDE files also contain PARAMETER statements, type definitions and dimensions associated with the variables defined in the file.

Argument lists are used to pass variables to subroutines and functions if use of a formal argument list facilitates program development, verification, and maintenance. Variables are passed to functions via argument lists. Common blocks are not used to pass information to functions.

Data statements used to define variables contained in common blocks are placed in a BLOCK DATA element. The BLOCK DATA element is included at the end of the file that contains the code for the main program.

The use of system dependent calls has been limited to two tasks. System calls in the ARCON95 main program get the name of the run specification file (data input file) from the command line invoking program execution, and system subroutines are used to get the date and time of program execution from the system clock and the cpu time used for various program functions.

Structured programming techniques (IF ... THEN, ELSE IF... THEN, DO WHILE) have been used, and the unnecessary use of statement numbers has been avoided. END DO statements have been used to decrease the number of statement numbers.

The ARCON95 code aborts execution in the event that an abnormal condition is encountered during execution of the code. Traps have been provided for abnormal conditions related to file operations, data input, and data output. In general, the error messages are written to the console, to the $\log$ file, and to other output files to describe the abnormal condition causing code execution to be aborted. However, when the program is run in the Visual Basic shell, the error messages may be overwritten before they can be read. If this happens, run ARCON95 from the DOS command line by typing ARCONF followed by the run specification file name.

\subsection{Data Input}

ARCON95 runs in a batch mode. User interactions and data input are via data files except for input of the name of the run specification file and a name for the file used for expanded output if needed. The name of the run specification file is entered as a command line argument at the time code execution is initiated. If expanded output is selected in the run specification file, a name for the file will be requested as soon as program execution begins.

The files used to enter the information required by ARCON95 are described below. 


\subsubsection{Run Specification File}

User input to the model for the purpose of program control is via a run specification file. The information included in the run specification file includes but is not limited to:

- run identification

- model option controls

- input data file names

In normal operation, the run specification file is created by the Visual Basic shell. It is an ASCII text file that can be modified in the Visual Basic shell or in a text editor.

The run specification file consists of 23 records if there is one meteorological data file. Each additional meteorological data file adds another record. The format for the run specification file is shown in Figure 25. The text on the right of the exclamation points is not part of a normal run specification file. It has been added to provide a brief explanation of the information being passed in the record. The format use to read the record is shown in parentheses at the end of the text.
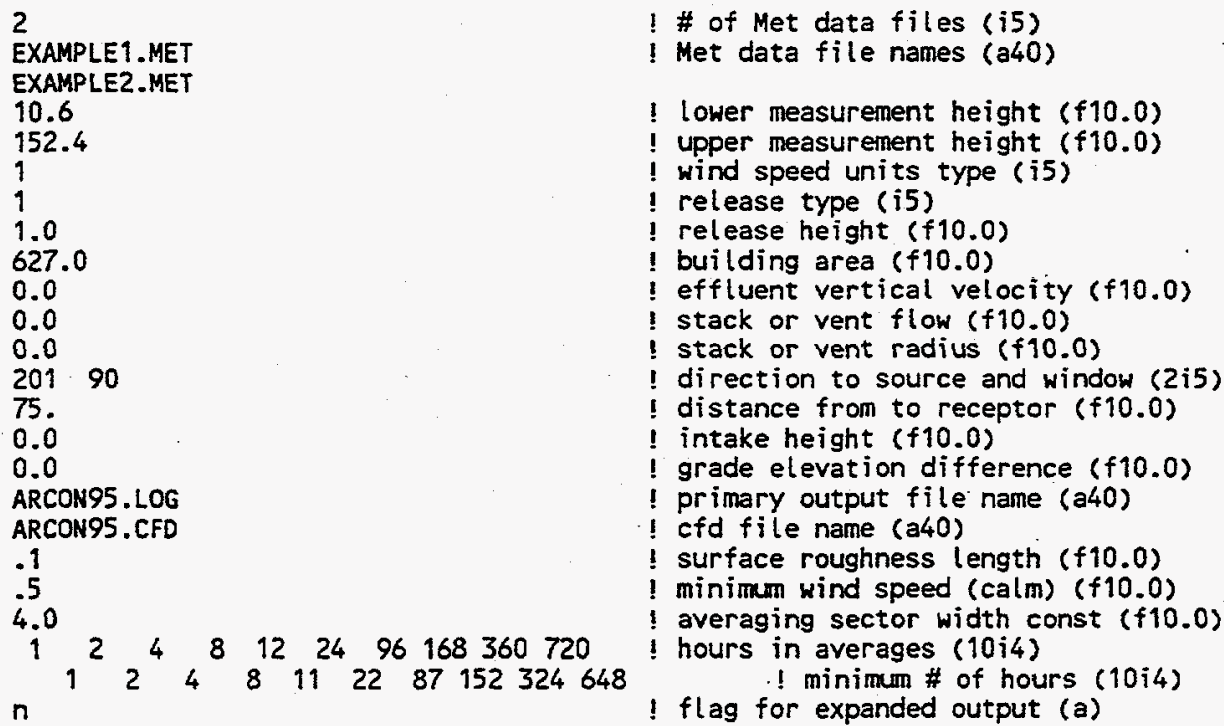

Figure 25 Annotated run specification file

\subsubsection{Meteorological Data Files}

ARCON95 uses information contained in meteorological data files. The name/names of one or more meteorological data files must be passed to the program via the run specification file.

The meteorological data file must have one record per hour. Each record must include the day of the year, the hour of the day, the stability, and the wind direction and wind speed at the 
lower measurement level. The record may also include a five-character location identifier, and a wind direction and speed for the upper level. The format for the records is

$$
(1 x, A 5,3 x, I 3, I 2,2 x, I 3, I 4,1 x, I 2,2 x, I 3, I 4)
$$

The order of information in the record is location identifier, Julian day, hour of the day, lower-level wind direction, lower wind speed, stability class, upper wind direction, and upper wind speed. Julian day is the day of the year and ranged from 1 to 366 . The hour is entered using a 24-hour clock with midnight being entered as hour 0 .

Wind directions are entered in degrees. A north wind (wind from the north) is entered as $360^{\circ}$, and a south wind is entered as $180^{\circ}$. Wind speeds are entered to the nearest tenth of a reporting unit without the decimal. A wind speed of $5.3 \mathrm{~m} / \mathrm{s}$ would be entered as 53 , while a speed of $5 \mathrm{~m} / \mathrm{s}$ would be entered as 50 .

Atmospheric stability is entered as a number from 1 through 7. A stability class of 1 represents extremely unstable conditions, and a stability class of 7 represents extremely stable conditions. Any other number will be interpreted as missing data.

\subsection{Model Output}

Normal ARCON95 output consists of two files. The first file is a run log. The run log documents the ARCON95 run and is the primary output file. It includes the program name and version number, appropriate disclaimers, the date and time of program execution (taken from the computer clock), a listing of the data entered via the run specification file, summary statistics related to the relative concentration calculations and the cumulative frequency distributions. The second file contains a heading record and the relative concentration cumulative frequency distributions. The primary output file is described in detail and examples of the log and cumulative distribution files are shown in the User's Guide.

When expanded output is selected in the run specification file, ARCON95 will create a third output file. This file contains information that may be used for code trouble-shooting and code verification. The expanded output file is called the QA_file in the program. It includes the following information:

- values for scenario-dependent parameters calculated during program initialization

- a listing of the meteorological data read by the program

- a listing of the hourly centerline and sector-average $X / Q s$ calculated by the program along with the meteorological data used in the calculations

- frequency distributions for each of the averaging periods.

Consequently, the size of the expanded output file can become large. It approaches one megabyte when the meteorological data file contains data for a full year. 


\subsection{Program Description}

The ARCON95 code consists of three executable programs. Two of these programs, ARCONVB and ARCONVB2 are primarily used for user input and to permit users to run several scenarios in rapid succession without having to restart the program. The third executable program, ARCONF, does the calculations. Figure 26 shows the interactions among these programs.

Figure 27 shows the same organization but emphasizes the program functions rather than the program names. In addition, Figure 27 shows all three of the output files. The breaks between the programs are shown by dashed lines.

The following sections describe the ARCON95 FORTRAN code in detail. The main program and each of the subroutine and functions that comprise the code are discussed. Flow charts are provided for the main program and those program elements that calculate, process, and summarize the X/Qs. Appendix A contains a listing of the FORTRAN code, and Appendix B is a glossary of variable used in more than one ARCON95 program element.

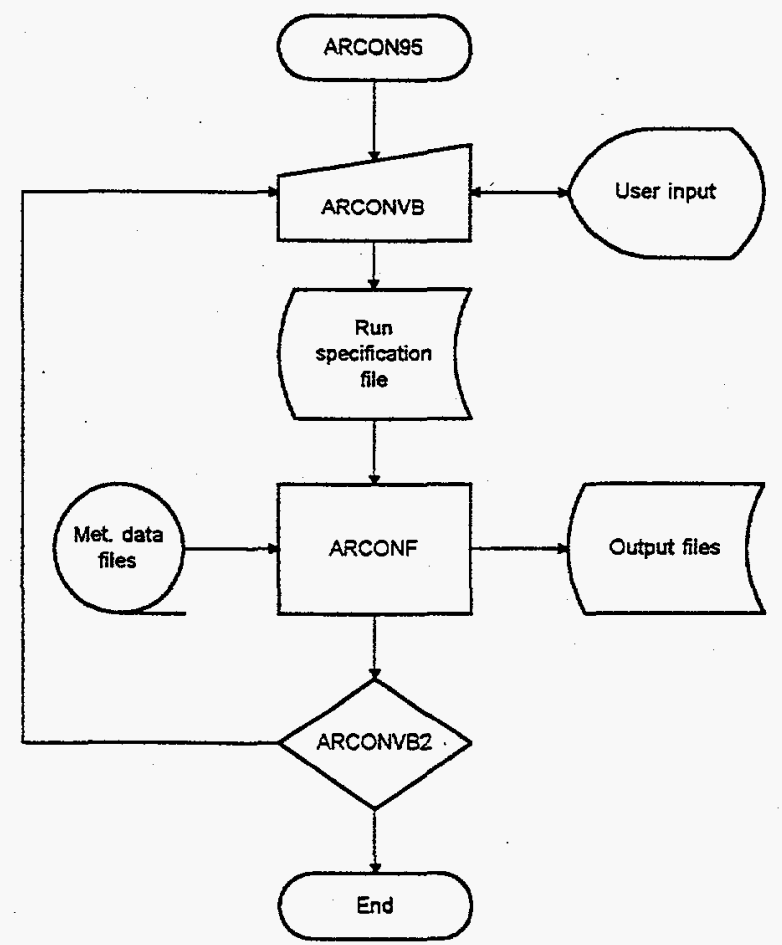

Figure 26 ARCON95 executable code organization 


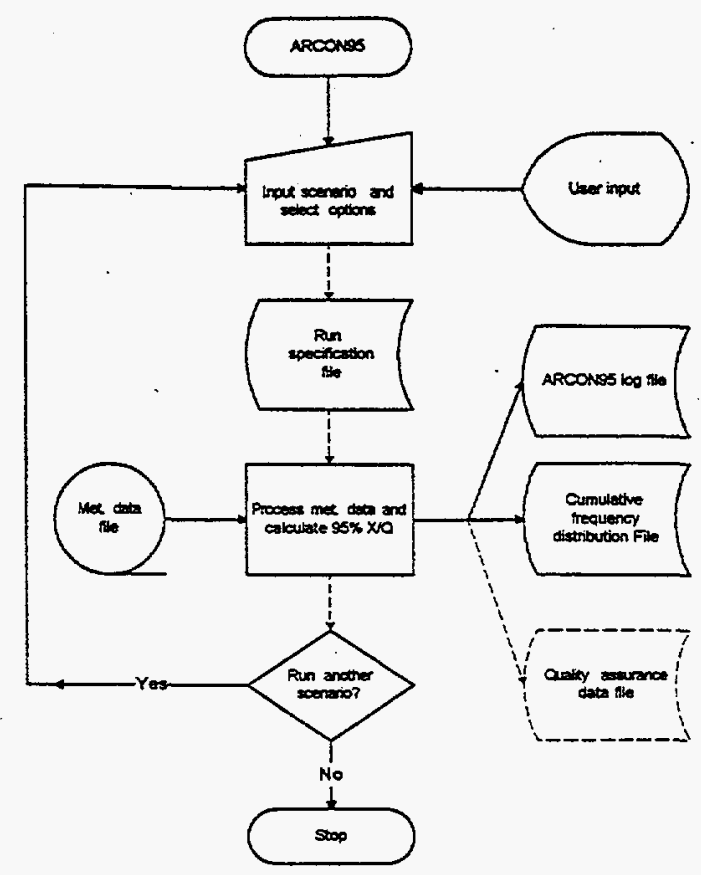

Figure 27 ARCON95 executable code organization by function

\subsubsection{ARCON95}

ARCON95 is the main program. It provides the general framework for the code. ARCON95 contains three parts -- an initialization section, main program section, and an end section. The initialization section determines the date and time of model execution and calls program elements used to initialize the code. The main section of the code controls the flow of the program as it reads meteorological data files, calculates hourly relative concentrations, combines the hourly concentrations into averages for longer periods, and store the results of these calculations in frequency distributions. The end section of the program summarizes the results of the calculations when all meteorological data have been processed and writes the results of the calculations to the log and cumulative frequency distribution files. When the results have been written to these files, the end section writes a message indicating normal model termination in the log file, and closes files, as appropriate.

Figure 28 shows the logical organization of ARCON95 FORTRAN code. The initialization section of the program is shown at the top of the flow chart. The main section of the program starts with reading the meteorological data and ends when all meteorological data have been read and processed. When there are no more data to be processed, the program enters its final phase. Here the cumulative frequency distributions and 95 th percentile $X / Q s$ are calculated and written to the output files. This flow chart also shows which portions of the program write to each of the files. 
Programmer's Guide

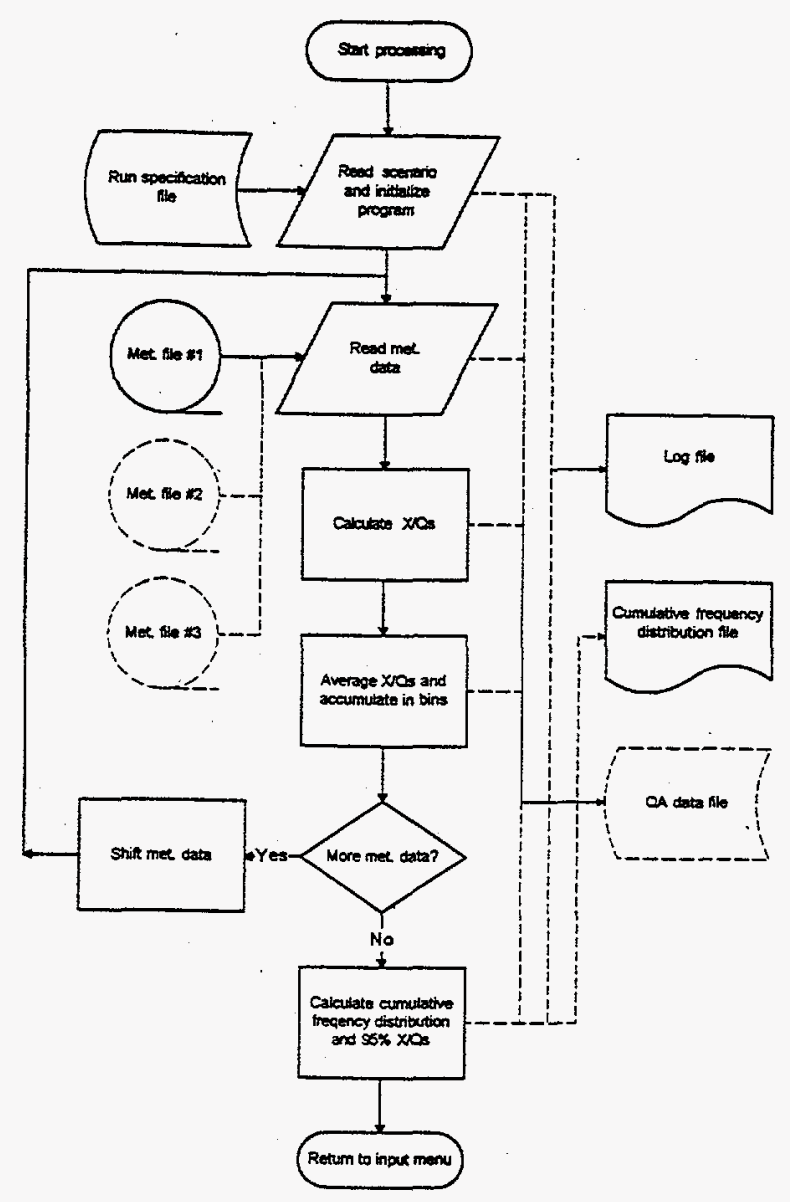

Figure 28 ARCON95 FORTRAN code organization

The organization of the program elements in the FORTRAN code is shown in Figure 29. Each rectangular box in the figure represents a subroutine or function. The flow of information in the code can be followed by noting the arrows. The single-headed arrows are generally associated with subroutines and functions called directly from the ARCON95 code. The two-headed arrows show calls to subroutines and functions that are not called directly by ARCON95.

Data transfer in ARCON95 is generally by named common blocks. These blocks are found in sections of code that are maintained separately in what are called "include files." These files are incorporated in the main program and subroutines when the program elements are compiled. Five "include files" are part of ARCON95. Each of these files contains information related to a specific area of the code. For example, the MET.INC file contains the meteorological data and associated information. Similarly, the SCENARIO.INC file contains information on the release point/receptor geometry, and the XOQ.INC file contains information related to $X / Q$ s. In contrast, the PARAM.INC and UNITS.INC files are directly related to the code operations. The PARAM.INC file contains the parameters that limit the 


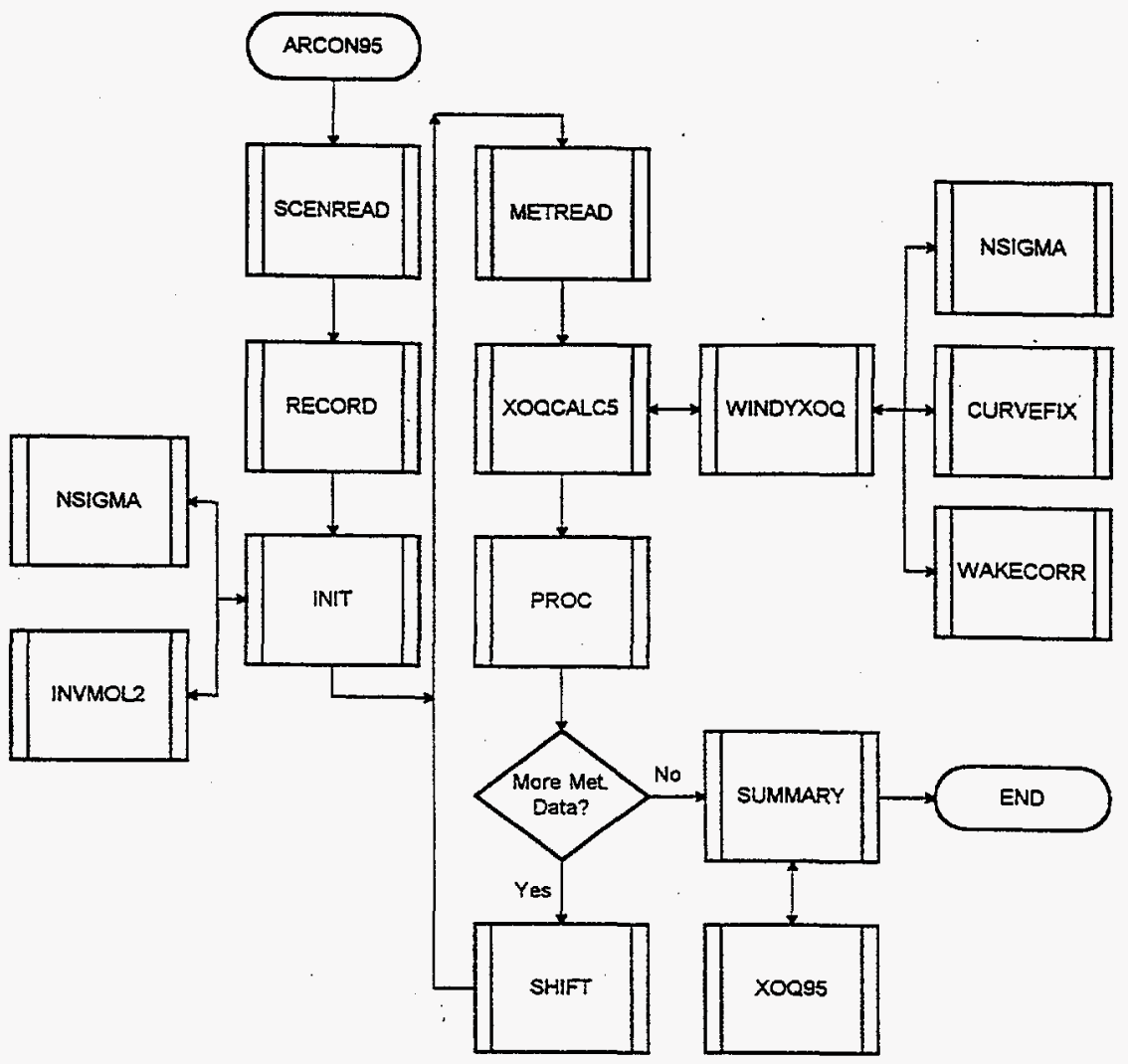

Figure 29 ARCON95 program element organization

number of hours of meteorological data that can be stored within the program and the number of meteorological data files that can be processed in any run. These parameters are used as dimensions for arrays. The UNITS.INC file contains the variables that store file names and the logical unit assigned to each of the files. Table 1 shows the program elements and the "include files" that are incorporated in each element.

\subsubsection{Subroutine CURVEFIX}

Subroutine CURVEFIX calculates low-wind speed corrections to the diffusion coefficients used in the PAVAN (Sagendorf et al. 1982) and XOQDOQ (Bander 1982) programs. These corrections, which are described in Section 3.2, are functions only of distance and wind speed. Ramsdell and Fosmire (1995) present a detailed derivation and evaluation of the equations used to calculate the correction factors.

\subsubsection{Subroutine INIT}

Subroutine INIT calculates several model parameters that are depend only on the scenario.

These parameters include the standard NRC diffusion coefficients and factors that adjust the 
Table 1 Relationship between INCLUDE blocks and program elements

\begin{tabular}{||l|c|c|c|c|c||}
\hline \multirow{2}{*}{ PROGRAM ELEMENT } & \multicolumn{5}{|c|}{ INCLUDE BLOCK } \\
\cline { 2 - 6 } & $\mathrm{MET}$ & $\mathrm{PARAM}$ & $\mathrm{SCENARIO}$ & $\mathrm{UNITS}$ & $\mathrm{XOQ}$ \\
\hline ARCON95 & $\mathrm{XXX}$ & $\mathrm{XXX}$ & $\mathrm{XXX}$ & $\mathrm{XXX}$ & $\mathrm{XXX}$ \\
\hline BLOCK DATA & $\mathrm{XXX}$ & $\mathrm{XXX}$ & $\mathrm{XXX}$ & $\mathrm{XXX}$ & $\mathrm{XXX}$ \\
\hline CURVEFIX & & & & & \\
\hline INIT & $\mathrm{XXX}$ & $\mathrm{XXX}$ & $\mathrm{XXX}$ & $\mathrm{XXX}$ & \\
\hline INVMOL2 & & & & & \\
\hline METREAD & $\mathrm{XXX}$ & $\mathrm{XXX}$ & & $\mathrm{XXX}$ & $\mathrm{XXX}$ \\
\hline NSIGMA & & & & & \\
\hline PROC & & $\mathrm{XXX}$ & $\mathrm{XXX}$ & $\mathrm{XXX}$ & $\mathrm{XXX}$ \\
\hline RECORD & $\mathrm{XXX}$ & $\mathrm{XXX}$ & $\mathrm{XXX}$ & $\mathrm{XXX}$ & $\mathrm{XXX}$ \\
\hline SCENREAD & $\mathrm{XXX}$ & $\mathrm{XXX}$ & $\mathrm{XXX}$ & $\mathrm{XXX}$ & $\mathrm{XXX}$ \\
\hline SHIFT & $\mathrm{XXX}$ & $\mathrm{XXX}$ & & $\mathrm{XXX}$ & $\mathrm{XXX}$ \\
\hline SUMMARY & & $\mathrm{XXX}$ & $\mathrm{XXX}$ & $\mathrm{XXX}$ & $\mathrm{XXX}$ \\
\hline WAKECORR & & & & & \\
\hline WINDYXOQ & & & & $\mathrm{XXXX}$ & \\
\hline XOQCALC5 & & $\mathrm{XXX}$ & & $\mathrm{XXX}$ & \\
\hline XOQ95 & & & & & $\mathrm{XXX}$ \\
\hline
\end{tabular}

measured wind speeds to a standard 10-meter measurement height and the release height. The standard NRC diffusion curves are functions of stability class and the distance between the release point and the intake.

The wind speed adjustment factors are based on the diabatic wind profiles (Panofsky and Dutton 1984). They are functions of the wind speed measurement heights, the stability class, and the surface roughness at the site. The surface roughness is one of the model parameters that may be changed using the Default Values form. Its default value is 0.1 meter.

If the expanded output option is selected, subroutine INIT will write the diffusion coefficients and the wind speed adjustment factors to the quality assurance file. 


\subsubsection{Function INVMOL2}

Function INVMOL2 converts the stability class to the reciprocal of the Monin-Obukhov length that used in the diabatic wind profiles. The conversion is based on Figure 5 in a paper by Golder (1972). This figure, which is based on analysis of experimental data, shows MoninObukhov length ranges as a function of stability class and surface roughness length. Function INVMOL2 is based on a function by the same name in the RATCHET computer code (Ramsdell et al. 1994) that includes uncertainty in the conversion process.

\subsubsection{Subroutine METREAD}

Subroutine METREAD reads the meteorological data file one record at a time and places the input data in the meteorological data vectors. The required meteorological data format is described in Section 4.4.2.

The data are read in a loop that is terminated when either 1) there are 10,000 hours of data in the vector, or the subroutine reaches the end of the last meteorological data file. If the subroutine reaches the end of a data file before it reaches 10,000 hours, it closes the file and increments the variable NEXT_MET by one. If NEXT_MET doesn't exceed the total number of meteorological data files, the subroutine opens the next file and continues reading data. If NEXT_MET exceeds the number of data files, the subroutine sets the logical flag END_MET to .TRUE. and places the index of the last data record in the variable LAST_MET.

As the meteorological data are read, the data are checked to ensure that each value is within the appropriate range. The ranges are

- Stability class

1 through 7

- Wind directions $001^{\circ}$ through $360^{\circ}$

- Wind speed 000 through 750 .

Recall that wind speeds are enter in tenths of the measurement unit. If an out-of-range value is detected, 99 is used to indicate an invalid stability class, 999 is used to indicate an invalid wind direction, and 9999 is used indicate an invalid wind speed. If expanded output has been selected, MET_READ will write each input record to the quality assurance file. In addition, every 100 hours subroutine MET_READ writes the hour of the year to the screen.

\subsubsection{Subroutine NSIGMA}

Subroutine NSIGMA calculates the initial diffusion coefficients using the algorithms for approximating the Pasquill-Gifford diffusion coefficient curves (Gifford 1961) described by Martin and Tikvart (1968) and Tadmor and Gur (1969). These algorithms are the same as algorithms used in PAVAN (Sagendorf et al. 1982) and XOQDOQ (Bander 1982). Given a distance and stability class as input, the subroutine returns a horizontal diffusion coefficient $\left(\sigma_{y}\right)$ and a vertical diffusion coefficient $\left(\sigma_{z}\right)$. 


\subsubsection{Subroutine PROC}

Subroutine PROC processes the hourly X/Q data. It is called after the meteorological data have been read and subroutine XOQCALC5 has calculated the hourly X/Q values. Subroutine $P R O C$ combines the hourly values into running mean values for averaging periods specified in the Default Values Form and accounts for the data in the X/Q frequency distributions. If, during any period there are too many missing hourly values, subroutine PROC discards the period.

Figure 30 shows the procedure followed in subroutine PROC. The first time that subroutine PROC is called it sets the range of bins for the cumulative frequency distribution. The upper limit to the range for the 1- and 2-hour average X/Qs is based on the maximum 1-hour centerline $X / Q$ encountered in the first 10,000 hours of data. The upper limit for longer period averages is based on the maximum sector-average $X / Q$.

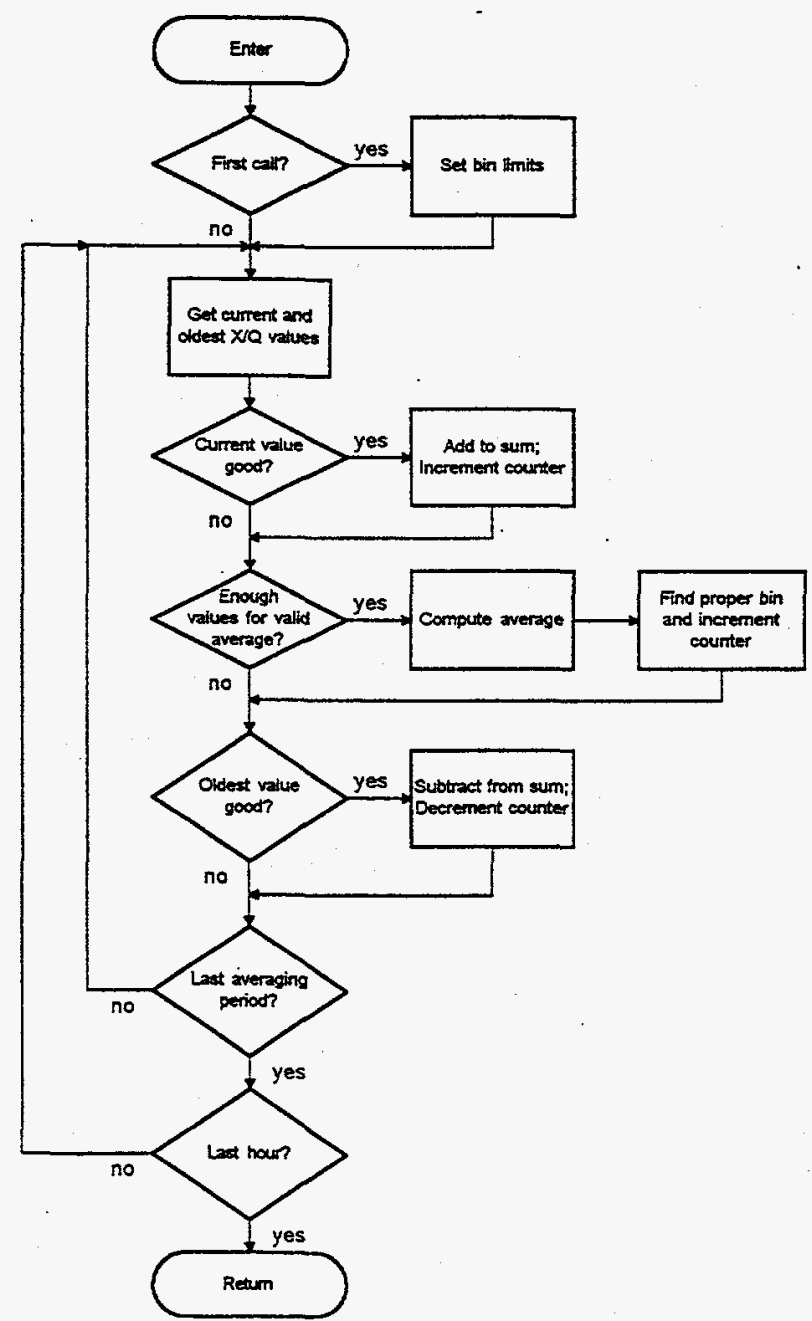

Figure 30 Subroutine PROC organization 
The subroutine then steps through the hourly $X / Q$ values and averaging periods. The procedure used to calculate the running mean $X / Q$ s uses the current hourly $X / Q$ and the oldest hourly $X / Q$ included in the current average. If the current $X / Q$ is good, it is added to a running sum and the counter associated with the sum is incremented. If there are sufficient good values in the sum, a new running mean is calculated and the value is counted in the appropriate frequency distribution bin. Next, the subroutine checks the oldest value. If it is good, the value is subtracted from the sum and the counter is decremented to prepare for processing the next bour.

\subsubsection{Subroutine RECORD}

Subroutine RECORD writes the information read from the run specification file by Subroutine SCENREAD to the primary output $(\mathrm{log})$ file. In addition, the subroutine writes the lower and upper bounds for the wind direction window used to determine when effluent from the release point reaches the intake and the name of the expanded output file to the log file. Combined with Subroutine SCENREAD, Subroutine RECORD provides users with the opportunity to confirm that scenario used in ARCON95 calculations is the intended scenario.

\subsubsection{Subroutine SCENREAD}

Subroutine SCENREAD reads the run specification file identified in the command line invoking the ARCONF FORTRAN code. This file, which contains the user input to ARCON95, is described in detail in Section 4.4.1. In addition to reading the run specification file, the subroutine performs two functions. It calculates the lower and upper bounds of the wind direction window that determines when the plume reaches the intake, and it requests a file name for the expanded output file when expanded output is selected in the run specification file.

\subsubsection{Subroutine SHIFT}

Subroutine SHIFT is called when processing of available data is complete and the is more meteorological data. The subroutine determines the length in hours, $n$, of the longest averaging period. It then moves the stability, wind, and hourly X/Q data for the last $n-1$ hours from the ends of the vectors containing these data to the beginning of the vectors.

After the data have been moved, the subroutine sets the variable FIRST_MET to $n$. FIRST_MET is the index of the meteorological data vectors where the first new meteorological data will be place. FIRST_XOQ will be set to this value in subroutine XOQCALC5 after it completes calculating the hourly $\mathrm{X} / \mathrm{Q}$ values.

\subsubsection{Subroutine SUMMARY}

Subroutine SUMMARY is the primary output routine for ARCON95. It is called after all meteorological data bave been read and after all hourly X/Qs have been calculated and processed. Then, subroutine SUMMARY calculates totals and writes summary statistics to the $\log$ file. If expanded output has been selected, subroutine SUMMARY writes the $X / Q$ 
frequency distributions to the quality assurance file. It calculates the cumulative frequency distributions and writes them to the cumulative frequency distribution file.

After the cumulative frequency distributions have been written subroutine SUMMARY calls subroutine $\mathrm{XOQ} 95$, which calculates the $\mathrm{X} / \mathrm{Q}$ for each averaging period that is exceeded no more than 5 percent of the time. These 95 th percentile $X / Q s$ are written to the log file by subroutine SUMMARY. The last section of subroutine SUMMARY calculates the 95th percentile X/Qs for standard averaging intervals, e.g. 2 to 8 hours and 8 to 24 hours.

Figure 31 shows a flow chart for subroutine SUMMARY.

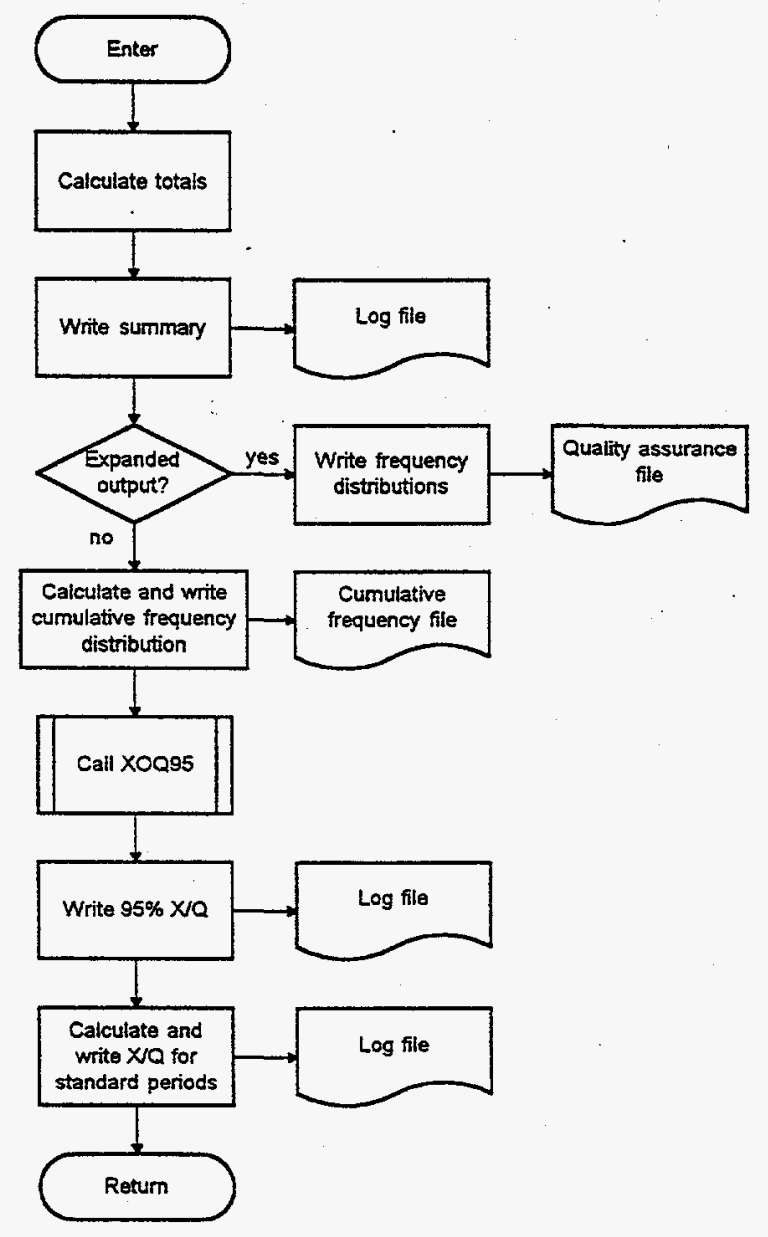

Figure 31 Subroutine SUMMARY organization

\subsubsection{Subroutine WAKECORR}

Subroutine WAKECORR calculates the building-wake corrections to the diffusion coefficients calculated by subroutine NSIGMA. The corrections are functions of the building cross- 


\section{ARCON95}

sectional area, wind speed, and distance from the release point to the receptor. These corrections are described in Section 3.2. Ramsdell and Fosmire (1995) present a detailed derivation of the equations used to calculate the corrections.

\subsubsection{Subroutine WINDYXOQ}

Subroutine WINDYXOQ is used to calculate the hourly centerline and sector-average X/Qs. When the wind is less than the minimum wind speed set in the Default Values form, the subroutine is called with the minimum wind speed regardless of wind direction. When the wind speed is greater than the minimum speed, the subroutine is called only if the wind direction falls within the wind direction window. In this case, the 10-meter wind is used if the release is at ground level ( $\leq 10$ meters) and the release-height wind is used if the release is at a height greater than 10 meters.

The argument list for subroutine WINDYXOQ includes all of the parameters that define the release point, the release point-receptor geometry, and the meteorological conditions. It also includes the release type definition supplied by the user in the Source Input form. This type definition is specified by the value of the variable rtype. It is 1 for ground-level releases, 2 for vent releases, and 3 for stack releases.

Figure 32 shows the process followed in subroutine WINDYXOQ. If thype is two or greater the $\mathrm{X} / \mathrm{Q}$ for a stack release is calculated, and if it two or less $\mathrm{X} / \mathrm{Q}$ is calculated for a groundlevel release.

If rtype is two $X / Q$ is calculated for both an elevated release and a ground-level release. The two $X / Q$ values are combined to get a single value using the methodology for mixed-mode

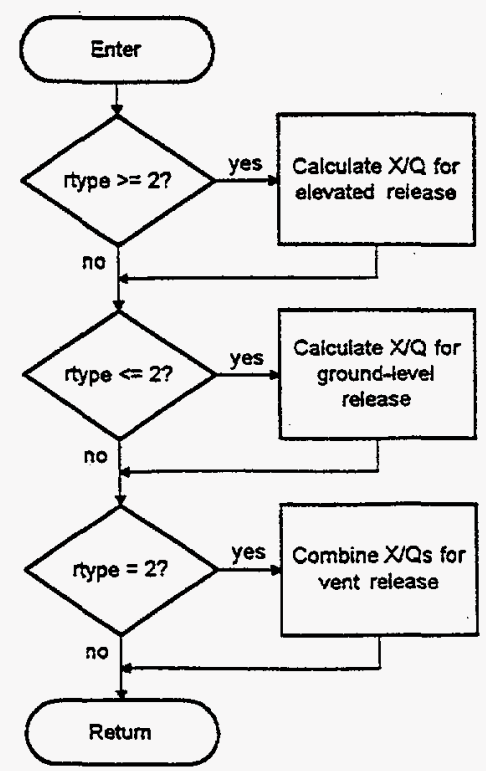

Figure 32 Subroutine WINDYXOQ organization 
releases described in Section 3.2. This methodology follows the procedure described in Regulatory Guide 1.111 (NRC 1977) and implemented in the XOQDOQ computer code (Sagendorf et al. 1982).

\subsubsection{Subroutine XOQCALC5}

Subroutine XOQCALC5 processes the hourly meteorological data. It is called by ARCON95 following subroutine MET_READ. When subroutine XOQCALC5 is called, it steps through the meteorological data an hour at a time from the hour specified in the variable FIRST_MET to the hour specified in LAST_MET. The first time subroutine WINDYXOQ is called, FIRST_MET will be 1, in all subsequent calls FIRST_MET will be equal to the longest averaging period defined in the Default Values form. LAST_MET will be 10,000 until the last meteorological data file is read. Then it will have a value $\leq 10,000$ that is the index of the end of the meteorological data read from the last meteorological data file.

Figure 33 shows the procedure followed as subroutine XOQCALC5 processes the meteorological data. First the subroutine checks the stability class. If the stability class is missing, the subroutine cannot calculate a X/Q. Consequently, the subroutine sets both the centerline and sector-average $X / Q$ s to -1.0 to indicate missing values. Next, the subroutine checks to see if both wind speeds are missing. If they are, the $X / Q s$ are set to -1.0 . If either the wind speed is present the 10 -meter and release-height wind speeds are calculated.

The subroutine then checks for calm winds. If the wind is less than the minimum wind speed set in the Default Values form, subroutine WINDYXOQ is called with the minimum speed as the wind speed. In this case the wind direction is not checked because the effluent is assumed to drift from the release point to the receptor regardless of wind direction.

Finally if the wind is not calm, the subroutine checks the wind direction. If both wind directions are missing, the $\mathrm{X} / \mathrm{Q}$ are set to -1.0 . When the wind direction is good, the direction is compared with the wind direction window that contains the wind directions assumed to carry the effluent from the release point to the receptor. If the wind direction is not in the window, the X/Qs are set to 0.0 . Otherwise, subroutine XOQCALC5 calls subroutine WINDYXOQ to calculate the hourly X/Qs.

After all hourly X/Qs have been calculated, subroutine XOQCALC5 updates the record of maximum hourly values. These values are used to set the range of bins for the X/Q frequency distributions the first time subroutine PROC is called, and the final values are written to the log file. The last task performed by subroutine XOQCALC5 prior to retuming to the main program is to set the values of FIRST_XOQ, LAST_XOQ, and TOT_XOQ.

\subsubsection{Subroutine XOQ95}

Subroutine XOQ95 calculates the 95 th percentile X/Q for each averaging period. The subroutine start by checking the number of averages calculated for each period. If fewer than 20 averages were calculated, the subroutine sets the 95 th percentile value to 0.0 and skips further calculations. 


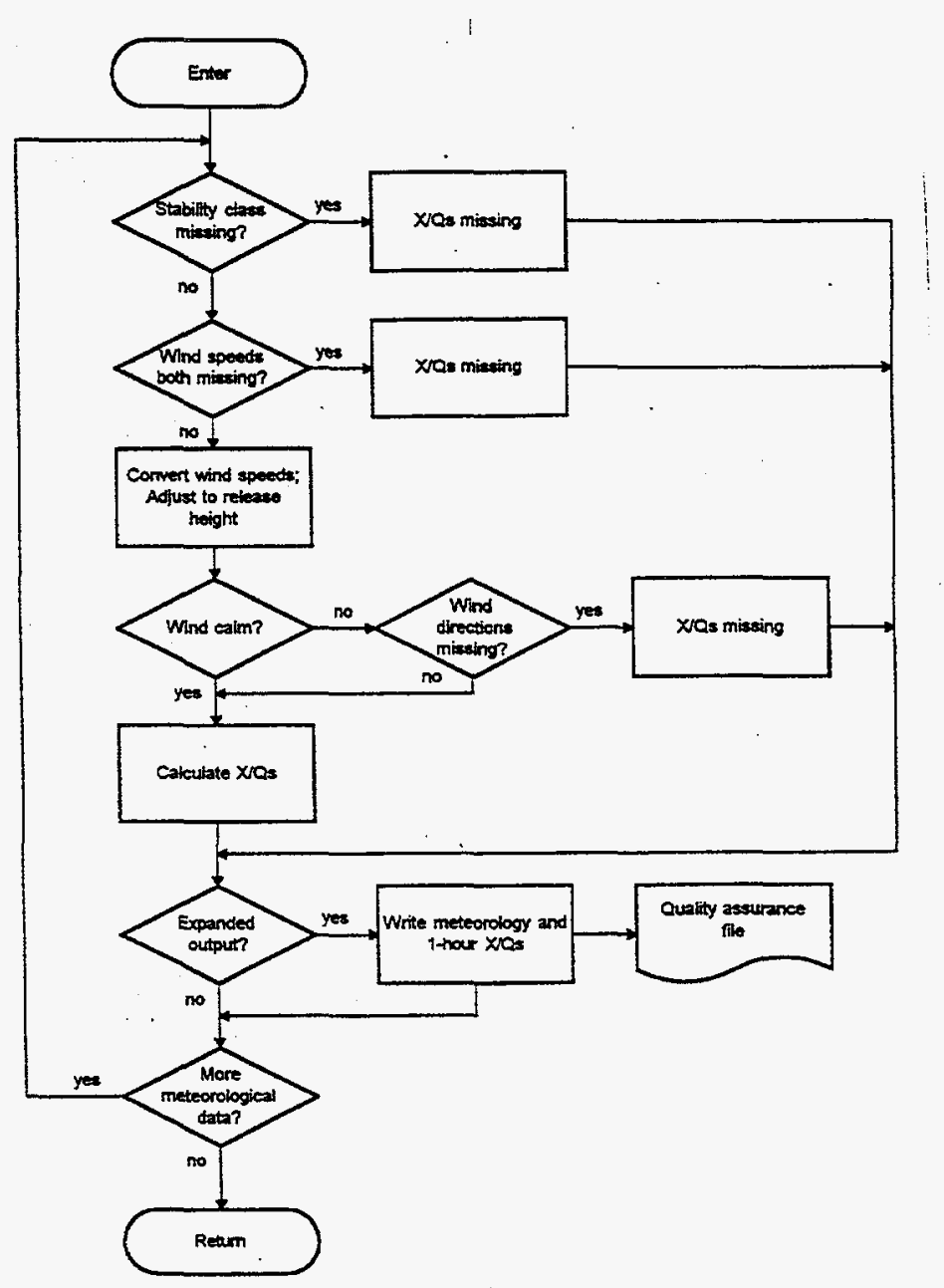

Figure 33 Subroutine XOQCALC5 organization

When the number of averages is sufficient to permit calculation of the 95 th percentile value, the subroutine calculates the number of hours represented by five percent of the total number of averages. It then searches the cumulative frequency distribution bins to find the bin containing the 95 th percentile $X / Q$. The 95 th percentile $X / Q$ can not be determined if this bin is the bin used to count the number of values above the range of the cumulative frequency distribution. In this case, the 95 th percentile $X / Q$ is set to -99999 . If the 95 th percentile $X / Q$ is in the bin that is used to count the number of values below the range, the 95 th percentile $\mathrm{X} / \mathrm{Q}$ is set to the lower bound of the range. Finally, if the 95 th percentile $\mathrm{X} / \mathrm{Q}$ falls in a bin within the cumulative frequency distribution range, the 95 th percentile $X / Q$ is calculated by linear interpolation between the upper and lower bounds of the bin. 
Programmer's Guide

\subsection{Quality Assurance}

ARCON95 has been developed, and tested in accordance with the requirements of ANSI/ASME NQA-1, 1986 edition (ASME 1986), Quality Assurance Program Requirements for Nuclear Facilities, as interpreted by the PNL Quality Assurance (QA) Program. PNL QA procedures have been used to determine specific Quality Assurance requirements. In addition to the use of the programming standards listed above the following measures undertaken to ensure program quality:

- Individual program elements that perform calculations have been tested independently. The tests includes hand check of representative calculations. The functioning of these elements was then rechecked in conjunction with tests of other program elements when ARCON95 was run.

- Program elements involved in data input were checked by writing input data to output files and comparing the data in the input and output files. This process also checked the storage and transfer of input data within ARCON95.

- A series of test cases were run using the full ARCON95 code. These test cases exercised the range of program options. Input and output files for each of the test cases were examined for accuracy and consistency.

- The code was placed under configuration control at the beginning of the developer's code tests. Changes in the code during the tests are logged in the code of the program element changed.

- Following completion of the ARCON95 code and a draft of this manual, an independent review was conducted. This review included examination of the design specification for ARCON95, the ARCON95 code, the records of the code tests by the developer, and this manual. No coding errors were identified during the review. This user's guide has been revised based on the reviewer's comments.

- The ARCON95 code included a disclaimer during development that stated that the code had not completed quality assurance tests. This disclaimer and the date of the were written to the ARCON95 log until the quality assurance tests were completed. The disclaimer was removed from the output and the ARCON95 code was recompiled with a version date and time of April 1, 1995, 7:00 am.

- The files distributed as part of Version 1.0 of ARCON95 have all been given an April 1, 1995 date and a 7:00 a.m. time. 



\section{References}

ASME. 1986. Quality Assurance Program Requirements for Nuclear Facilities. ANSI/ASME NQA1, American Society of Mechanical Engineers.

Bander, T. J. 1982. PAVAN: An Atmospheric Dispersion Program for Evaluating Design Basis Accidental Releases of Radioactive Materials from Nuclear Power Stations. NUREG/CR-2858. U.S. Nuclear Regulatory Commission, Washington D.C.

Frenkiel, F. N. 1953. "Turbulent Diffusion: Mean Concentration in a Flow Field of Homogeneous Turbulence." Advances in Applied Mechanics 3:61-107.

Gifford. F. A. 1961. "Use of Routine Meteorological Observations for Estimating Atmospheric Dispersion." Nuclear Safety 17(1):68-86.

Golder, D. 1972. "Relations Among Stability Parameters in the Surface Layer." BoundaryLayer Meteorology 3(1):47-58.

Kao, S. K. 1984. "Theories of Atmospheric Transport and Diffusion." In Atmospheric Science and Power Production. DOE/TIC-27601, D. Randerson, ed. U.S. Department of Energy, Washington, D.C. pp. 189-239.

Martin, D. O. and J. A. Tikvart. 1968. "A General Atmospheric Diffusion Model for Estimating the Effects on Air Quality of One or More Source." Presented at 61st Annual Meeting of the Air Pollution Control Association for NAPCA. St. Paul, Minnesota.

Murphy, K. G. and K. M. Campe. 1974. "Nuclear Power Plant Control Room Ventilation System Design for Meeting General Criterion 19." In Proceedings of the 13th AEC Air Cleaning Conference, August 12-15, 1974, San Francisco, Califomia. CONF-740807, U.S. Atomic Energy Commission, Washington, D.C.

NRC. 1972. Onsite Meteorological Programs. Regulatory Guide 1.23. U.S. Nuclear Regulatory Commission, Washington, D.C.

NRC. 1977. Methods for Estimating Atmospheric Transport and Dispersion of Gaseous Effluents in Routine Releases from Light-Water-Cooled Reactors. Regulatory Guide 1.111, Revision 1. U.S. Nuclear Regulatory Commission, Washington, D.C.

NRC. 1981. "Standard Review Plan 6.4 Control Room Habitability System." In Standard Review Plan for the Review of Safety Analysis Reports for Nuclear Power Plants. NUREG0800. (1987) U.S. Nuclear Regulatory System, Washington, D.C.

Panofsky, H. A. and J. A. Dutton. 1984. Atmospheric Turbulence. J. Wiley \& Sons, New York.

Ramsdell, J. V., Jr. 1988. Atmospheric Diffusion for Control Room Air Habitability Assessments. NUREG/CR-5055, U.S. Nuclear Regulatory Commission, Washington, D.C. 


\section{ARCON95}

Ramsdell, J. V., Jr. 1990. Diffusion in Building Wakes for Ground-Level Releases. Atmospheric Environment 24B:377-388.

Ramsdell, J. V., Jr. 1991. EXTRAN: A Computer Code for Estimating Concentrations of Toxic Substances at Control Room Air Intakes. NUREG/CR-5656, U.S. Nuclear Regulatory Commission, Washington, D.C.

Ramsdell, J. V. Jr. and C. J. Fosmire. 1995. Atmospheric Dispersion Estimates in the Vicinity of Buildings. PNL-10286. Pacific Northwest Laboratory, Richland, Washington.

Ramsdell, J. V., Jr., C. A. Simonen, and K. W. Burk. 1994. Regional Atmospheric Transport Code for Hanford Emission Tracking (RATCHET). PNWD-2224 HEDR. Battelle, Pacific Northwest Laboratories, Ricbland, Washington.

Sagendorf, J. F., J. T. Goll, and W. F. Sandusky. 1982. XOQDOQ: Computer Program for the Meteorological Evaluation of Routine Releases at Nuclear Power Stations. NUREG/CR2919 , U.S. Nuclear Regulatory Commission, Washington, D.C.

Tadmor, J. and Y. Gur. 1969. "Analytical Expressions for Vertical and Lateral Dispersion Coefficients in Atmospheric Diffusion." Atmospheric Environment. 3:688-689. 
Appendix A ARCON95 FORTRAN Computer Code 



\section{A. 1 ARCON95}

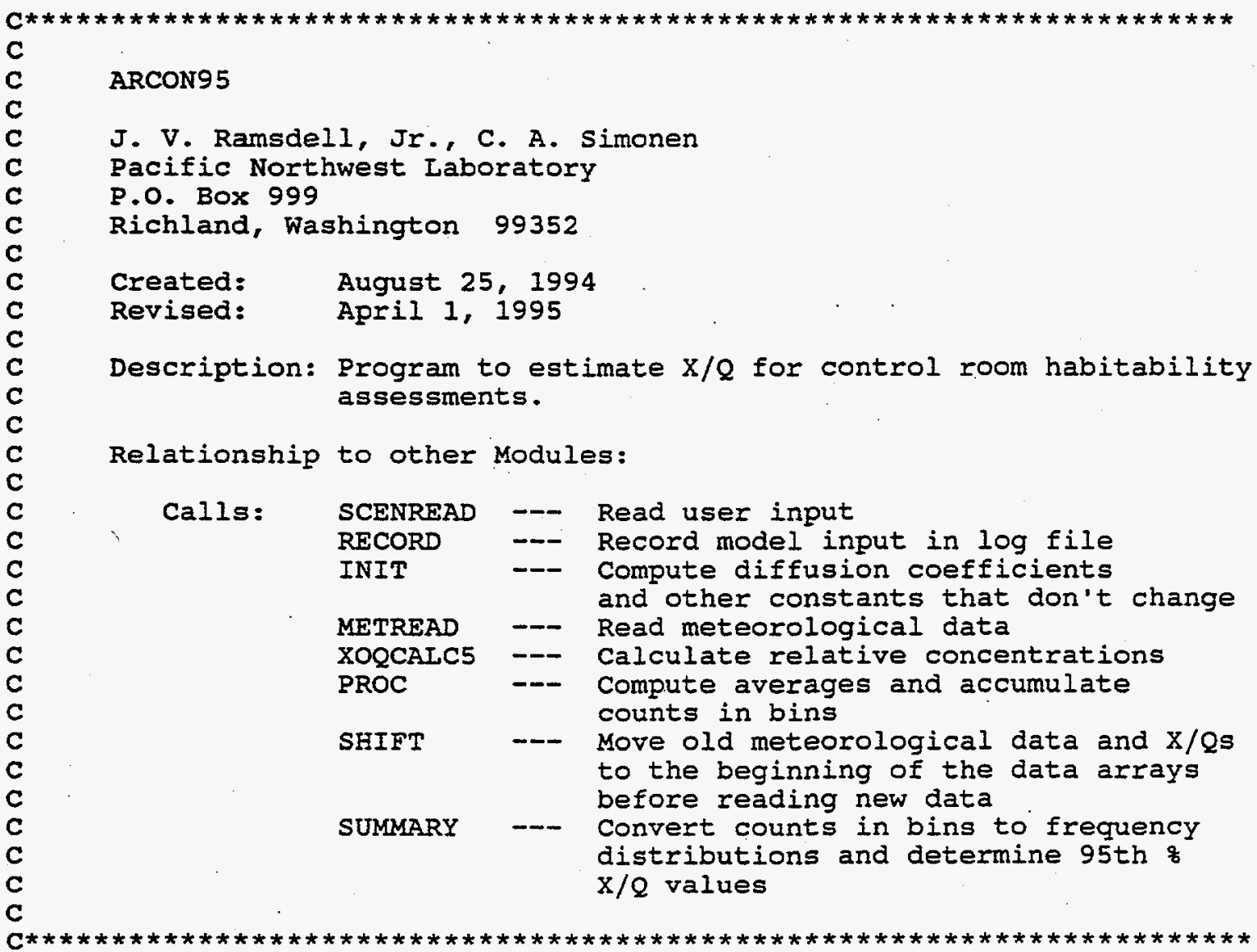

IMPLICIT NONE

INCLUDE 'PARAM. INC'
INCLUDE 'MET.INC'
INCLUDE 'SCENARIO.INC'
INCLUDE 'UNITS.INC'
INCLUDE 'XOQ.INC'

LOGICAL*I UO

CHARACTER *8 RTIME

CHARACTER* 10 RDATE

INTEGER 2 SHR, SMIN, SSEC, S100, EHR, EMIN, ESEC, E100

INTEGER*2 YY, MM, DD, HH, MIN, SS, HS

REAL DETIME, PROCTIME, SUMTIME, XOQTIME

C Get date and time of code execution

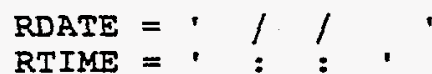




\section{ARCON95}

CAIL GETDAT ( $Y Y, M M, D D)$

CAIL GETTIM (HH, MIN, SS, HS)

WRITE( $\operatorname{RDATE}(1: 2)$,' (I2)') MM

WRITE( $\operatorname{RDATE}(4: 5), '(I 2) '$ ). DD

WRITE ( RDATE $(7: 10)$, '(I4)', YY

WRITE( $\left.\operatorname{RTIME}(1: 2), '(I 2.2)^{\prime}\right) \mathrm{HH}$

WRITE( RTIME (4:5), '(I2.2)' ) MIN

WRITE( $\operatorname{RTIME}(7: 8),(\operatorname{I2.2)})$ ) SS

DETIME $=0.0$

PROCTIME $=0.0$

XOQTIME $=0.0$

SUMTIME $=0.0$

C

Open Scenario Input File

OPEN( SCENUNIT, FILE=' ', STATUS='OLD', ERR=997)

C Read Scenario Data

CALL SCENREAD

IF ( TEST FLG) THEN

OPEN (UNTIT=qa unit, FIIE=qa file, status='unknown')

C

Open log file and output program name and run date

OPEN (UNIT=LOG_UNIT, FILE=LOG_FILE, STATUS='NEW', ERR=998)

WRITE (IOG_UNIT, 1)

1 FORMAT (//-Program Title: ARCON95.'//

+ 'Developed For: U.S. Nuclear Regulatory Commission'/

+ - Office of Nuclear Regulatory Research'/

+ Division of Regulatory Applications'//

+ Date: April 1, 1995 7:00 a.m.'//

+ NRC Contact(s): A. K. Roecklein Phone: (301) $4156223 \%$

+ J. J. Hayes Phone: (301) $4153167 \%$

+ J. Y. Lee Phone: (301) $4151080 \%$ /

+ Code Developer: J.V. Ramsdell Phone: (509) $3726316 \%$

+ Code Documentation: NUREG/CR-6331 //

+ 'The program was prepared for an agency of the United States',

+ 'Government. Neither'/' the United States Government nor any',

+ ' agency thereof, nor any of their'/' employees, makes any',

+ warranty, expressed or implied, or assumes any legal'/

+ ' liability or responsibilities for any third party' 's use,',

+ ' or the results of such'/' use, of any portion of this'.

+ ' program or represents that its use by such third'/' party',

+ ' would not infringe privately owned rights. '/ )

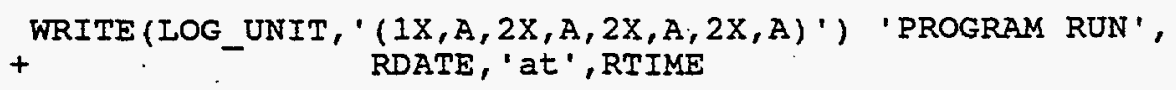

C Record user input on log file

CALL RECORD

C Compute variables that are functions of the scenario and

c stability but not functions of wind speed or direction

NUREG/CR-6331 


\section{CALI INIT}

C Read and process data

DO WHILE ( . NOT. END_MET )

C

Check on status of met data file, open new file if necessary

INQUIRE（UNIT=MET_UNIT, OPENED=UO )

IF( . NOT. UO ) THEN

C

Open Meteorological Data File if another file exists

IF ( NEXT MET .IE. NMETFILE) THEN

OPEN( MET UNIT, FILE=MET FIIE (NEXT_MET), STATUS='OLD',

$+\quad$ ERR $\equiv 999$ ) NEXT MET $=$ NEXT MET +1

ELSE -

$$
\text { ENDIF }
$$

ENDIF

CALL GETTIM(SHR, SMIN, SSEC, S100)

C Read meteorological data files $(<=10,000$ hours)

CALL METREAD

CALL GETTIM( EHR, EMIN, ESEC, E100)

DETIME = DETIME + 3600.* (EHR-SHR) + 60.* (EMIN-SMIN)

$+$

$+($ ESEC-SSEC $)+($ E100-S100)/100.

IF( TEST_FLG) THEN

WRITE $(\bar{q} a$ unit, '( $/ 2 x, a)$ ') 'ARCON95'

WRITE (QA_UNIT,'(/5X,A,I6)') 'FIRST MET $=$ ', FIRST_MET

WRITE (QA_UNIT,' $\left.(5 X, A, I 6)^{\prime}\right)$ 'LAST MET $=$ ', LAST_METT ENDIF

C Compute hourly $X / Q$ values

CALL GETTIM(SHR, SMIN, SSEC, S100)

WRITE $\left(*, \cdot(/ / A)^{\prime}\right)$ ' CALCULATING $X / Q$ '

CALI XOQCALC5

CALL GETTIM(EHR, EMIN, ESEC, E100)

XOQTIME $=$ XOQTIME $+3600 . *($ EHR-SHR $)+60 . *($ EMIN-SMIN $)$

$+($ ESEC-SSEC $)+($ E100-S100)/100.

C

Process first set of $\mathrm{X} / \mathrm{Q}^{\prime} \mathrm{s}$-- set cfd limits, accumulate values

CALI GETTIM(SHR, SMIN,SSEC,S100)

WRITE(*,'(/A)') ' PROCESSING X/Q DATA'

CALI PROC 


\section{ARCON95}

CALI GETTIM(EHR, EMIN, ESEC, E100)

PROCTIME $=$ PROCTIME + 3600.* (EHR-SHR) $+60 . *$ (EMIN-SMIN)

$+($ ESEC-SSEC $)+($ E100-S100)/100.

c

IF（.NOT. END_MET ) THEN

Move residual met. data AND $X / Q$ 's to front of data arrays

CALL SHIFT

ENDIF

ENDDO

! End of data input and processing

C Summarize and output results of calculations

CALL GETTIM(SHR, SMIN, SSEC, S100)

WRITE(*,'(/A)')' SUMMARIZING CALCULATIONS

CALI SUMMARY

CALI GETTIM(EHR, EMIN, ESEC, EIOO)

SUMTIME $=3600 . *($ EHR-SHR $)+60 . *(E M I N-S M I N)$

$+($ ESEC-SSEC $)+($ E100-S100)/100.

C Normal end of program

IF( TEST_FLG) THEN

WRITE ('̆a unit, ' $(/ 2 x, a)$ ') 'ARCON95'

WRITE ( QA $\bar{A}$ UNIT, 100) DETIME, XOQTIME, PROCTIME, SUMTIME

FORMAT $(/ \overline{5} \mathrm{X}$, 'DATA ENTRY TIME (SEC)

- $\quad / 5 \mathrm{X}, \mathrm{X} / \mathrm{Q}$ COMPUTATION TIME (SEC)

- $\quad / 5 X$, 'DATA PROCESSING TIME (SEC)

CLOSE ( QA UNIT)

$/ 5 \mathrm{X}$, ' SUMMARY TIME (SEC)

ENDIF

WRITE(LOG_UNIT,' $(2 \mathrm{X}, / \mathrm{A})$ ') ' NORMAI PROGRAM COMPLETION '

GO TO 1000

C Error end of program

997 STOP ' UNABLE TO OPEN SCENARIO INPUT DATA FILE '

998 STOP ' UNABLE TO OPEN LOG FILE ... CHECK FOR EXISTING NAME'

999 WRITE ( LOG_UNIT,' $(2 \mathrm{X}, / \mathrm{A})^{\prime}$ ')

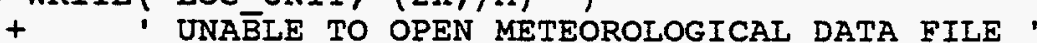

1000 CONTINUE

END 


\section{A.2 BLOCK DATA}

BLOCK DATA

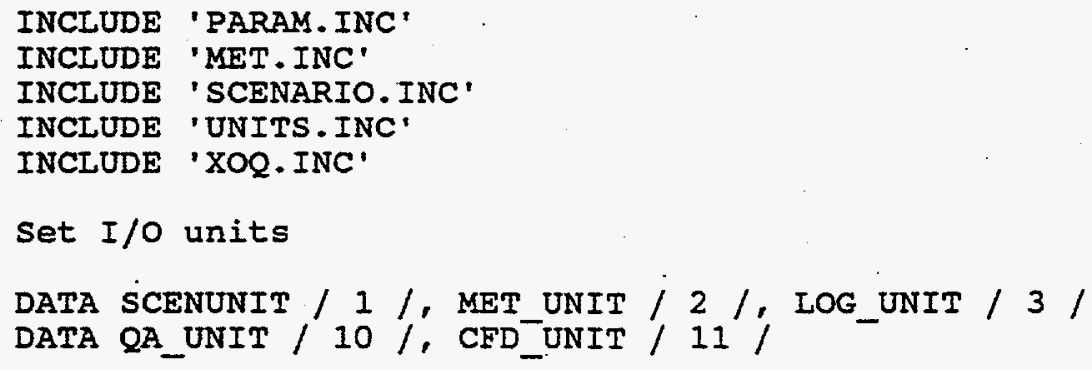

DATA SCENUNIT / $1 /$, MET_UNIT / $2 /$, LOG_UNIT $/ 3 /$ DATA QA_UNIT / 10 /, CFD_UNIT / 11 /

C Set I/O units

c Initialize the met data counters

DATA END_MET / .FALSE. /, NEXT_MET / 1 /, TOT_MET / $0 /$

$+\quad$ FIRST_MET / 1 /, LAST_MET / MAXHOURS /

c Initialize the $\mathrm{XOQ}$ counters

DATA FIRST XOQ / $0 /$, LAST XOQ / $0 /$, TOT XOQ $/ 0 / \%$

$+\quad$ calm_xog $/ 0 /$, in_sect $/ 0 /$ out_sect $/ 0 /$, elevated $/ 0 /$

c wind Speed Conversion Factors

DATA CF / 1.0, .447,.5144/

C Initialize the upper and lower $X / Q$ bounds

DATA CLMAX / $0.0 /, \operatorname{CLMIN~/~} 1.0 /, \operatorname{SAMAX} / 0.0 /, \operatorname{SAMIN} / 1.0 /$

C Set flag for calculation of bin limits

DATA LIMITS / .TRUE. /

END 


\section{ARCON95}

\section{A.3 CURVEFIX}

SUBROUTINE CURVEFIX( dist, UBAR, dsy, dsz )

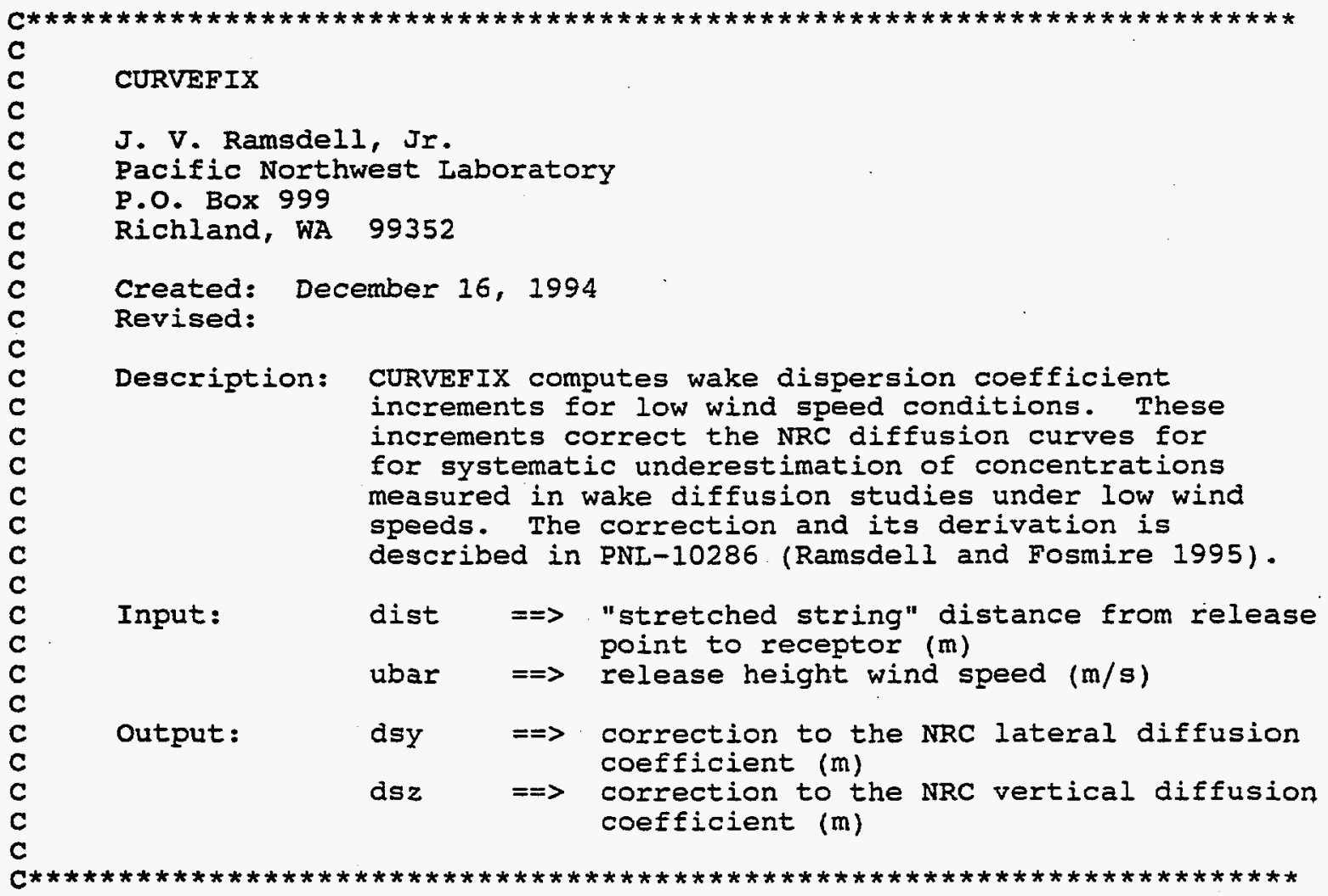

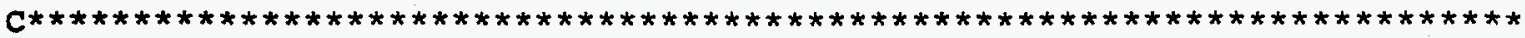

IMPLICIT None

REAL dist, ubar, dsy, dsz, hts, tt, vts

C Horizontal Time scale for Meander in seconds $==>$ hts

hts $=1000.0$

c Vertical Time scale for Meander in seconds $==>$ vts

vts $=100.0$

c Travel Time $=$ dist $/$ ubar $\Rightarrow t t$

tt $=$ dist / ubar

C Compute low wind speed diffusion coefficient corrections

dsy $=\operatorname{sQRT}(9.13 \mathrm{ES} *(1.0-(1.0+t t / \mathrm{hts}) * \operatorname{EXP}(-t t / \mathrm{hts})))$

$\mathrm{dsz}=\operatorname{sQRT}(6.67 \mathrm{E} 2 *(1.0-(1.0+t t / v t s) * \exp (-t t / v t s)))$

RETURN

END 


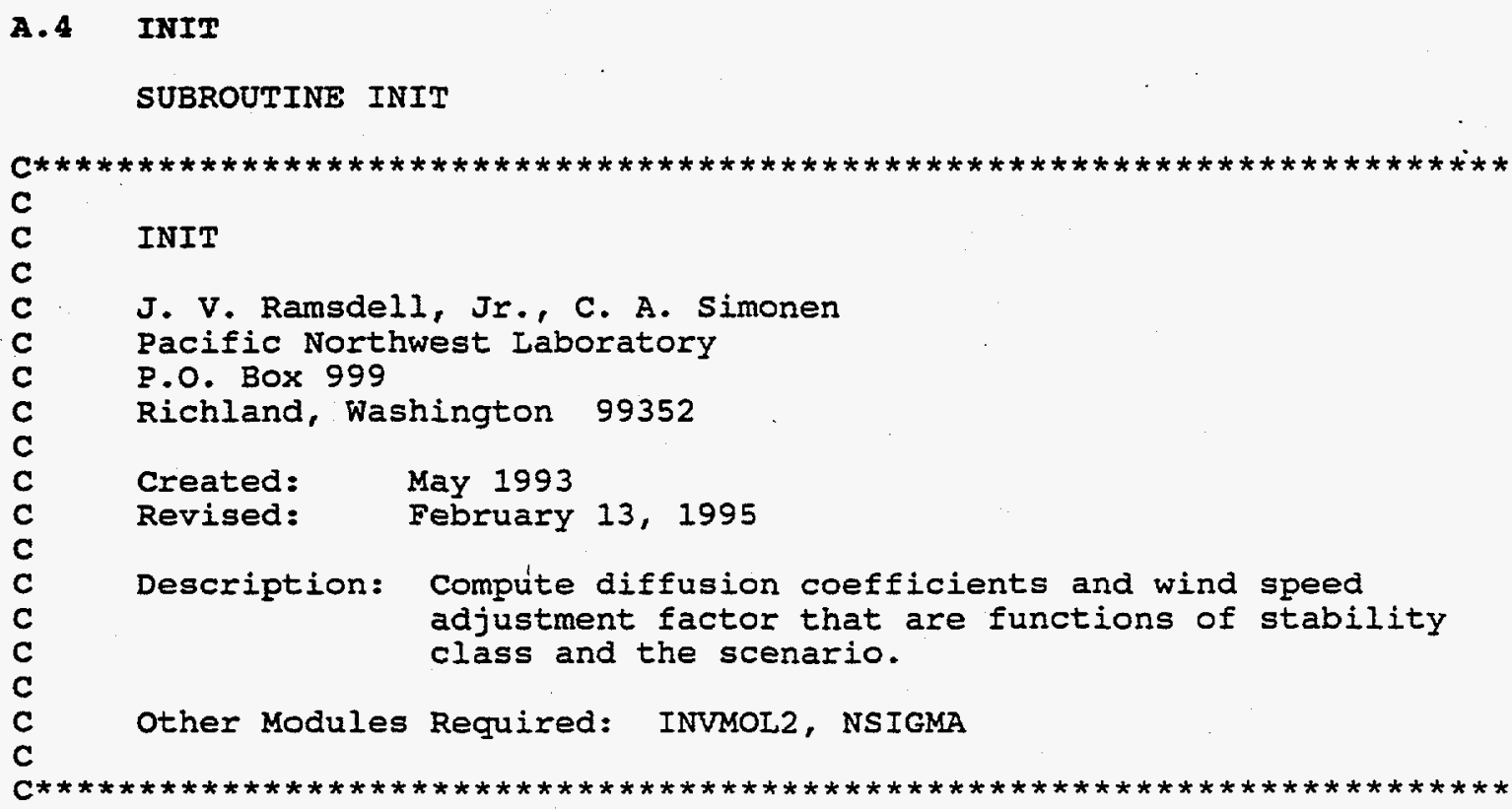

\section{IMPIICIT NONE}

INCLUDE 'PARAM. INC'

INCLUDE 'MET. INC'

INCLUDE 'SCENARIO. INC'

INCLUDE 'UNITS. INC'

INTEGER II

REAL INVMOL2

REAL INVI (7), PI, TRHT, SIGY, SIGZ, PSI,

$+\quad$ PSI1, PSI2, PSI10, PSIRH, X1, X2, Y10, YRH

$\mathrm{PI}=3.141593$

C Compute variables that are functions of the scenario and

c stability but not functions of wind speed or direction

DO $I 1=1,7$

C

Normal Diffusion Coefficients

CALI NSIGMA(DIST, II, SIGZ, SIGY)

NSIGY $(I 1)=$ SIGY

NSIGZ $(I 1)=S I G Z$

C

$z / L$ for the wind profile model

$\operatorname{INVL}(I 1)=\operatorname{INVMOL} 2(I 1, \mathrm{ZO})$

$\operatorname{ZOL}(I I)=10.0 * \operatorname{INVL}(I 1)$

c wind profile factors from the diabatic profile relationships 


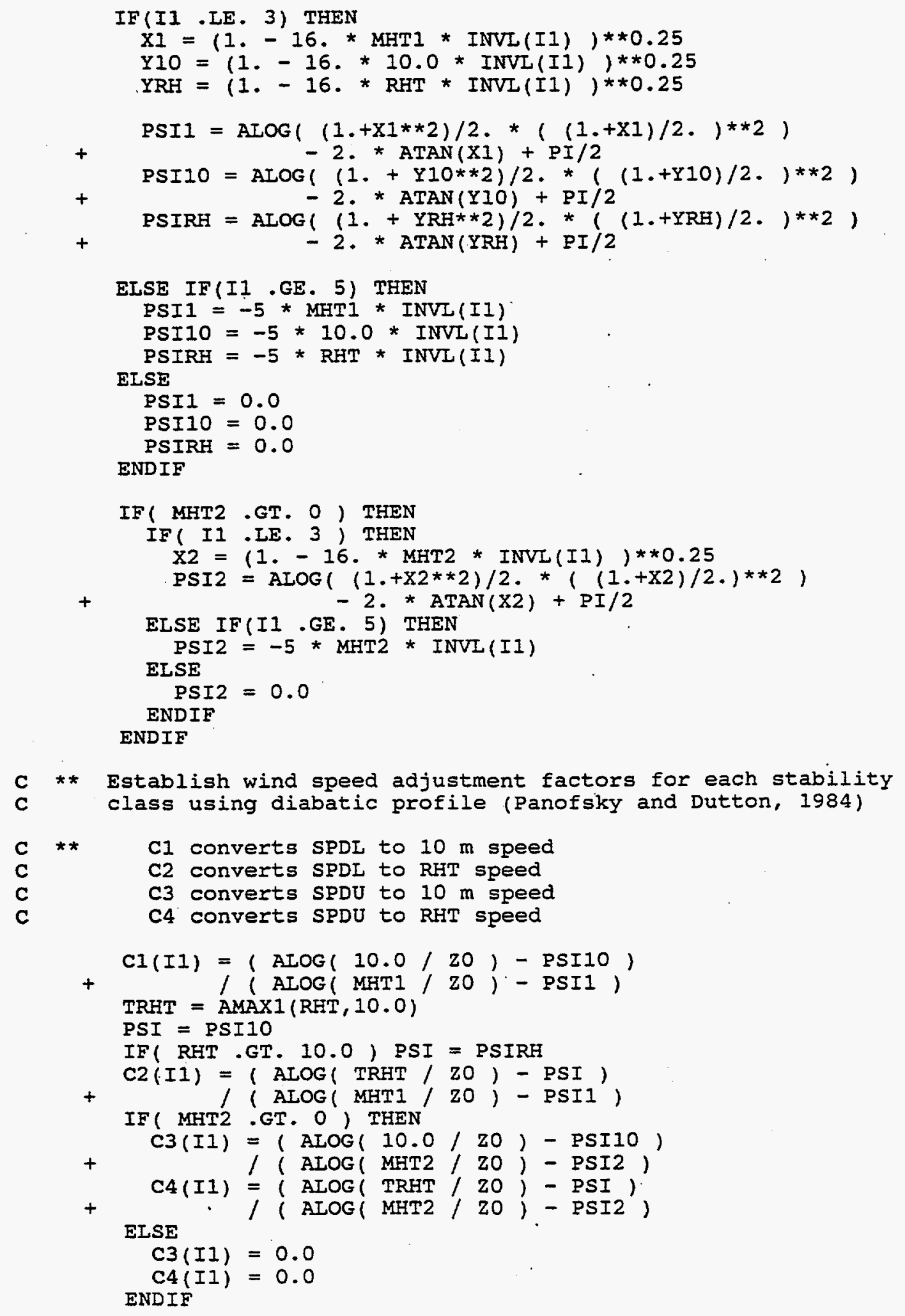

ENDDO 


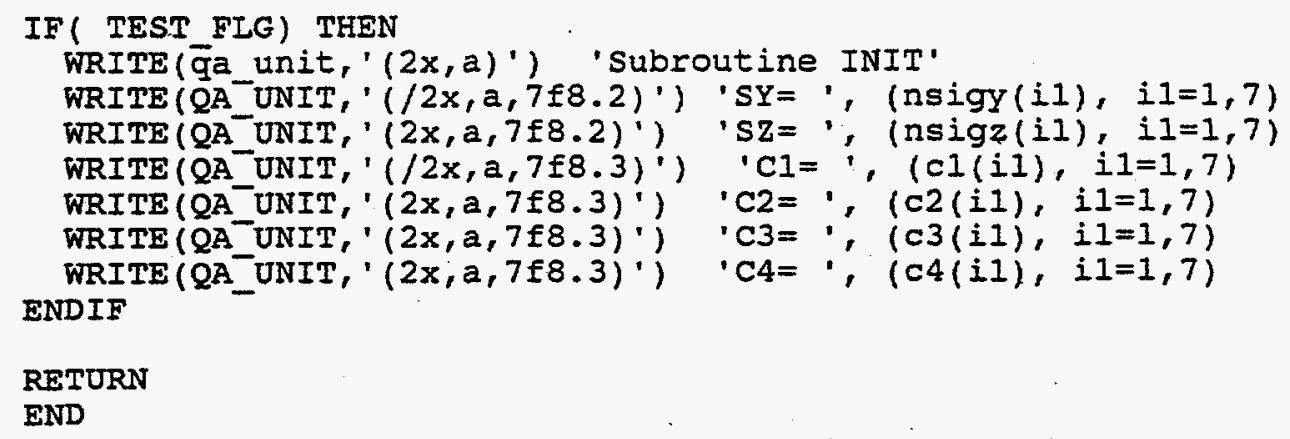




\section{ARCON95}

\section{A.5 INVMOL2}

FUNCTION INVMOL2( Stab, zo)

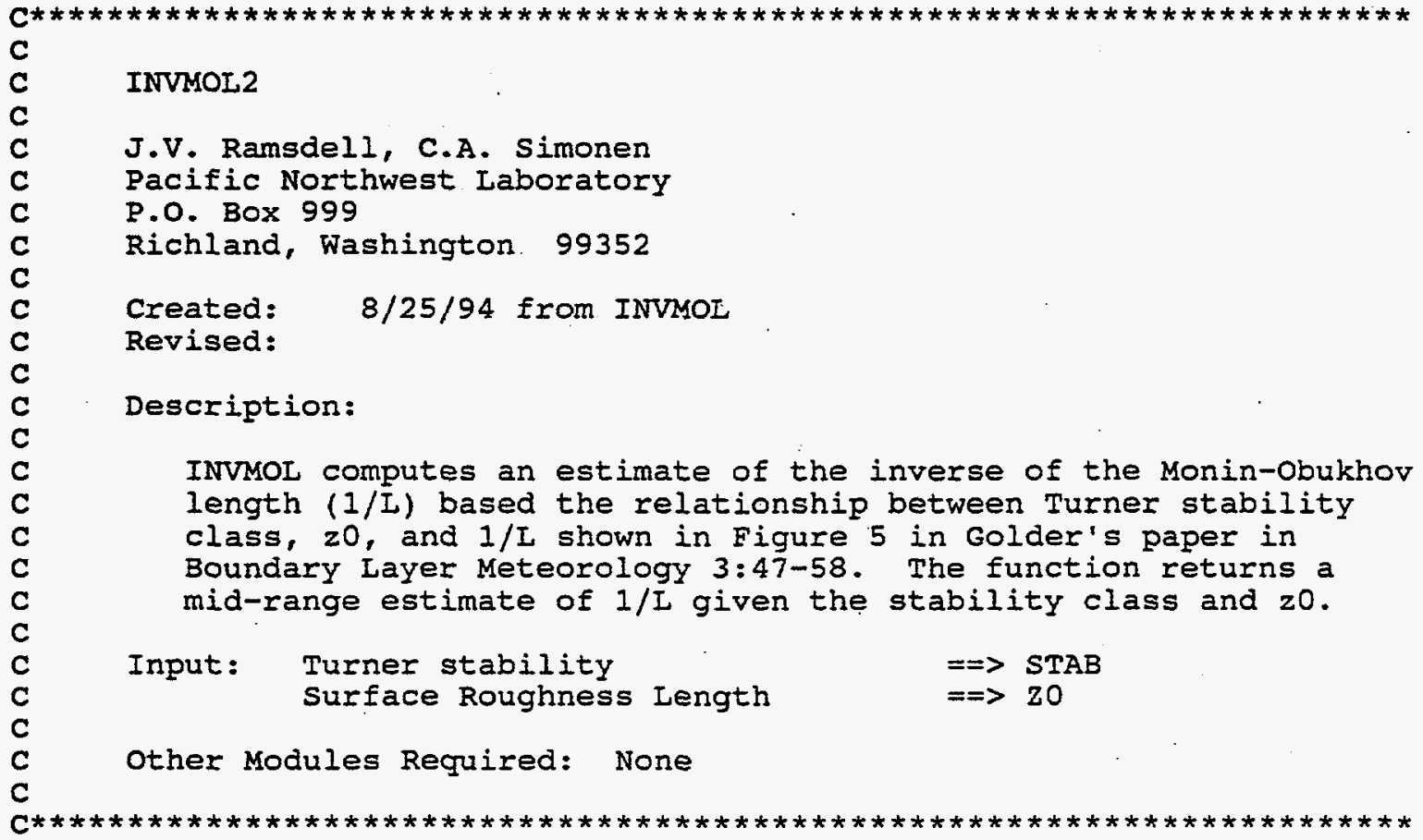

\section{IMPLICIT NONE}

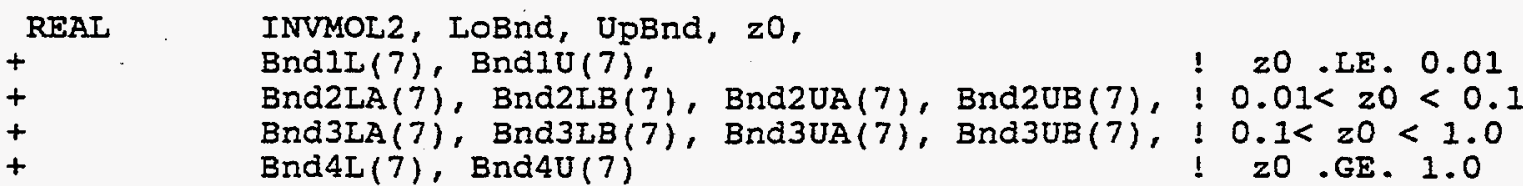

\section{INTEGER Stab}

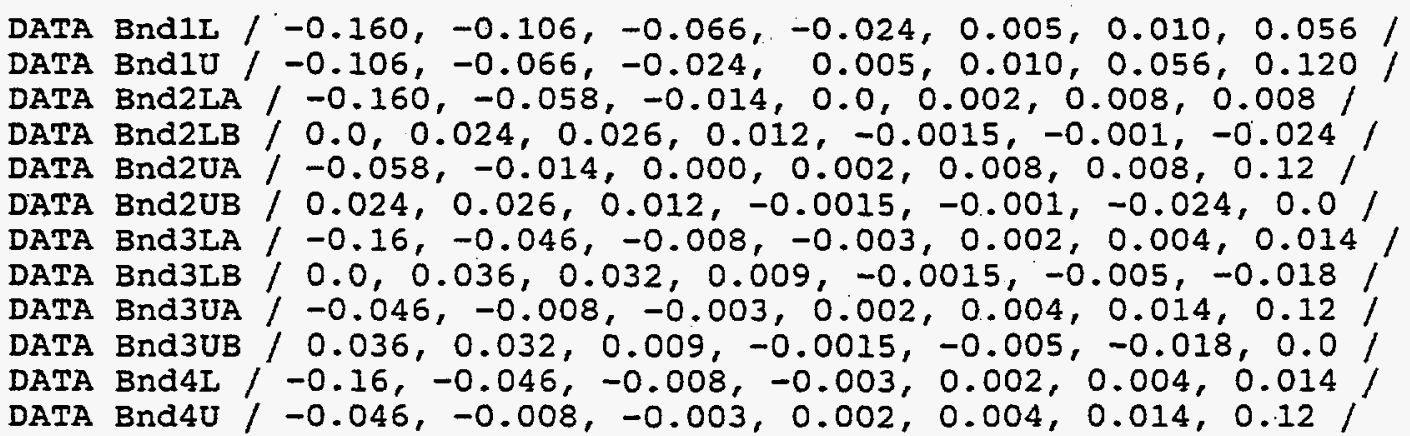

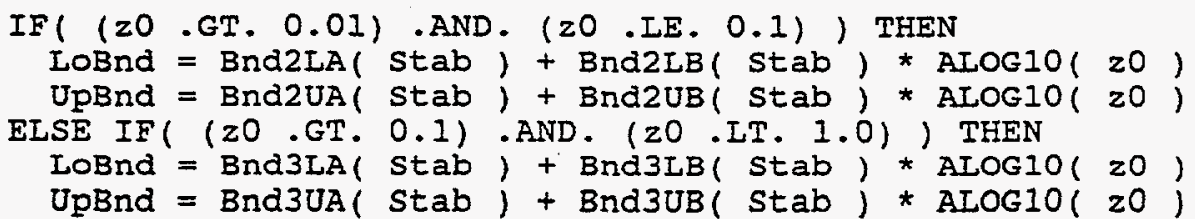




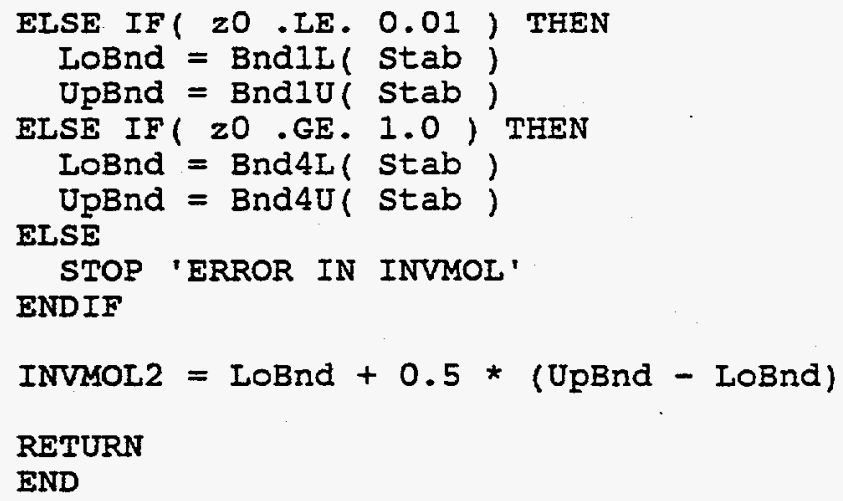

END 


\section{ARCON95}

A.6 METREAD

SUBROUTINE METREAD

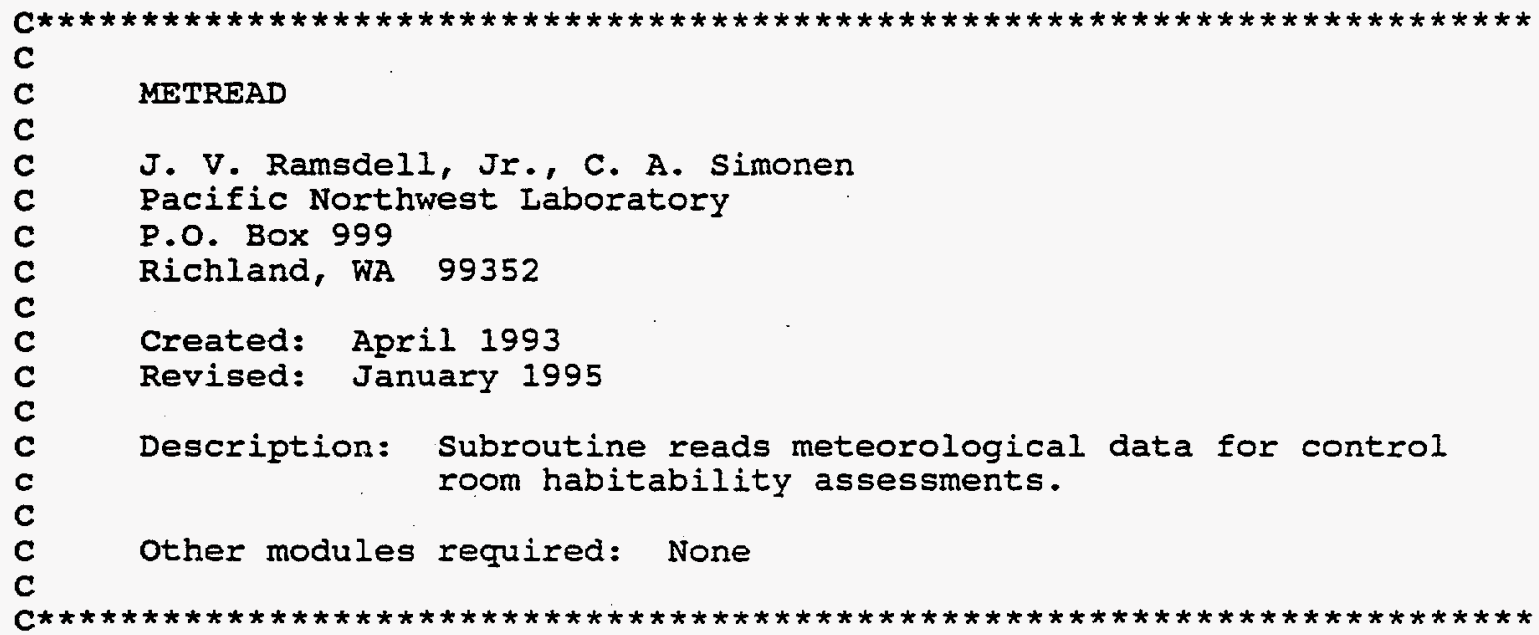

IMPLICIT NONE

INCLUDE 'PARAM. INC'

INCLUDE 'MET.INC'

INCLUDE 'UNITS. INC'

INCLUDE ' $\mathrm{XOQ}$. INC'

INTEGER STL, NMET

INTEGER*2 IDIR, LSPD, UDIR, USPD

INTEGER II, HR, MF

CHARACTER * 5 SITE

C Read first set of meteorological data records

WRITE(*,' (A)') ' READING METEOROLOGICAI DATA '

$\mathrm{NMET}=0$

DO II = FIRST MET, LAST MET

READ (MET UNIT, 1000, $\overline{\mathrm{N} D}=10, \mathrm{ERR}=998$ ) SITE, JULDAY(I1), CHOUR(I1),

$+\quad$ IDIR, ISPD, STL, UDIR, USPD

1000 FORMAT $(I X, A 5,3 X, I 3, I 2,2 X, I 3, I 4,1 X, I 2,2 X, I 3, I 4)$

$\mathrm{NMET}=\mathrm{NMET}+1$

$\mathrm{HR}=(\operatorname{JULDAY}(\mathrm{II})-1) * 24+\mathrm{CHOUR}(\mathrm{II})+1$

IF( (STI .GE. 1) A AND. (STL .LE. 7) ) THEN $\operatorname{STAB}(I I)=S T L$

ELSE

$\operatorname{STAB}(I I)=99$

ENDIF

IF( (IDIR . GE. 1) .AND. (IDIR .IE. 360) ) THEN $\operatorname{DIRL}(I I)=\operatorname{IDIR}$

ELSE

$\operatorname{DIRI}(I I)=999$

ENDIF 


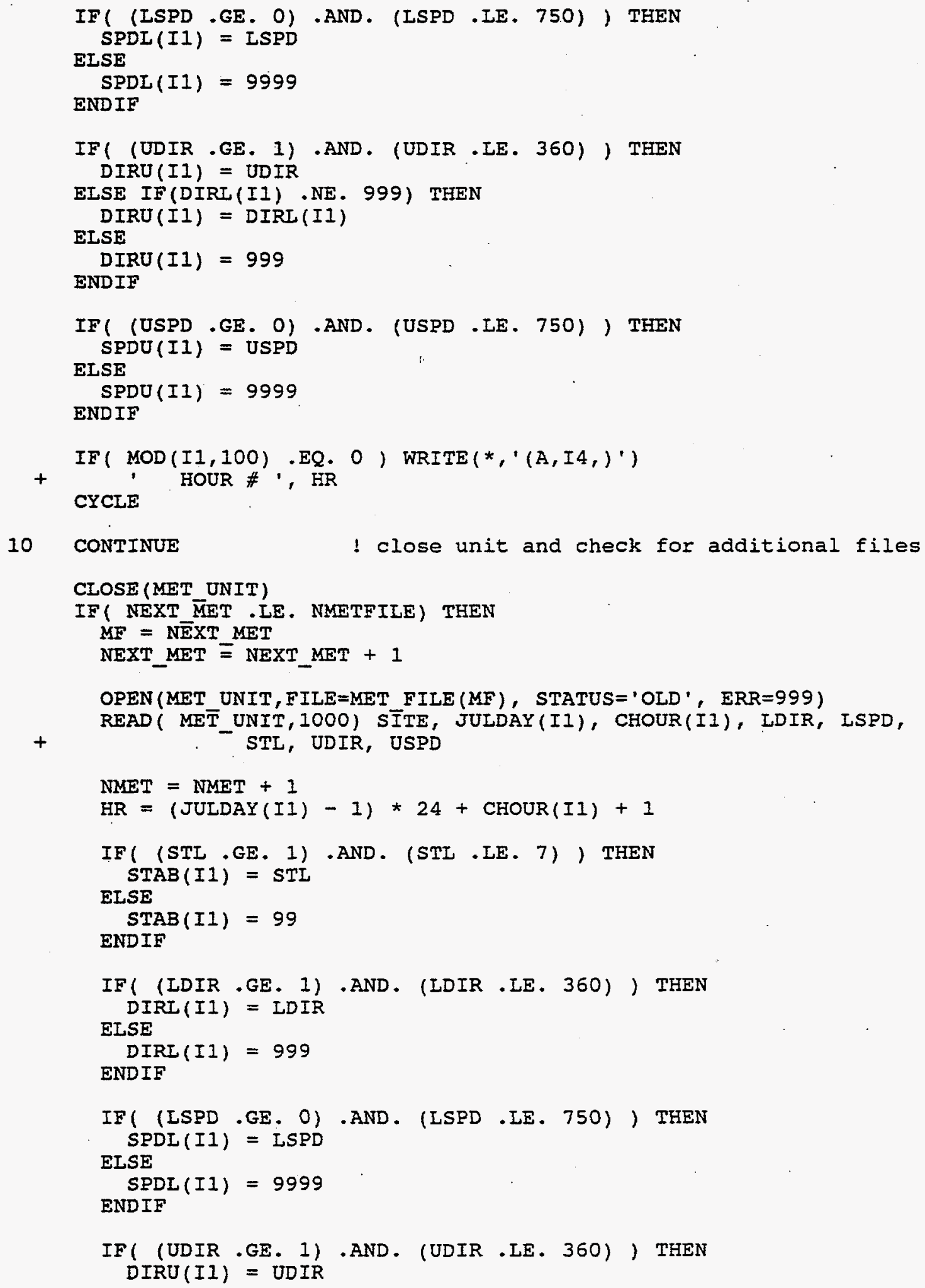




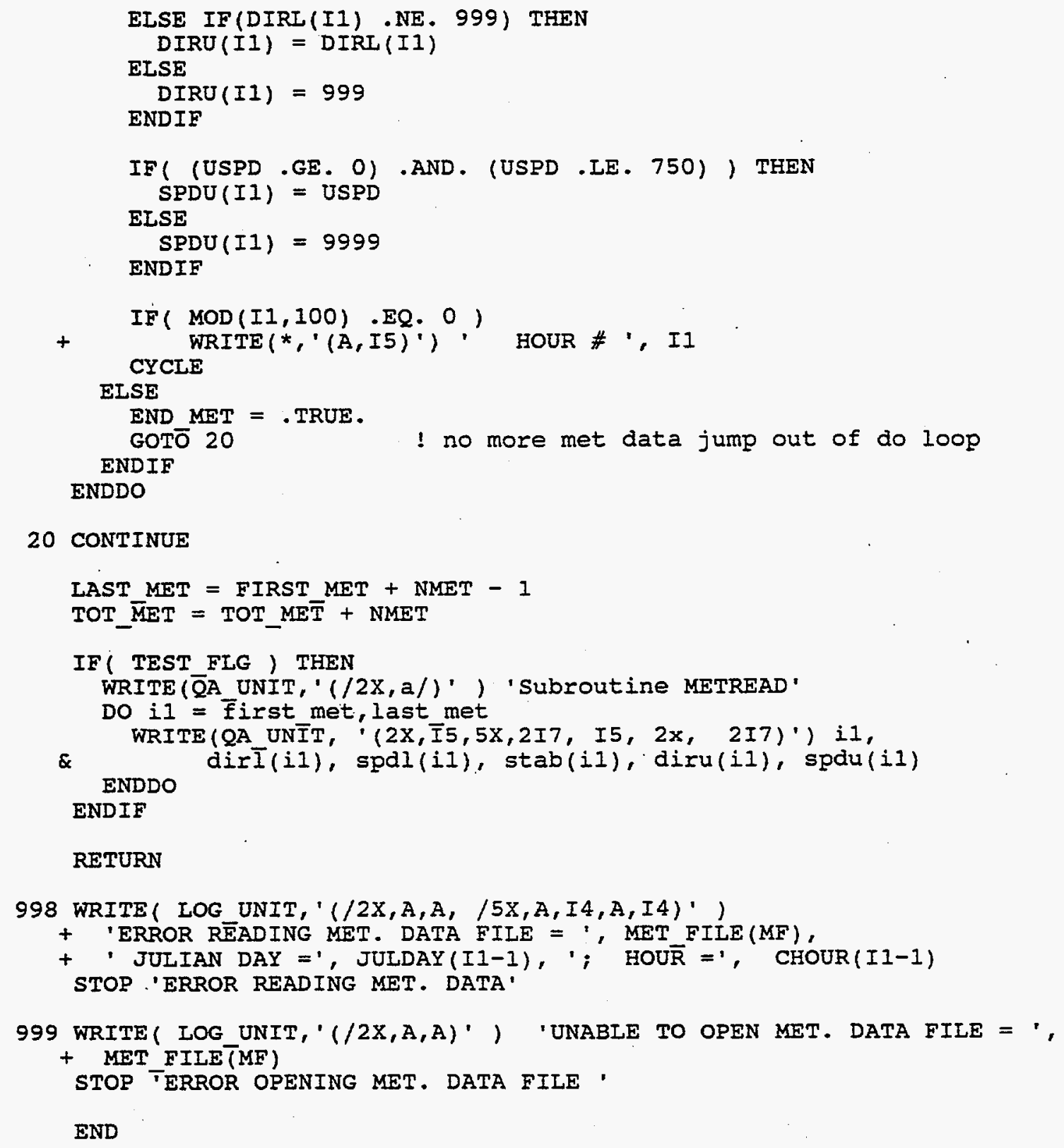




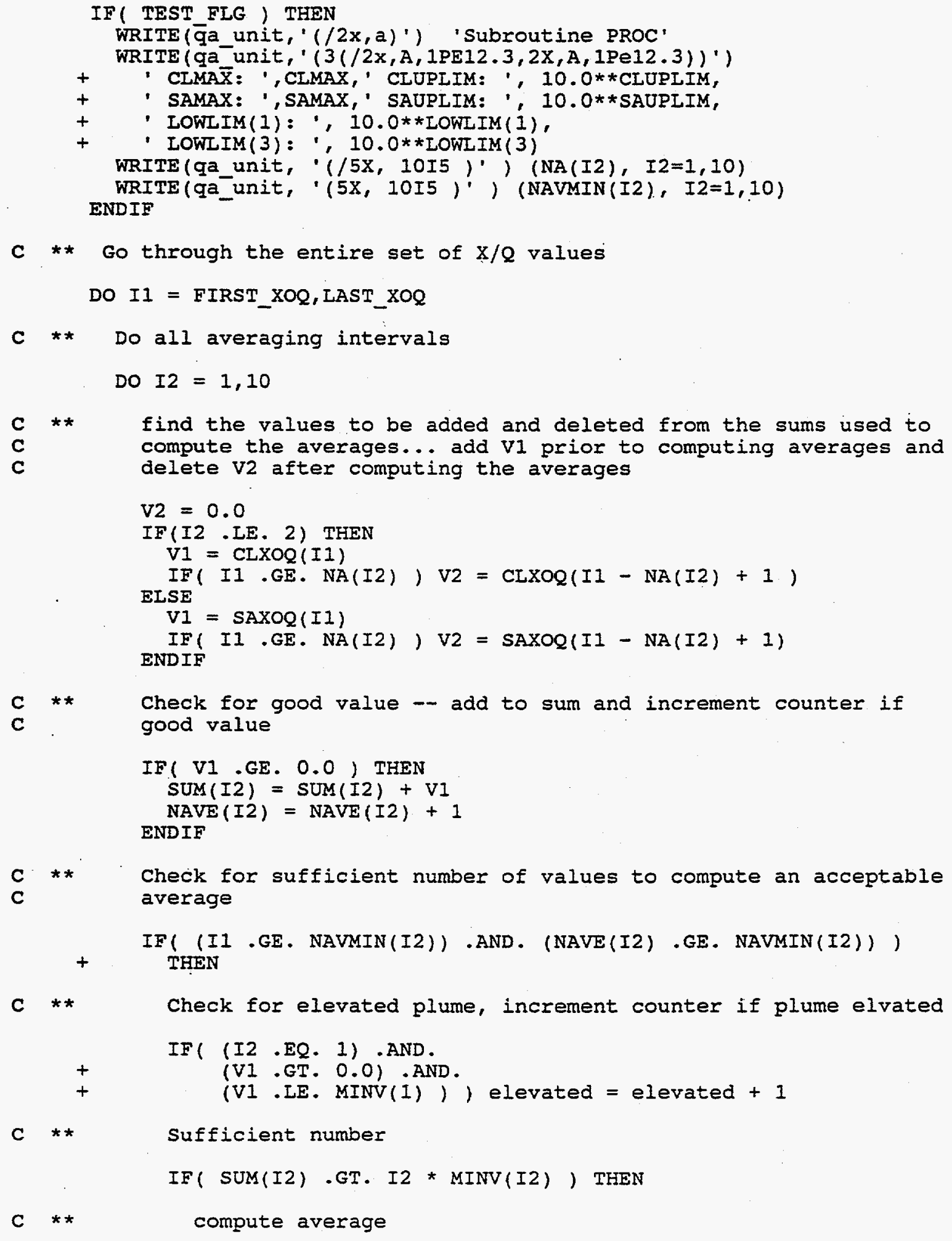




\section{ARCON95}

C $\star \star *$

$\operatorname{AVE}(I 2)=\operatorname{SUM}(I 2) / \operatorname{NAVE}(I 2)$

compute index for bin, bin size $=1 / 25$ order of mag.

RATIO = ALOG10( $\operatorname{AVE}(I 2))-\operatorname{IOWLIM(I2)~}$

IF( RATIO . GE. 0.0 ) THEN

$I 3=\operatorname{IFIX}(25 * \operatorname{RATIO})+2$

ELSE

$I 3=1$

ENDIF

$\operatorname{INDX}(I 2)=I 3$

C $\star \star$

accumulate in proper bin

IF( I3 . GE. 2 ) THEN

IF( I3 .LE. 101) THEN

$\operatorname{DISTR}(I 3, I 2)=\operatorname{DISTR}(I 3, I 2)+1.0$

ELSE

$\operatorname{DISTR}(102, \operatorname{I2})=\operatorname{DISTR}(102, I 2)+1.0$

ENDIF

ELSE

$\operatorname{DISTR}(1, I 2)=\operatorname{DISTR}(1, I 2)+1.0$

ELSE

C ** not necessary to compute average, sum $=0$

ENDIF

$\mathrm{ZERO}(I 2)=\mathrm{ZERO}(I 2)+1$.

$\operatorname{SUM}(I 2)=0.0$

ENDIF

C ** Remove oldest value if not missing and decrement counter

IF( (II .GE. NA(I2)) . AND.

(V2.NE. -1.1$)$, THEN

$\operatorname{SUM}(I 2)=\operatorname{SUM}(I 2)-V 2$

$\operatorname{NAVE}(I 2)=\operatorname{NAVE}(I 2)-1$

ENDIF

$\operatorname{IF}(\operatorname{SUM}(I 2) \cdot \operatorname{IT} \cdot \operatorname{MINV}(I 2)) \quad \operatorname{SUM}(I 2)=0.0$

ENDDO

DO $\mathrm{J}=1,10$

$\operatorname{AVE}(\mathrm{J})=0.0$

$\operatorname{INDX}(J)=0$

ENDDO

ENDDO

RETURN

END 


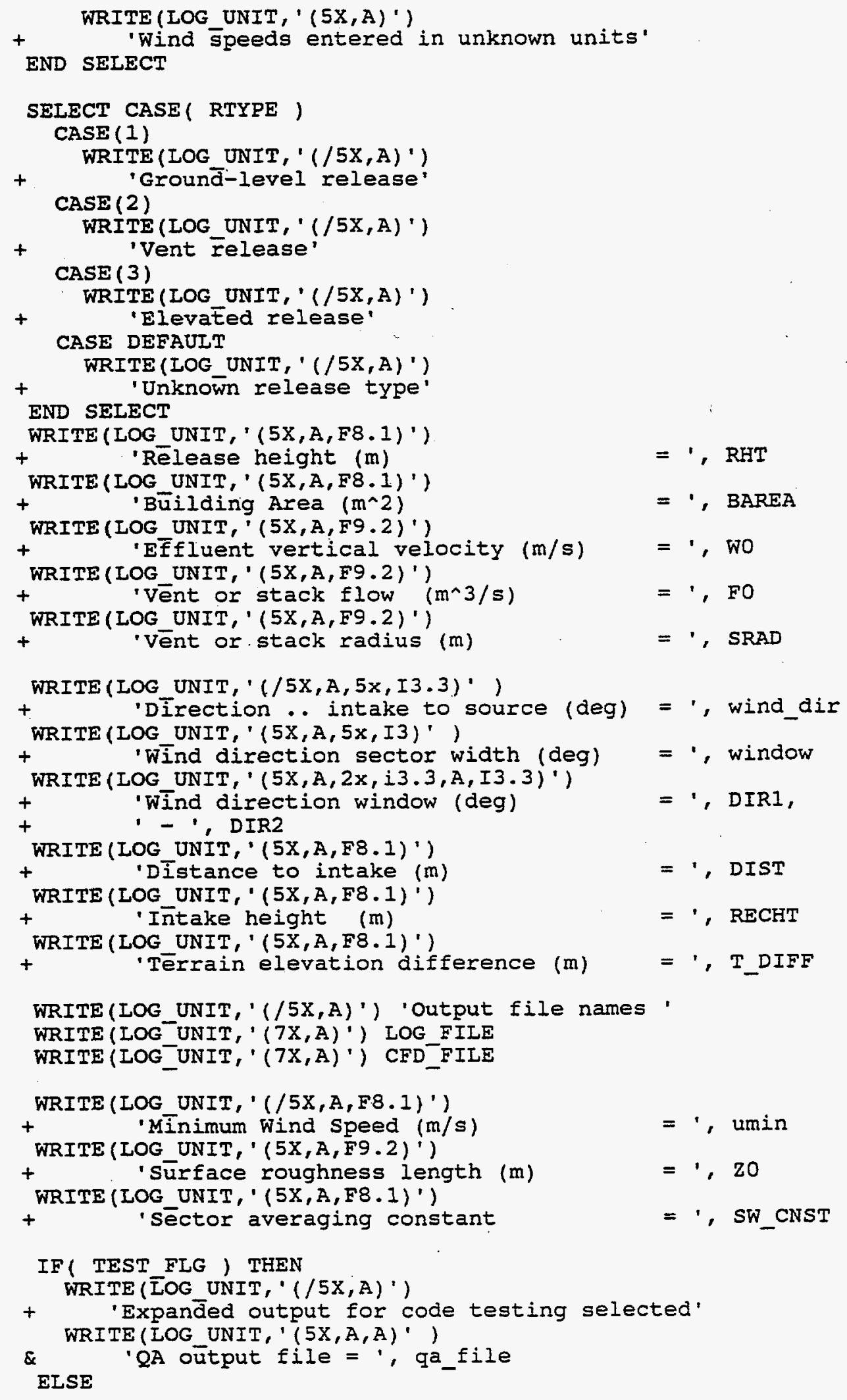


WRITE (IOG UNIT,' (/5X,A)')

$+$

'Expanded output for code testing not selected' ENDIF

RETURN

END 


\section{ARCON95}

\section{A. 10 SCENREAD}

SUBROUTINE SCENREAD

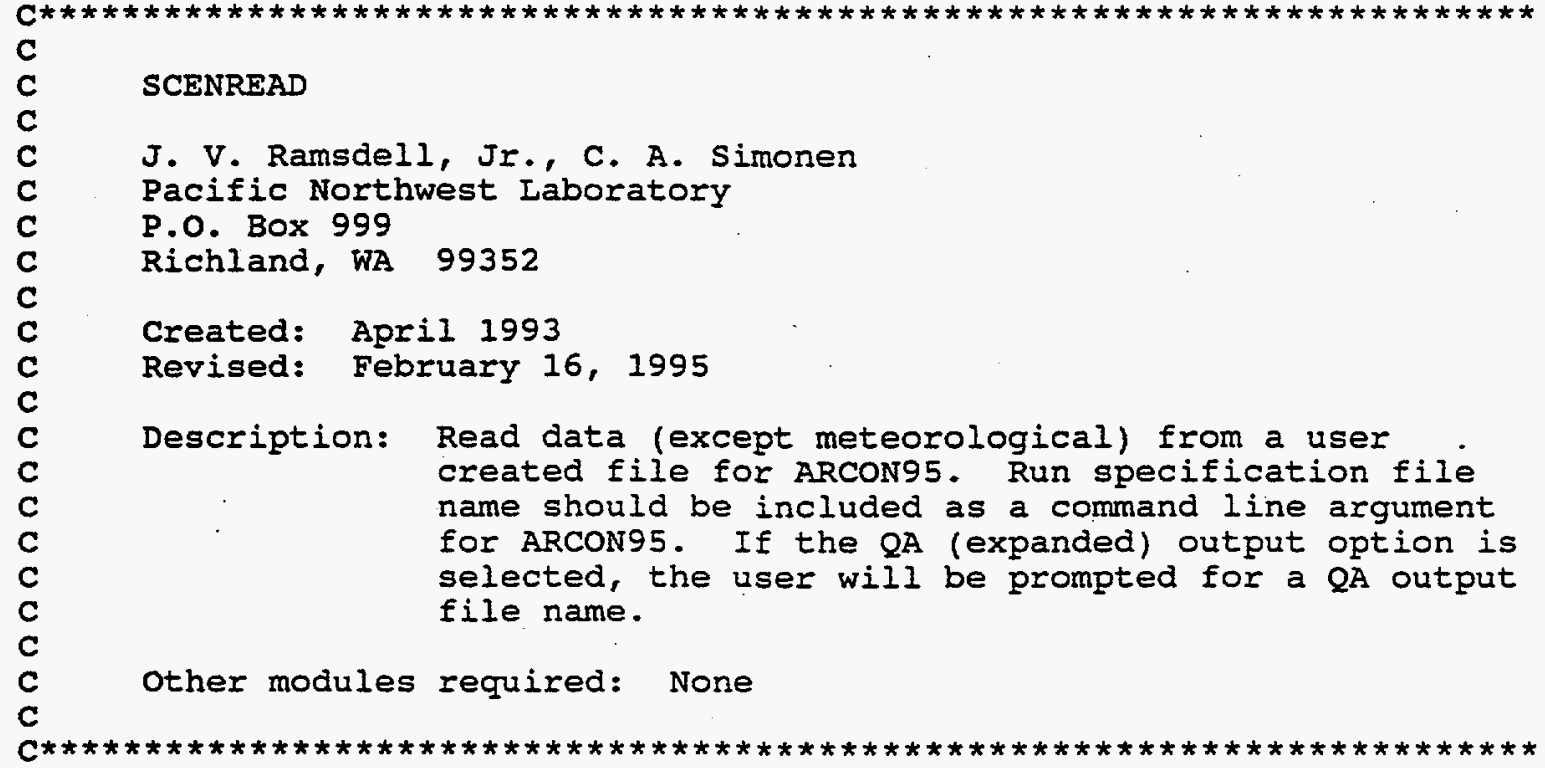

IMPLICIT NONE

INCLUDE 'PARAM. INC'

INCLUDE 'MET. INC'

INCLUDE 'SCENARIO. INC'

INCLUDE 'UNITS. INC'

INCLUDE ' $\mathrm{XOQ}$. INC'

INTEGER* 2 II

CHARACTER* 1 YN

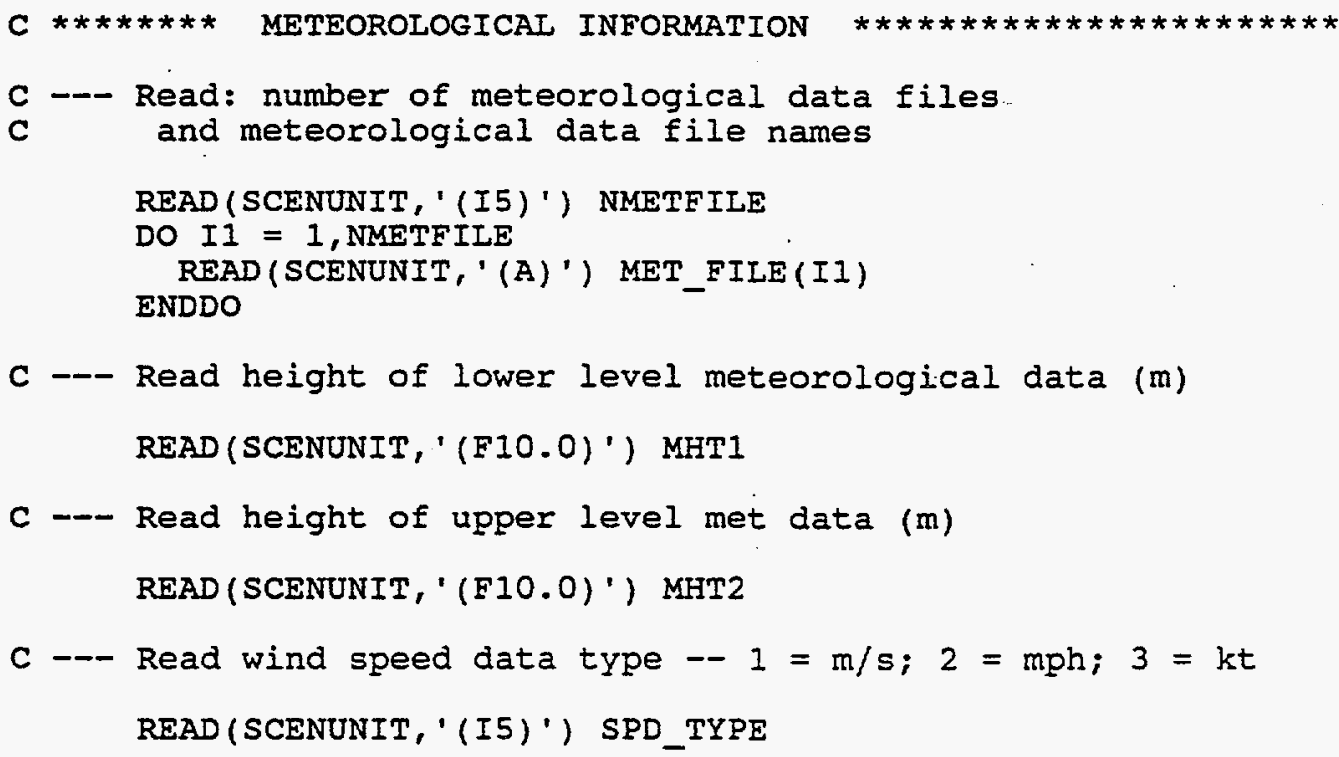




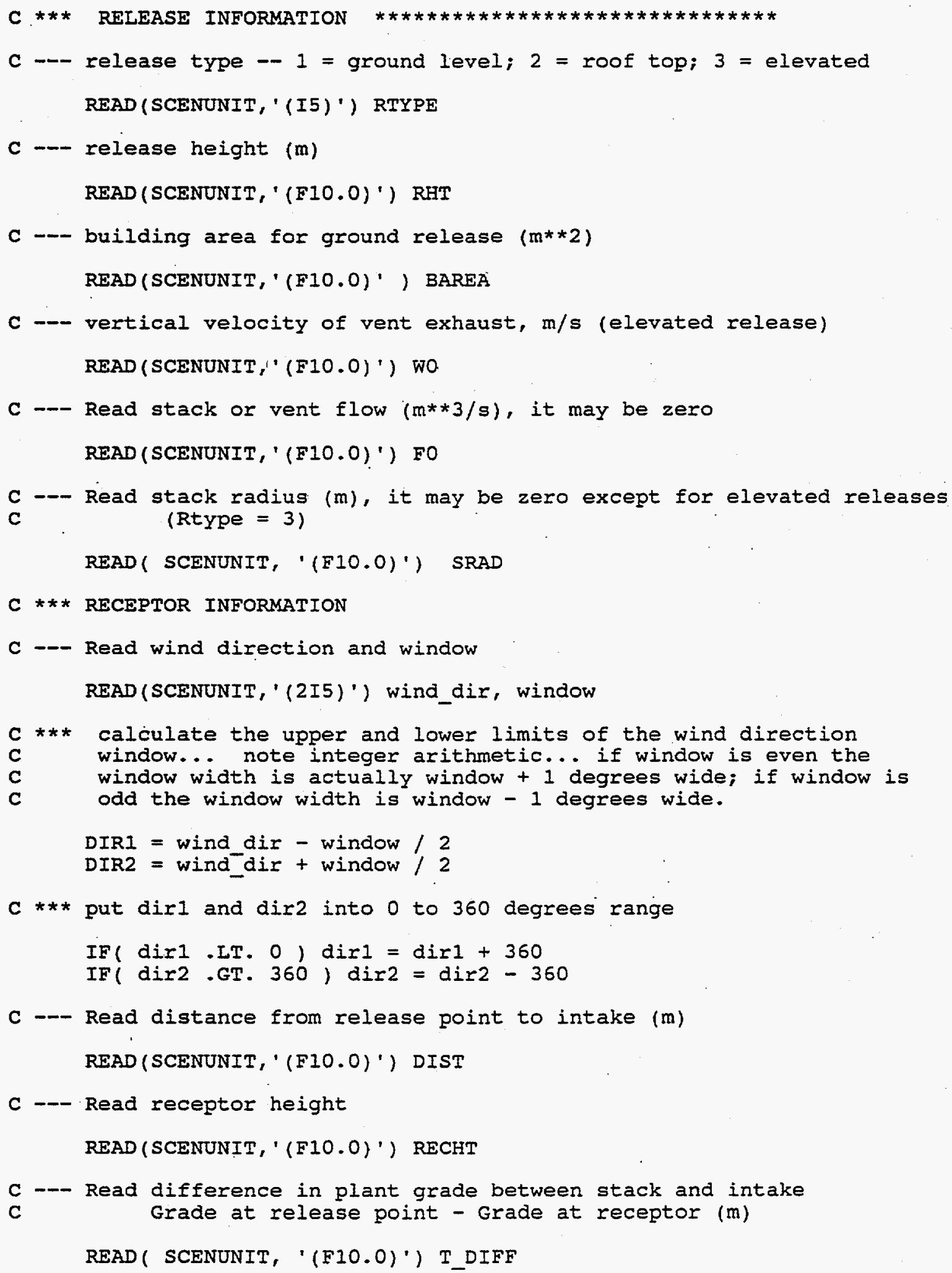




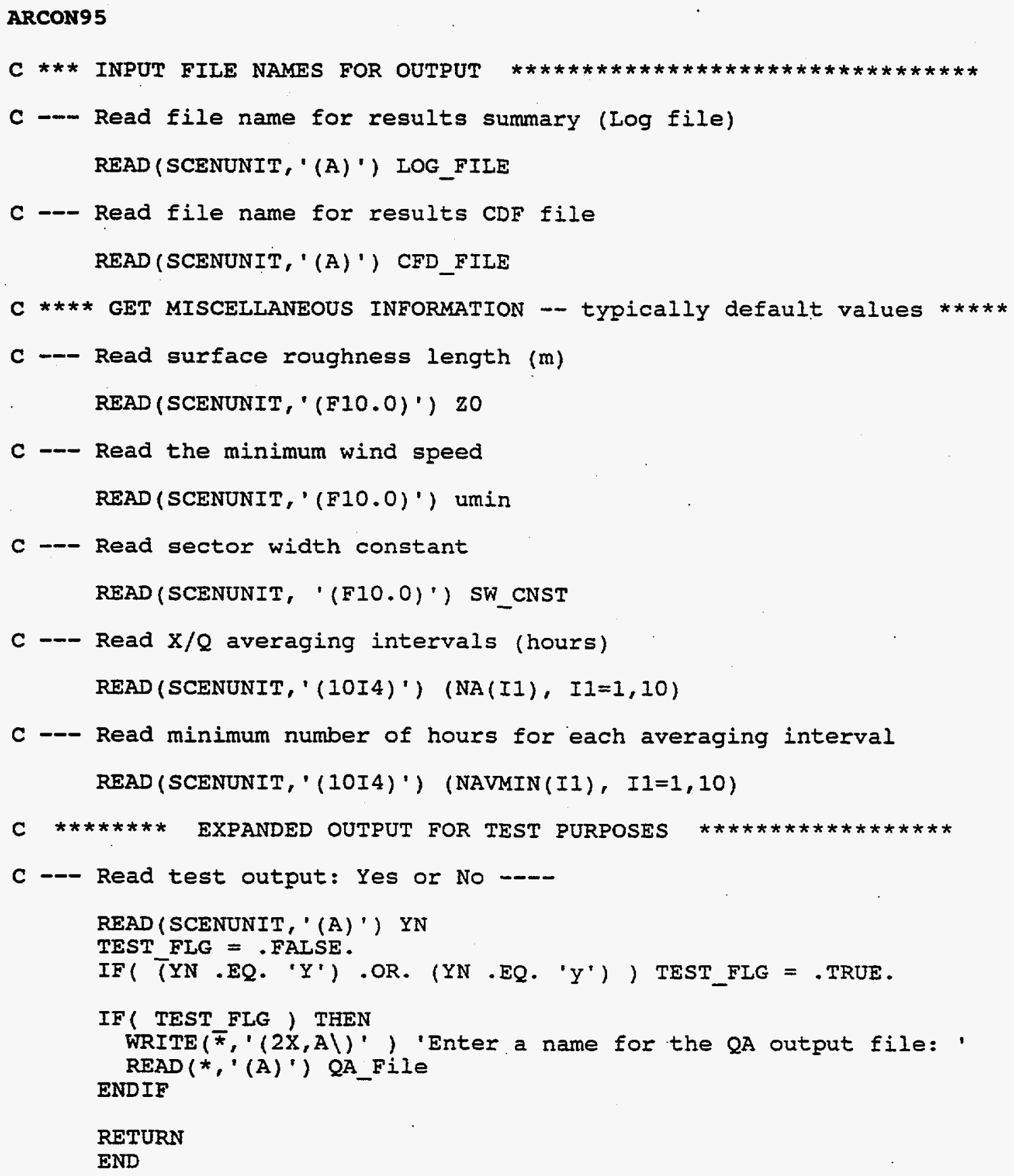




\section{A.11 SHIFT}

SUBROUTINE SHIFT

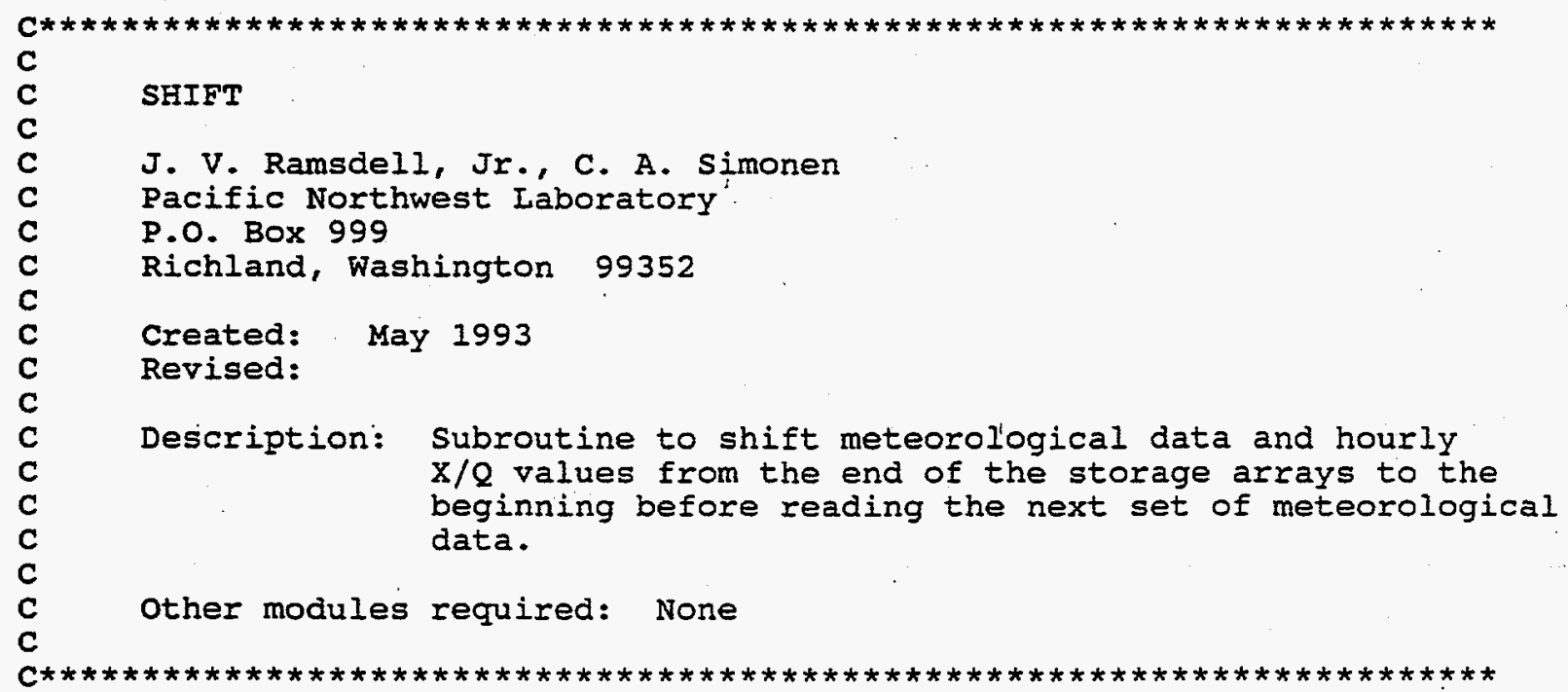

\section{IMPLICIT NONE \\ INCLUDE 'PARAM. INC' \\ INCLUDE 'MET. INC' \\ INCLUDE 'UNITS. INC' \\ INCLUDE 'XOQ. INC'}

INTEGER I1, Jo, J1, MET_SHIFT

C Move residual met. data AND $X / Q^{\prime} s$ to front of data arrays

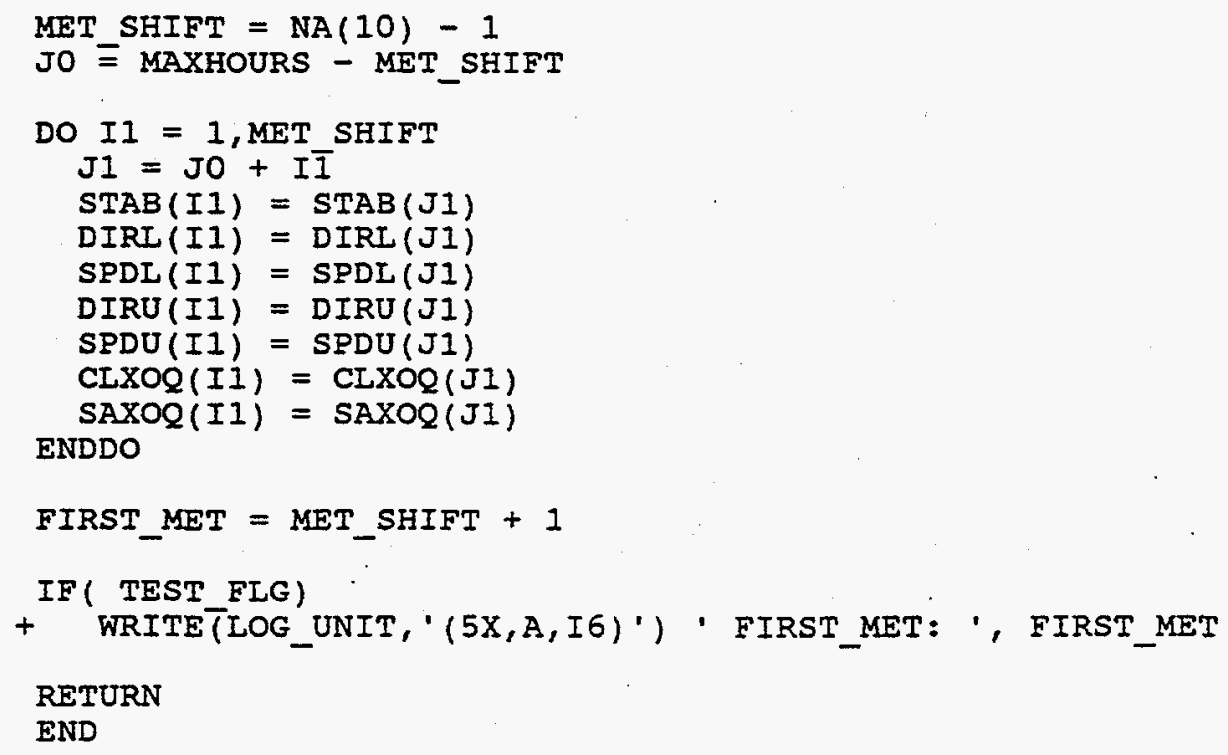




\section{ARCON95}

\section{A.12 SUMMARY}

SUBROUTINE SUMMARY
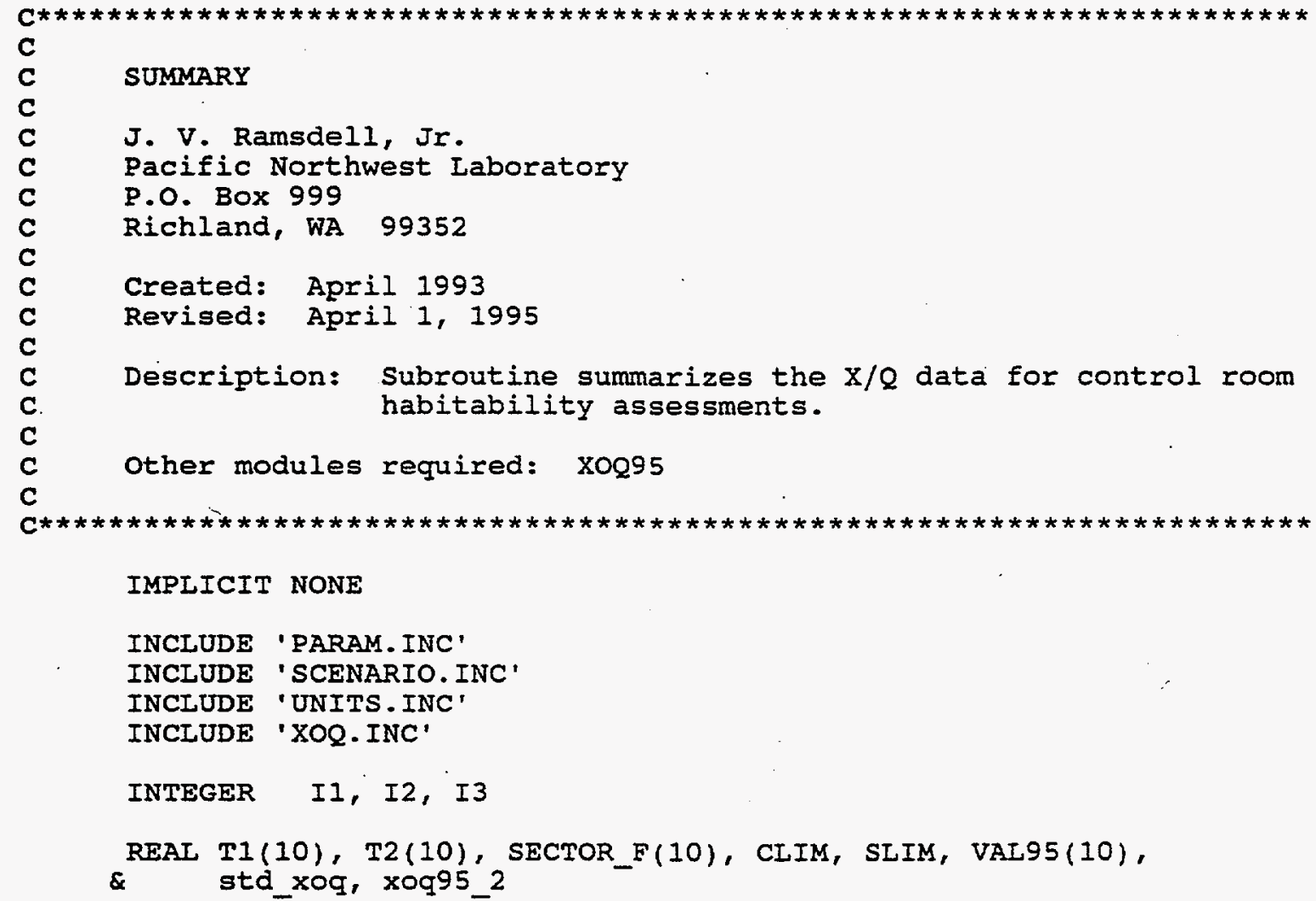

NUREG/CR-6331 


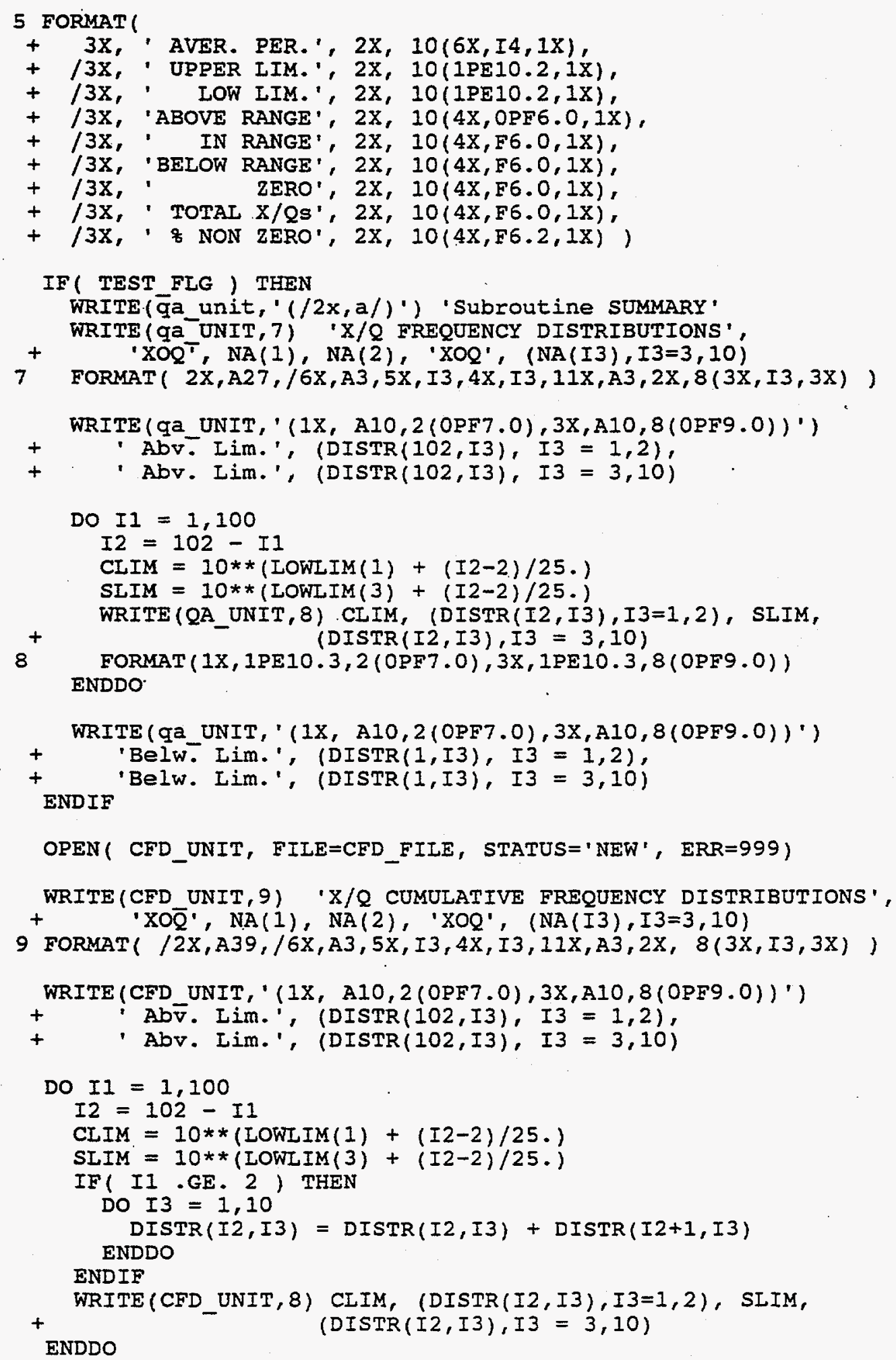




\section{ARCON95}

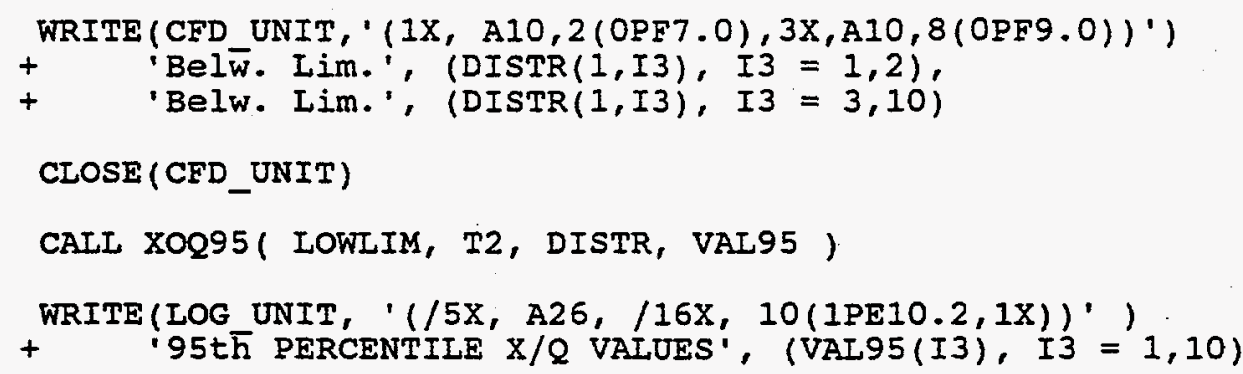

C calculate the $95 \% \mathrm{X} / \mathrm{Q}$ values for standard averaging intervals...

c 0 - 2 hours $(1$ hour $x / Q), 2-8$ hours, etc.... The calculations

C are based on the $95 \%$ concentrations above and the exposures

C required to go from one value to the next. IF statement check

C to see if the' averaging periods were changed.

WRITE(log unit, '( $(/ 5 x, a) '$ ')
$+\quad 95 \% \mathrm{X} / \mathrm{Q}$ for standard averaging intervals'

C 0 to 2 hour $X / Q$... select larger of the 1 and 2 hr values...
C normally, the 1 hr value, but with elevated release it can be the
C 2 hr value if there aren't sufficient 1 hr values.

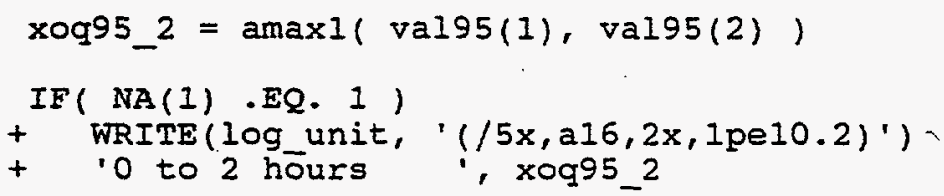

C 2 to 8 hour $x / Q$

IF( (NA(1) .EQ. 1) .AND. (NA(4) .EQ. 8) ) THEN

std_xoq $=(8.0 * \operatorname{val} 95(4)-2.0 *$ xog95_2) $/ 6.0$

IF ( std xog . IT. 0.0 ) std $x o q=0.0$

WRITE $(1 \overline{0 g}$ unit, ' $(5 \mathrm{x}, \mathrm{a} 16,2 \overline{\mathrm{x}}, 1 \mathrm{p}$
+ ENDIF

C 8 to 24 hour $x / Q$

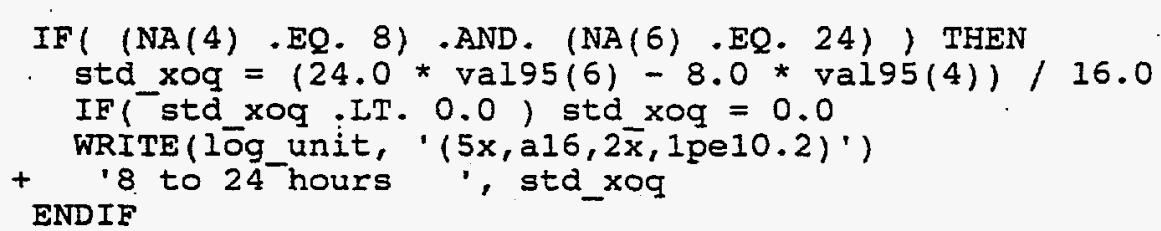

C 1 to 4 day $X / Q$

IF( (NA(6) .EQ. 24) . AND. (NA(7).EQ. 96)) THEN

std_xoq $=(4.0 * \operatorname{val95}(7)-1.0 * \operatorname{val95}(6)) / 3.0$

IF ( std $x o q$. LT. 0.0 ) std $x o q=0.0$

WRITE ( $1 \overline{0}_{\text {g }}$ unit, ' $(5 \mathrm{x}, \mathrm{a} 16,2 \overline{\mathrm{x}}, 1$ pe10.2)')

ENDIF

C 4 to 30 day $x / Q$

IF( (NA(7) .EQ. 96) .AND. (NA(10) .EQ. 720) ) THEN 


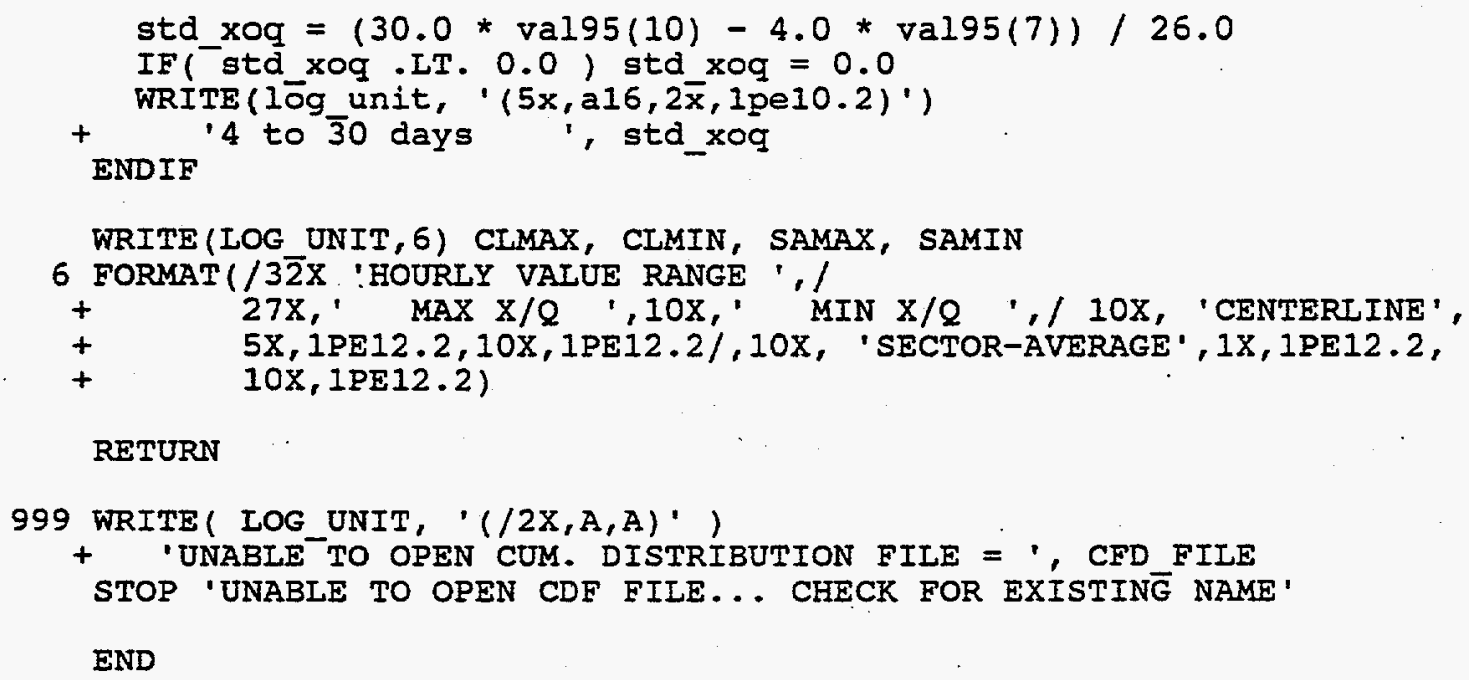




\section{ARCON95}

\section{A.13 WAKECORR}

SUBROUTINE WAKECORR( area, dist, ubar, dsy, dsz )
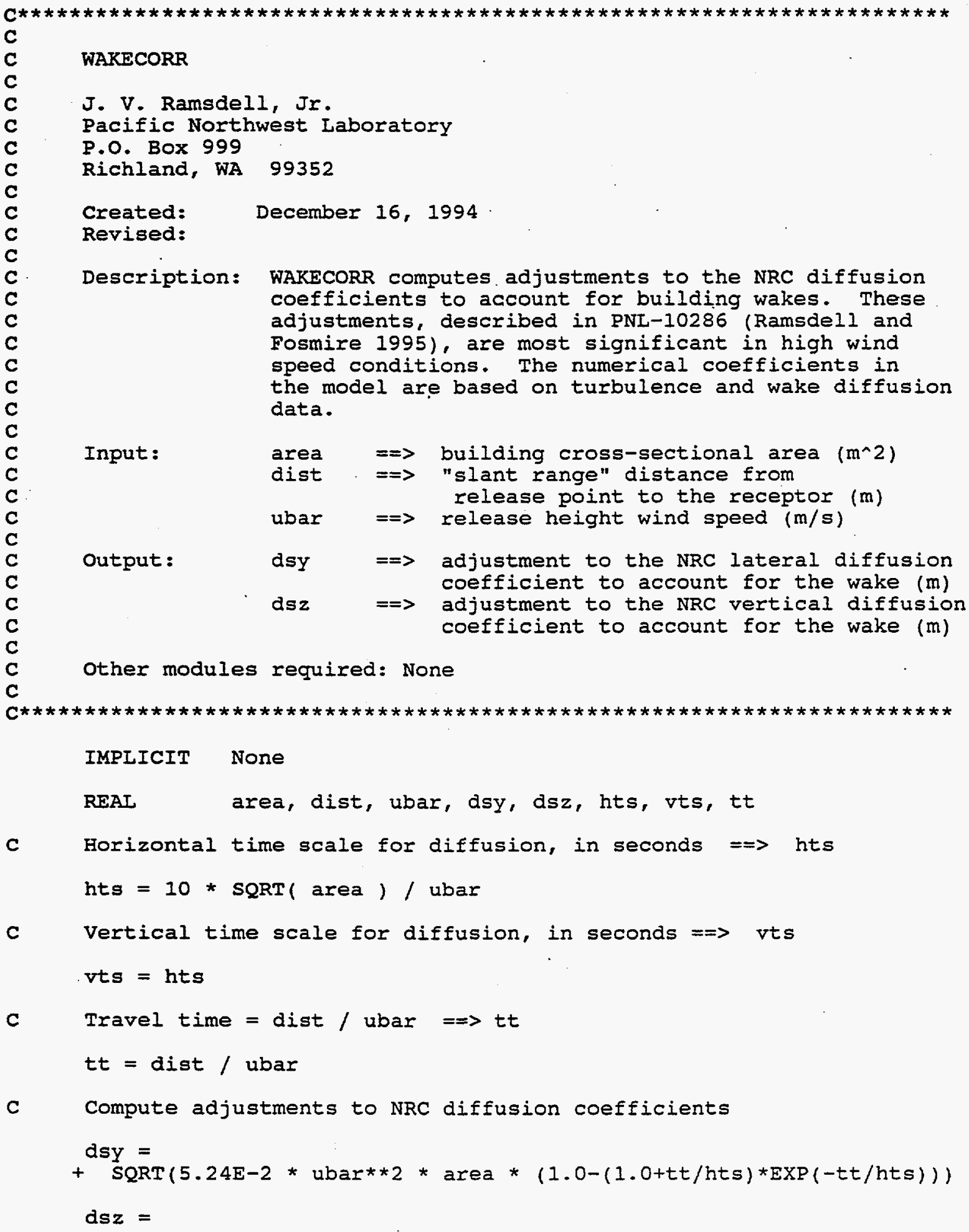


\section{FORTRAN Code}

$+\operatorname{sgRT}(1.17 E-2 *$ ubar**2* area *(1.0-(1.0+tt/vts)*EXP. $(-t t / v t s)))$

RETURN

END 


\section{ARCON95}

\section{A.14 WIXDYXOQ}

SUBROUTINE WINDYXOQ( rtype, area, dist, eff ht, stab, ubar, sigy, $+$ sigz, flow, wo, sw_const, clxog, saxog )

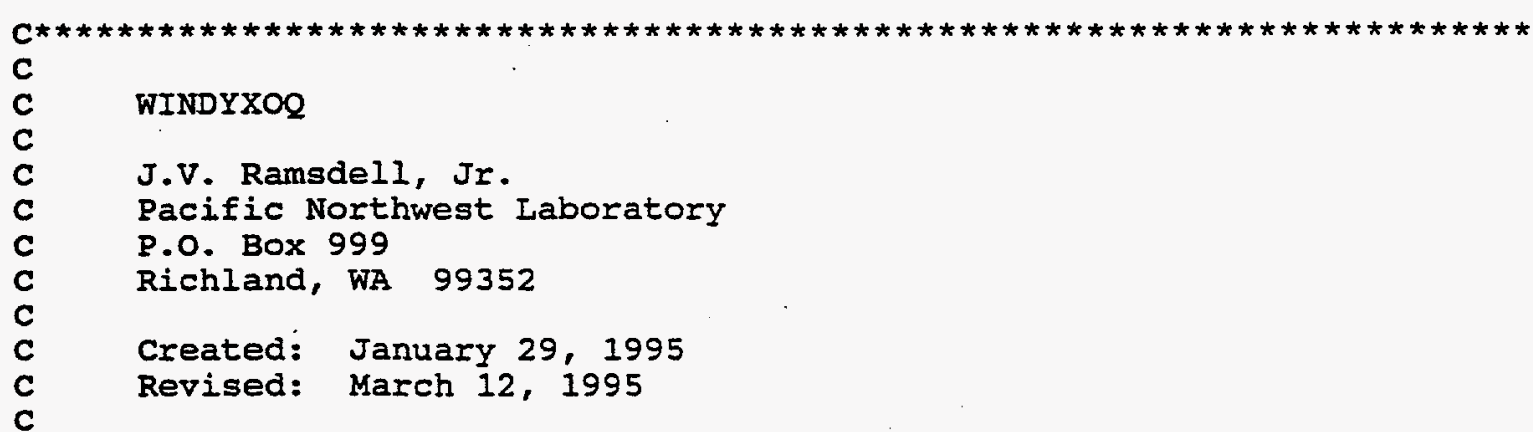

Description: WINDYXOQ computes $X / Q$ in windy conditions. For elevated releases it uses the standard Gaussian model. For releases in the vicinity of buildings is uses the model described in PNL-10286 (Ramsdell and Fosmire 1995). For elevated vent releases (RTYPE $=2$ ), the model uses the split-H approach of Reg. Guide 1.111.

Input:

\begin{tabular}{|c|c|c|}
\hline etype & $==>$ & $\begin{array}{l}\text { release type } 1=\text { ground, } 2=\text { vent, } \\
3=\text { stack }\end{array}$ \\
\hline area & $=$ & building cross-sectional area $\left(\mathrm{m}^{\wedge} 2\right)$ \\
\hline dis & $==>$ & $\begin{array}{l}\text { distance from release point to } \\
\text { intake }(\mathrm{m})\end{array}$ \\
\hline eff ht & $==>$ & effective release height (m) \\
\hline stab & $\begin{array}{l}==> \\
==>\end{array}$ & $\begin{array}{l}\text { stability class } \\
\text { wind speed at release height (m) }\end{array}$ \\
\hline sig. & $\Rightarrow$ & $\begin{array}{l}\text { NRC lateral diffusion coefficient } \\
\text { for the stability class and }\end{array}$ \\
\hline sigz & $==>$ & $\begin{array}{l}\text { NRC vertical diffusion coefficient } \\
\text { for the stability class and } \\
\text { distance }(m)\end{array}$ \\
\hline $\begin{array}{l}\text { flow } \\
\text { w0 }\end{array}$ & $\begin{array}{l}\Rightarrow=> \\
==>\end{array}$ & $\begin{array}{l}\text { release fiow rate }\left(\mathrm{m}^{\wedge} 3 / \mathrm{s}\right) \\
\text { stack effluent velocity }(\mathrm{m} / \mathrm{s})\end{array}$ \\
\hline sw_const & $=\Rightarrow$ & $\begin{array}{l}\text { assumed width of plume in units of } \\
\text { the adjusted sigma } y \text { (dimensionless }\end{array}$ \\
\hline oq & $==$ & $\begin{array}{l}\text { normalized concentration at center } \\
\text { line of plume }\left(\mathrm{s} / \mathrm{m}^{\wedge} 3\right)\end{array}$ \\
\hline $\operatorname{sax} 0$ & & $\begin{array}{l}\text { normalized concentration in a } \\
\text { sector-average plume }\end{array}$ \\
\hline
\end{tabular}

Other modules required: CURVEFIX, WAKECORR, NSIGMA

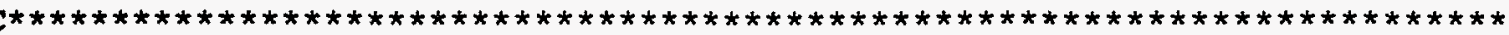

$\begin{array}{ll}\text { IMPLICIT } & \text { NONE } \\ \text { INTEGER*2 } & \text { rtype } \\ \text { INTEGER } & \text { stab } \\ \text { REAL } & \text { area, dist, dsy1, dsz1, dsy2, dsz2, flow, pi, sigy, } \\ + & \text { sigz, tsigy, tsigz, ubar, max_wide, eff_ht, wo, wr, wf }\end{array}$

NUREG/CR-6331 


\section{FORTRAN Code}

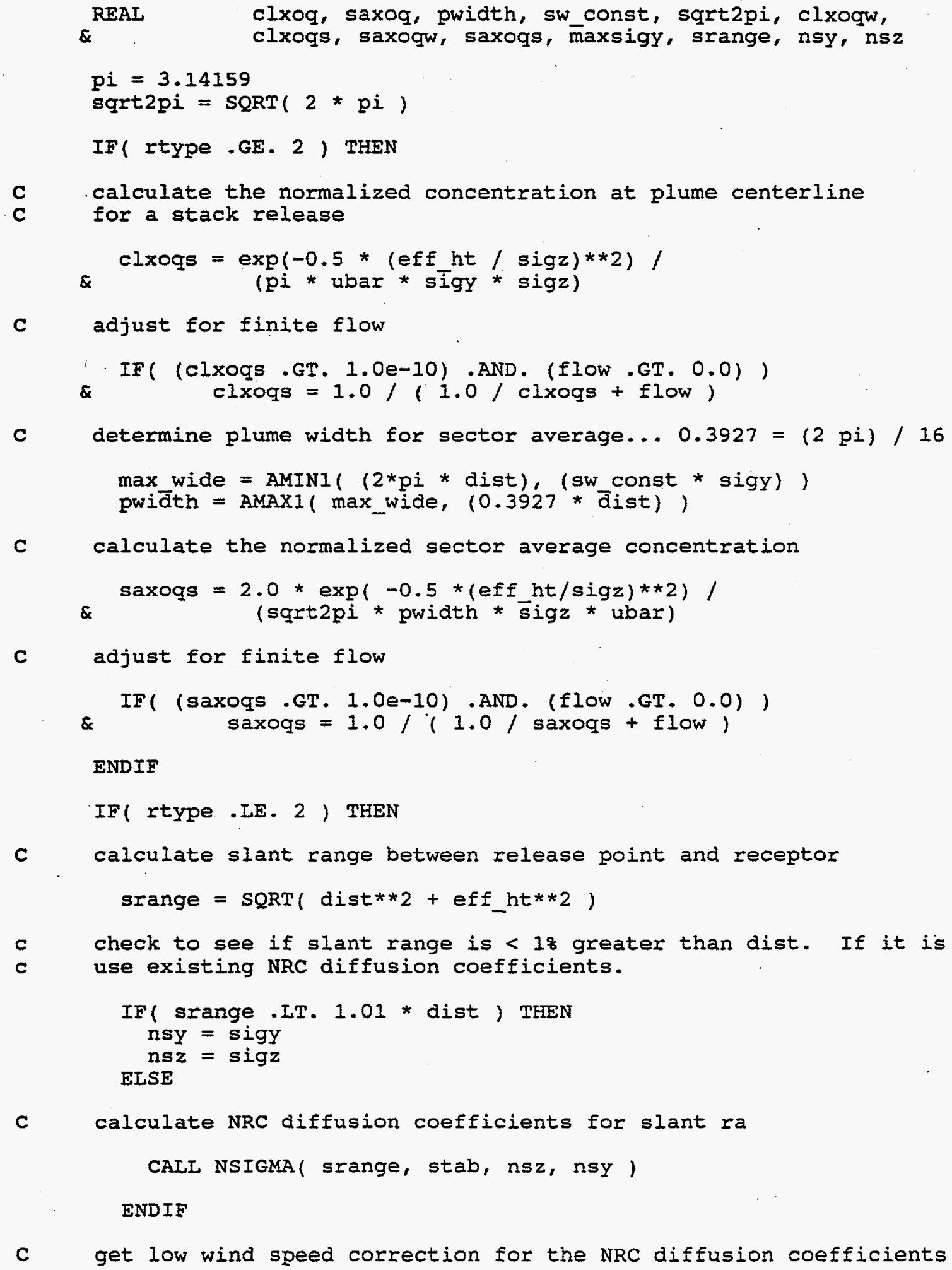

C

adjust for finite flow

IF( (saxoqs .GT. 1.0e-10) .AND. (flow .GT. 0.0) )

$\varepsilon$ saxoqs $=1.0 /(1.0 /$ saxogs + flow $)$

ENDIF

IF ( rtype .I.E. 2 ) THEN

C

calculate slant range between release point and receptor

$$
\text { srange }=\operatorname{sQRT}(\text { dist } * 2+\text { eff_ht } * * 2)
$$

c check to see if slant range is < 18 greater than dist. If it is c use existing NRC diffusion coefficients.

C calculate NRC diffusion coefficients for slant ra

CALL NSIGMA( srange, stab, nsz, nsy)

ENDIF

C get low wind speed correction for the NRC diffusion coefficients 


\section{ARCON95}

CAIL CURVEFIX( srange, ubar, dsyl, dszl)

c get the building wake correction

CAIL WARECORR( area, srange, ubar, dsy2, dsz2)

C

calculate the adjusted diffusion coefficients

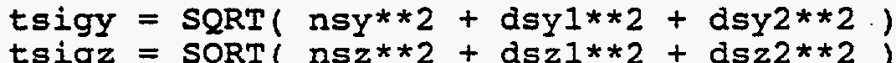

tsigz $=\operatorname{SQRT}(\mathrm{nsz} * * 2+\mathrm{dsz} 1 * * 2+\mathrm{dsz} 2 * * 2)$

C limit tsigy so that tsigy $<=2$ pi srange / sqrt(12) (sigma y for

c a uniform distribution across a line perpendicular to the plume

C axis with length equal to the circumference of a circle with radius srange

$\operatorname{maxsigy}=2.0 * \mathrm{pi} *$ srange / SQRT( 12$)$

tsigy = AMIN1 ( tsigy, maxsigy)

C calculate the normalized concentration at plume centerline

c for the entrained portion of the plume

clxoqw $=1.0 /(\mathrm{pi}$ * ubar * tsigy * tsigz $)$

C

adjust for finite flow

IF( (clxogw .GT. 1e-10) .AND. (flow.GT. 0.0) )

$\&$ clxogw $=1.0 /(1.0 /$ clxogw + flow $)$

C

determine plume width for sector average... $0.3927=(2 \mathrm{pi}) / 16$

$\max$ wide $=\operatorname{AMINI}((2 * p i *$ srange $),($ sw const * tsigy) $)$

pwi $\bar{d}$ h $=$ AMAX1 ( max_wide, $(0.3927 *$ srānge $)$ )

C

calculate the normalized sector average concentration

saxogw $=2.0 /($ sqrt $2 p i *$ pwidth * tsigz * ubar )

C adjust for finite flow

\&

IF( (saxoqw .GT. 1e-10) .AND. (flow .GT. 0.0) )

ENDIF

IF( rtype .EQ. I ) THEN

! Ground-Level Release

clxog $=c l \times o g w$

saxoq $=$ saxoqw

ELSE IF( rtype .EQ. 3 ) THEN ! stack Release

clxoq $=$ clxoqs

saxoq $=$ saxoqs

EISE IF( rtype.EQ. 2) THEN I Elevated Vent Release

C vent release... calculate fraction entrained in the building

C wake using Regulatory Guide 1.111 method.

NUREG/CR-6331 


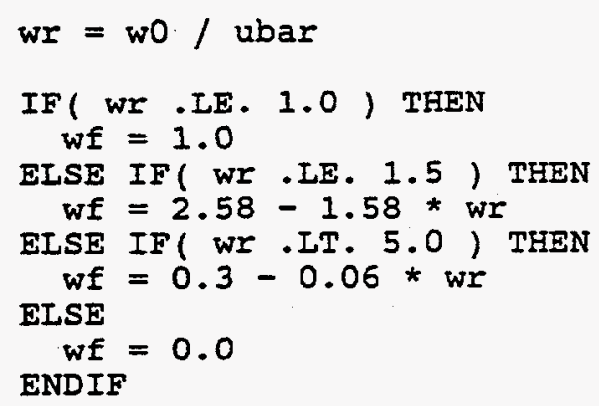

c calculate $x / Q$ using entrained fraction

$$
\begin{aligned}
& \text { clxoq }=(1.0-\text { wf }) * \text { clxoqs }+ \text { wf * clxoqw } \\
& \text { saxoq }=(1.0-\text { wf } * \text { saxoqs }+ \text { wf * saxoqw }
\end{aligned}
$$

ELSE

! Unknown Release

Stop 'Unknown release type"

ENDIF

RETURN

END 


\section{ARCON95}

\section{A.15 X0Q95}

SUBROUTINE XOQ95( LOWLIM, T2, DISTR, VAL95)
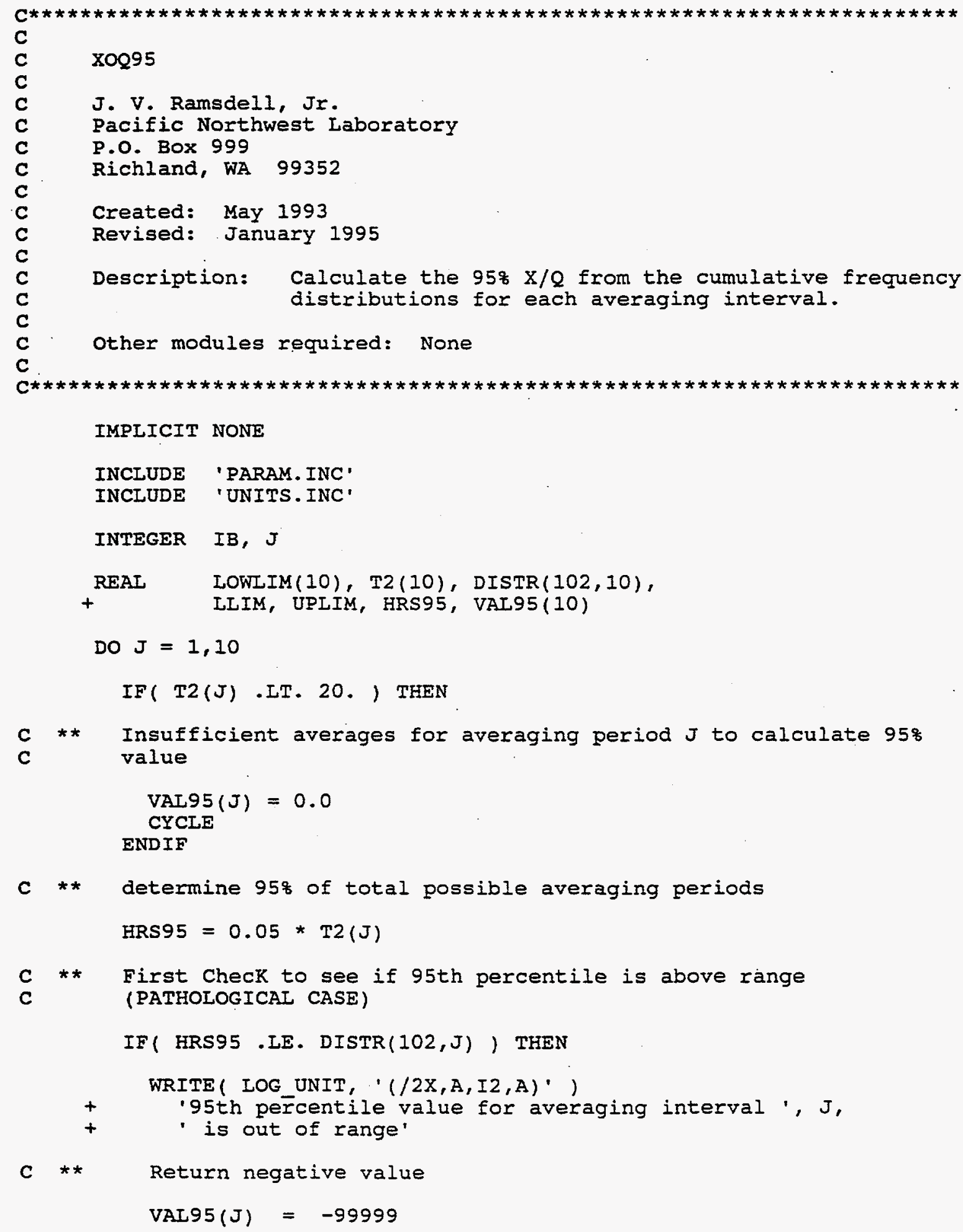


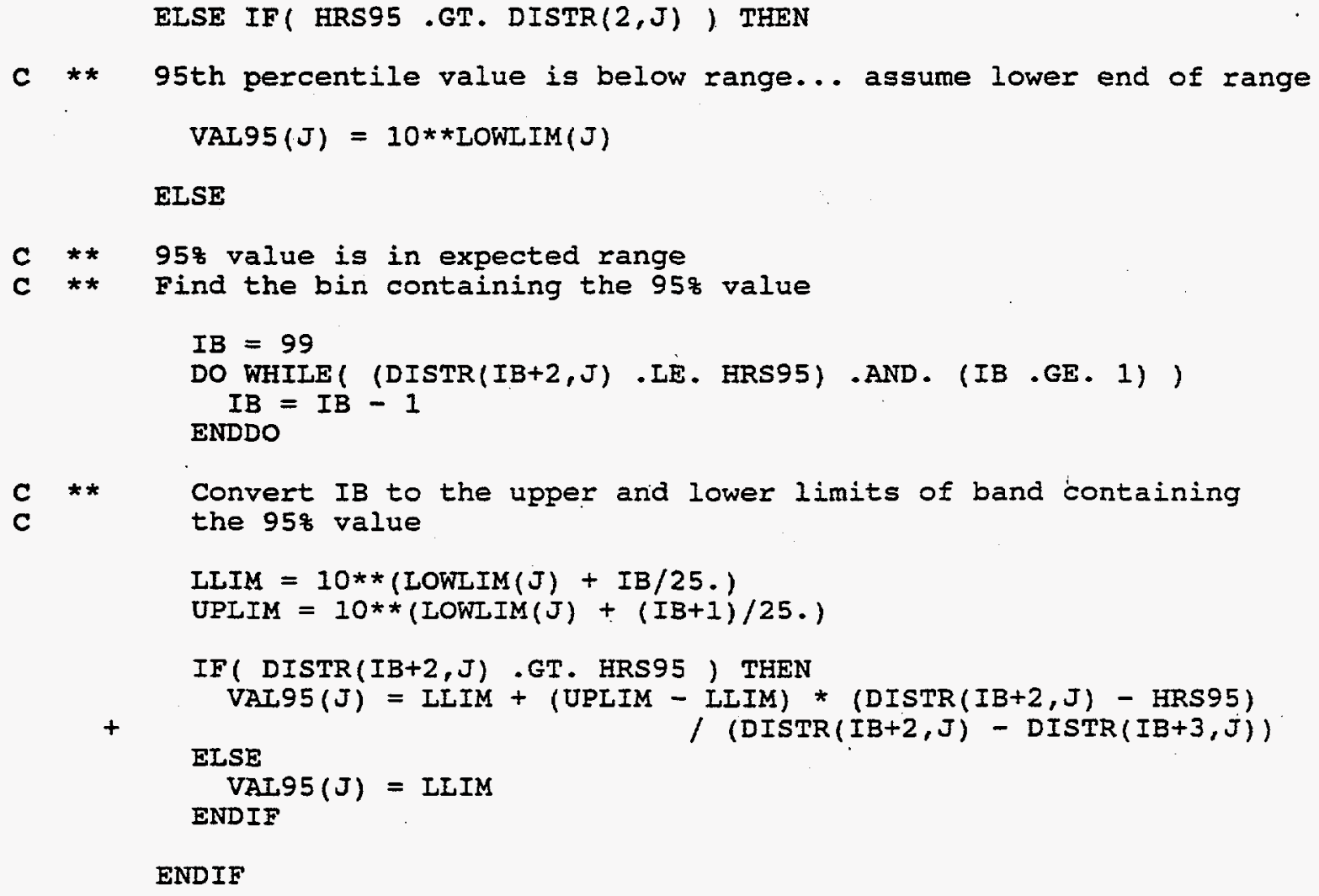




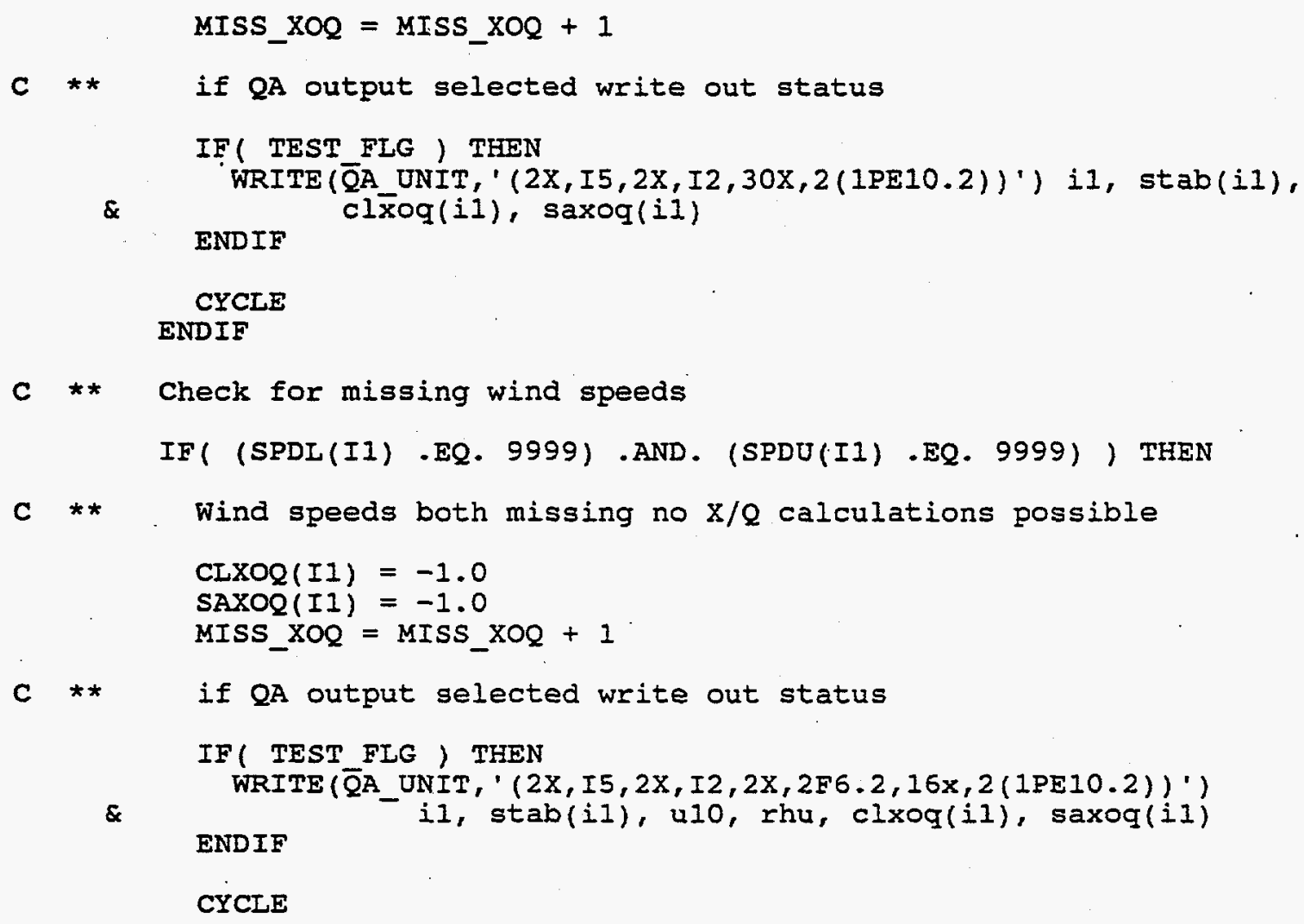


ARCON95

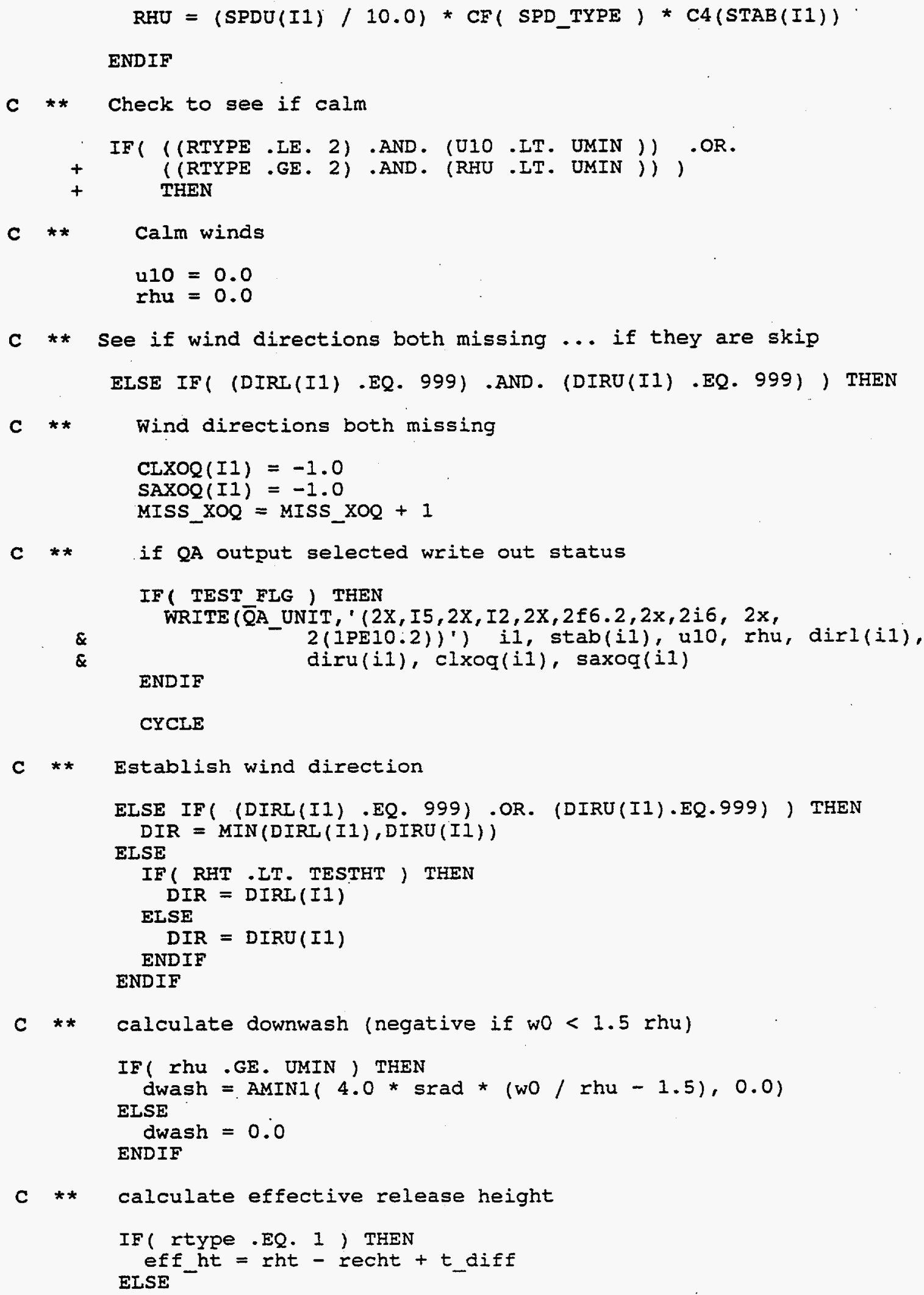

CYCLE

C * * Establish wind direction

ELSE IF( (DIRL(II) .EQ. 999) .OR. (DIRU(I1).EQ.999)) THEN

c ** calculate downwash (negative if wo $<1.5$ rhu)

IF ( rhu . GE. UMIN) THEN

dwash $=\operatorname{AMINI}(4.0 *$ srad * (w0 / rhu -1.5$), 0.0)$

EISE

dwash $=0.0$

ENDIF

c ** calculate effective release height

IF ( rtype .EQ. 1 ) THEN EISE eff ht $=$ rht - recht $+t$ diff 


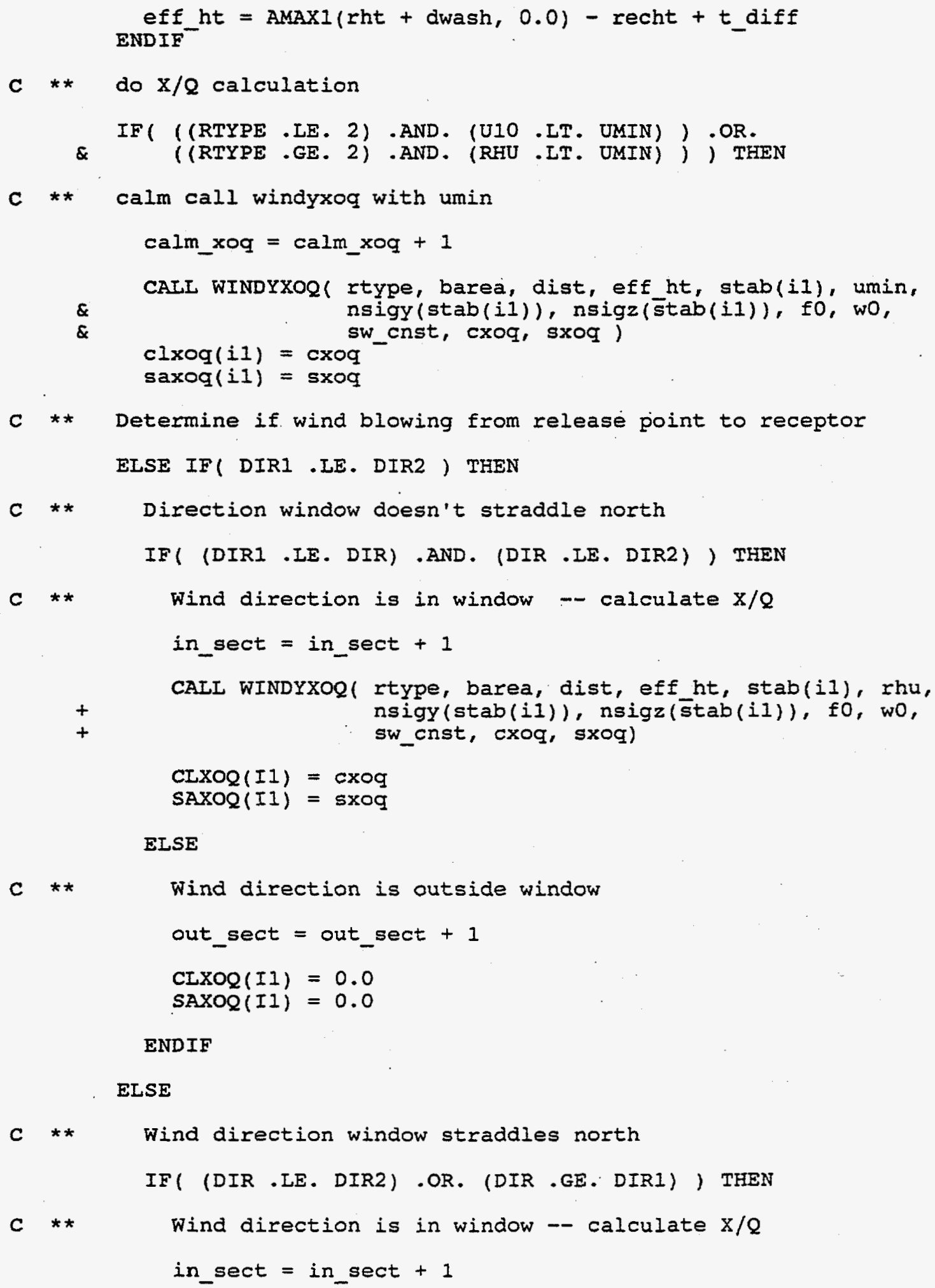


ARCON95

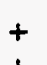

$+$

CALI WINDYXOQ( rtype, barea, dist, eff_ht, stab(iI), rhu, nsigy (stab(i1)), nsigz(stab(i1)), fo, wo, sw_enst, exoq, sxoq)

$\operatorname{CrxOQ}(I 1)=\operatorname{cxoq}$

$\operatorname{SAXOQ}(I 1)=\operatorname{sxOq}$

ELSE

C ** Wind direction is outside of the window

out_sect $=$ out_sect +1

$\operatorname{CLXOQ}(I 1)=0.0$

$\operatorname{SAXOQ}(I I)=0.0$

ENDIF

ENDIF ! end of $x / Q$ calculations

C ** if QA output selected write out status

IF( TEST FLG) THEN

WRITE ( $\bar{Q} A$ UNIT, $(2 X, I 5,2 X, I 2,2 X, 2 f 6.2,2 x, i 6,8 x$,

\& $\left.2(1 \mathrm{PE} 10.2))^{\prime}\right)$ il, stab(i1), u10, rhu, dir,

$\&$

ENDIF clxog(i1), saxog(i1)
ENDDO
! met data do loop

C ** Update maximum and minimum values

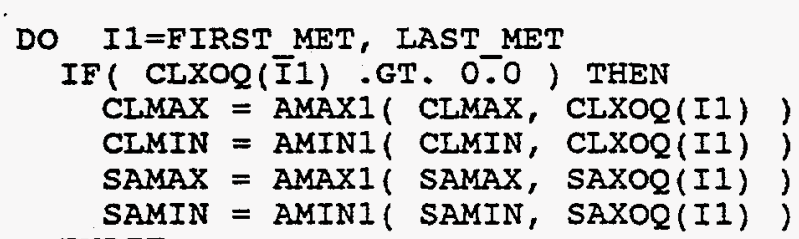

LAST $\bar{X} O Q=$ LAST MËT

TOT_XXQQ $=$ TOT_X $\bar{X} Q+($ LAST_XOQ - FIRST_XOQ $)+1$

RETURN

END 


\section{ARCON95}

\section{A.18 PARAM}

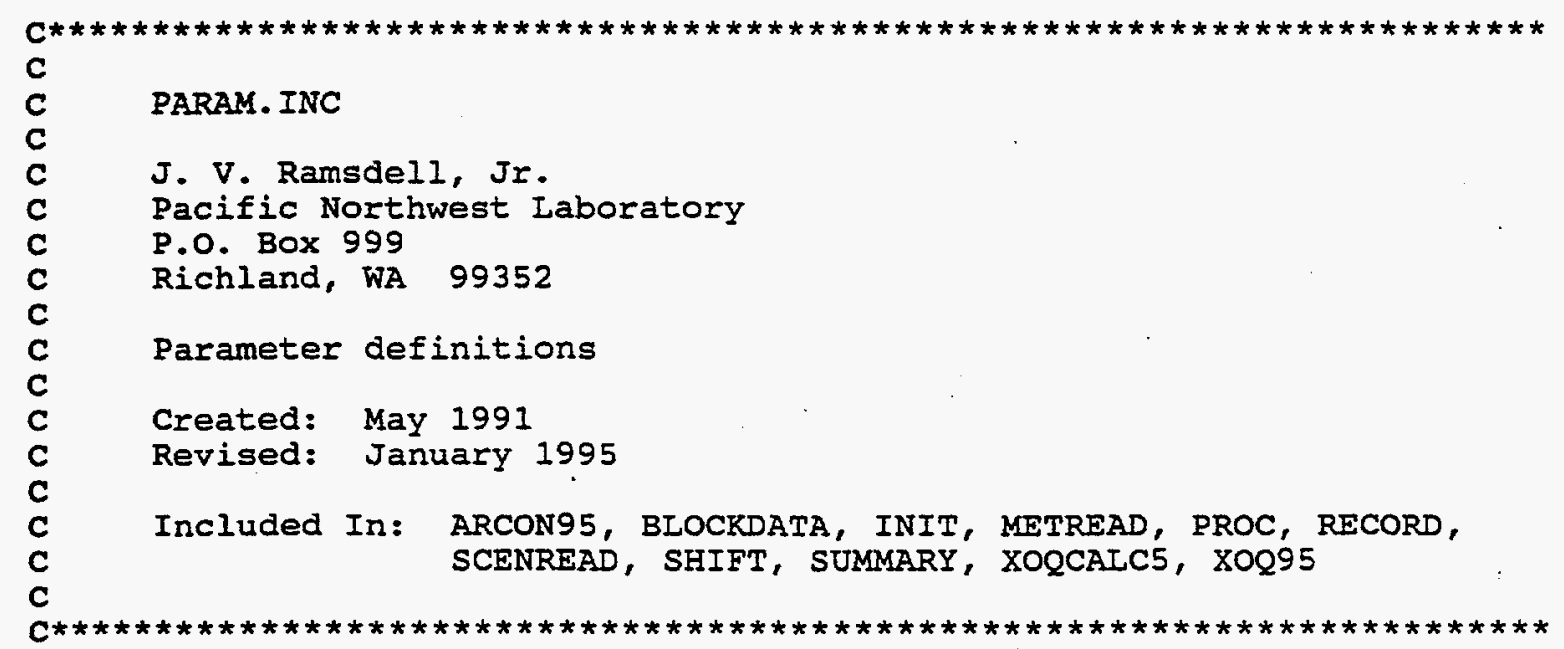

INTEGER MAXFILES, MAXHOURS

PARAMETER (MAXFILES $=10$, MAXHOURS $=10000)$

\section{A.19 SCENARIO}
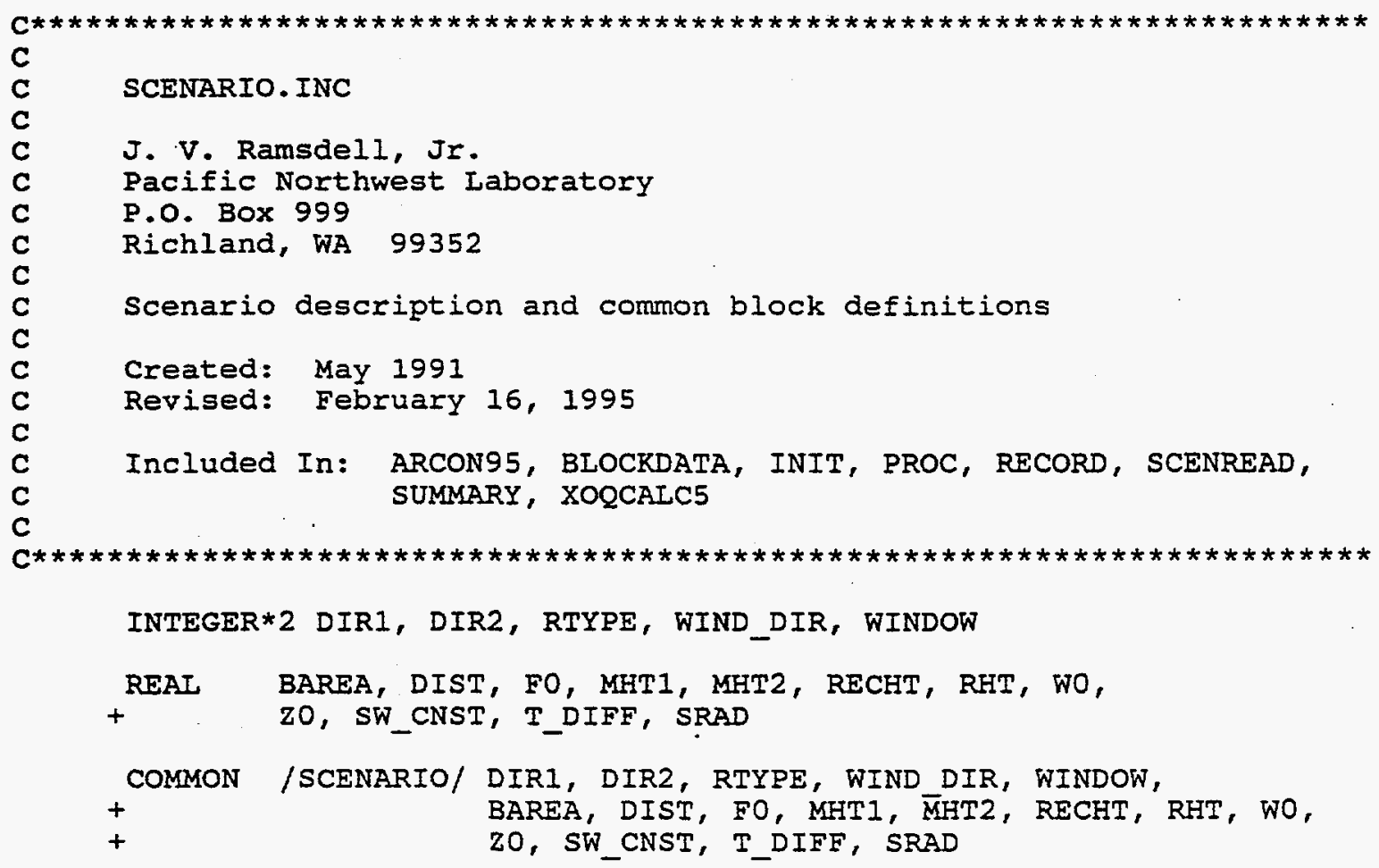
Appendix B Glossary 



\begin{tabular}{|c|c|c|c|}
\hline VARIABLE & TYPE & $\begin{array}{l}\text { NCLUDE } \\
\text { BLOCK }\end{array}$ & DEFINITION \\
\hline AREA & $R * 4$ & & $\begin{array}{l}\text { Building cross-sectional area }\left(\mathrm{m}^{2}\right) \text { in subroutine } \\
\text { WINDYXOQ }\end{array}$ \\
\hline BAREA & $\mathrm{R} * 4$ & SCENARIO & Building cross-sectional area $\left(\mathrm{m}^{2}\right)$ \\
\hline $\operatorname{c1}(7)$ & $\mathrm{R} * 4$ & MET & $\begin{array}{l}\text { Factor to adjust the lower wind speed to represent } \\
\text { the wind at } 10 \text { meters }\end{array}$ \\
\hline $\mathrm{C} 2(7)$ & $\mathrm{R} * 4$ & MET & $\begin{array}{l}\text { Factor to adjust the lower wind speed to represent } \\
\text { the wind at the release height }\end{array}$ \\
\hline $\mathrm{C} 3(7)$ & $\mathrm{R} * 4$ & MET & $\begin{array}{l}\text { Factor to adjust the upper wind speed to represent } \\
\text { the wind at } 10 \text { meters }\end{array}$ \\
\hline $\mathrm{C} 4(7)$ & $\mathrm{R} * 4$ & MET & $\begin{array}{l}\text { Factor to adjust the upper wind speed to represent } \\
\text { the wind at the release height }\end{array}$ \\
\hline CALM_XOQ & $I * 4$ & XOQ & $\begin{array}{l}\text { Counter for the number of hours of wind is calm } \\
\text { (less than Umin) }\end{array}$ \\
\hline $\mathrm{CF}(3)$ & $\mathrm{R} * 4$ & MET & Wind speed unit conversion factor \\
\hline CFD_FILE & $A * 40$ & UNITS & $\begin{array}{l}\text { Name of cumulative frequency distribution file, } \\
\text { including path }\end{array}$ \\
\hline CFD_UNIT & $\mathrm{I}^{*} \mathbf{1}$ & UNITS & $\begin{array}{l}\text { Logical unit assigned to cumulative distribution } \\
\text { file }\end{array}$ \\
\hline CHOUR(MAXHOURS) & $I^{*} 2$ & MET & $\begin{array}{l}\text { Hour of the meteorological observation } 00= \\
\text { midnight, } 23=11 \mathrm{pm}\end{array}$ \\
\hline CLMAX & $\mathrm{R} * 4$ & XOQ & Maximum one-hour centerline X/Q $\left(\mathrm{s} / \mathrm{m}^{3}\right)$ \\
\hline CLMIN & $\mathrm{R} * 4$ & XOQ & Minimum one-hour sector-average $X / Q\left(\mathrm{~s} / \mathrm{m}^{3}\right)$ \\
\hline CLXOQ & $\mathrm{R} * 4$ & & $\begin{array}{l}\text { One-hour centerline } X / Q\left(s / m^{3}\right) \text { in subroutine } \\
\text { WINDYXOQ }\end{array}$ \\
\hline CLXOQ(MAXHOURS) & $\mathrm{R} * 4$ & XOQ & $\begin{array}{l}\text { Vector containing one-hour centerline X/Qs } \\
\left(\mathrm{s} / \mathrm{m}^{3}\right)\end{array}$ \\
\hline DIR1 & $I * 2$ & SCENARIO & $\begin{array}{l}\text { Lower limit of the wind direction window } \\
\text { (farthest counter-clockwise looking into the wind) }\end{array}$ \\
\hline DIR2 & $I * 2$ & SCENARIO & $\begin{array}{l}\text { Upper limit of the wind direction window (farthest } \\
\text { counter-clockwise looking into the wind) }\end{array}$ \\
\hline DIRL(MAXHOURS) & $\mathrm{I} * 2$ & MET & $\begin{array}{l}\text { Vector of hourly wind directions at the lower } \\
\text { measurement level }\end{array}$ \\
\hline
\end{tabular}




\begin{tabular}{|c|c|c|c|}
\hline VARIABLE & TYPE & $\begin{array}{l}\text { INCLUDE } \\
\text { BLOCK }\end{array}$ & DEFINITION \\
\hline DIRU(MAXHOURS) & $\mathrm{I} * 2$ & MET & $\begin{array}{l}\text { Vector of hourly wind directions at the upper } \\
\text { measurement level }\end{array}$ \\
\hline DIST & $\mathrm{R} * 4$ & SCENARIO & $\begin{array}{l}\text { Horizontal distance between the release point and } \\
\text { the receptor }(\mathrm{m})\end{array}$ \\
\hline $\operatorname{DISTR}(102,10)$ & $\mathrm{R} * 4$ & XOQ & $\begin{array}{l}\text { Frequency distribution array prior to subroutine } \\
\text { SUMMARY; cumulative frequency distribution } \\
\text { array following subroutine SUMMARY }\end{array}$ \\
\hline DSY & $R * 4$ & & $\begin{array}{l}\text { Corrections to } \sigma_{y} \text { in subroutines CURVEFIX and } \\
\text { WAKECORR }(\mathrm{m})\end{array}$ \\
\hline DSZ & $\mathrm{R} * 4$ & & $\begin{array}{l}\text { Corrections to } \sigma_{Z} \text { in subroutines CURVEFIX and } \\
\text { WAKECORR (m) }\end{array}$ \\
\hline EFF_HT & $\mathrm{R} * 4$ & & $\begin{array}{l}\text { Vertical distance between the release point and the } \\
\text { receptor }(m)\end{array}$ \\
\hline ELEVATED & $I * 4$ & XOQ & $\begin{array}{l}\text { Counter for the number of hours that the wind } \\
\text { direction is in window, but the } X / Q \text { is }>5 \text { orders } \\
\text { of magnitude below the upper bound of the bins }\end{array}$ \\
\hline END_MET & $L * 1$ & MET & $\begin{array}{l}\text { Logical flag signalling that the end of the } \\
\text { meteorological data has been reached (no more } \\
\text { files) }\end{array}$ \\
\hline FLOW & $\mathrm{R} * 4$ & & $\begin{array}{l}\text { Flow of the effluent release }\left(\mathrm{m}^{3} / \mathrm{s}\right) \text { in subroutine } \\
\text { WINDYXOQ }\end{array}$ \\
\hline Fo & $\mathrm{R} * 4$ & SCENARIO & Flow of the effluent release $\left(\mathrm{m}^{3} / \mathrm{s}\right)$ \\
\hline FIRST_MET & $I * 4$ & MET & Index of the first new meteorological data \\
\hline FIRST_XOQ & $I * 4$ & $\mathrm{XOQ}$ & Index of the first new hourly $X / Q$ values \\
\hline IN_SECT & $I * 4$ & XOQ & $\begin{array}{l}\text { Counter for the number of hours that the wind } \\
\text { direction is in window an wind is }>U \text { min }\end{array}$ \\
\hline JULDAY(MAXHOURS) & $I * 2$ & MET & $\begin{array}{l}\text { Day of the year; } 1=\operatorname{Jan} 1,365 \text { or } 366=\text { Dec } \\
31 \text {. }\end{array}$ \\
\hline LAST_MET & $I * 4$ & MET & Index of the last meteorological data \\
\hline LAST_XOQ & $I * 4$ & $\mathrm{XOQ}$ & Index of the last hourly $X / Q$ values \\
\hline LIMITS & $L * 4$ & XOQ & $\begin{array}{l}\text { Logical flag enabling calculation of the range of } \\
\text { bins for the X/Q frequency distributions }\end{array}$ \\
\hline LOG_FILE & $A * 40$ & UNITS & Name of $\log$ file and path \\
\hline IOG_UNTT & $I * 1$ & UNITS & Logical unit assigned to the log file \\
\hline
\end{tabular}




\begin{tabular}{|c|c|c|c|}
\hline VARIABLE & TYPE & $\begin{array}{l}\text { INCLUDE } \\
\text { BLOCK }\end{array}$ & DEFINITION \\
\hline LOWLIM(10) & $\mathrm{R} * 4$ & XOQ & Vector of lower limits for the $X / Q$ bins \\
\hline MAXFILES & $I * 4$ & PARAM & Maximum number of meteorological data files \\
\hline MAXHOURS & $\mathrm{I} * 4$ & PARAM & $\begin{array}{l}\text { Maximum number of hours of data that can be } \\
\text { stored in memory at one time }\end{array}$ \\
\hline MET_FILE(MAXFILES) & $A * 40$ & UNITS & Vector of meteorological file names and paths \\
\hline MET_UNIT & $I * 1$ & UNITS & Logical unit assigned to the meteorological files \\
\hline MHT1 & $\mathrm{R} * 4$ & SCENARIO & $\begin{array}{l}\text { Measurement height for the lower level of wind } \\
\text { direction and wind speed }(\mathrm{m})\end{array}$ \\
\hline MHT2 & $R * 4$ & SCENARIO & $\begin{array}{l}\text { Measurement height for the upper level of wind } \\
\text { direction and wind speed (m) }\end{array}$ \\
\hline MISS_XOQ & $I * 4$ & $\mathrm{XOQ}$ & $\begin{array}{l}\text { Number of hours for which } X / Q \text { could not be } \\
\text { calculated }\end{array}$ \\
\hline $\mathrm{NA}(10)$ & $I^{*} 4$ & $\mathrm{XOQ}$ & $\begin{array}{l}\text { Vector with nominal number of hours for } \mathrm{X} / \mathrm{Q} \\
\text { averaging periods }\end{array}$ \\
\hline NAVMIN(10) & $I * 4$ & XOQ & $\begin{array}{l}\text { Vector with minimum number of hours for each } \\
X / Q \text { averaging period }\end{array}$ \\
\hline NEXT_MET & $I * 4$ & MET & Number of the next meteorological data file \\
\hline NMETFILE & $\mathrm{I} * 4$ & MET & Number of meteorological data files \\
\hline $\operatorname{NSIGY(7)}$ & $\mathrm{R} * 4$ & MET & $\begin{array}{l}\text { Vector of normal (PAVAN) } \sigma_{y} \text { by stability class } \\
(\mathrm{m})\end{array}$ \\
\hline NSIGY2(7) & $\mathrm{R} * 4$ & MET & $\begin{array}{l}\text { Vector of normal (PAVAN) } \sigma_{y}{ }^{2} \text { by stability class } \\
\left(\mathrm{m}^{2}\right)\end{array}$ \\
\hline $\operatorname{NSIGZ(7)}$ & $\mathrm{R} * 4$ & MET & $\begin{array}{l}\text { Vector of normal (PAVAN) } \sigma_{z} \text { by stability class } \\
(\mathrm{m})\end{array}$ \\
\hline $\operatorname{NSIGZ2(7)~}$ & $\mathrm{R} * 4$ & MET & $\begin{array}{l}\text { Vector of normal (PAVAN) } \sigma_{\mathrm{z}}^{2} \text { by stability class } \\
\left(\mathrm{m}^{2}\right)\end{array}$ \\
\hline OUT_SECT & $I * 4$ & $\mathrm{XOQ}$ & $\begin{array}{l}\text { Counter for the number of hours wind is not in } \\
\text { window, calm, or missing }\end{array}$ \\
\hline QA_FILE & $A * 40$ & UNITS & $\begin{array}{l}\text { Name and path for the file containing the } \\
\text { expanded output }\end{array}$ \\
\hline QA_UNIT & $I^{*} 1$ & UNITS & Logical unit assigned to the expanded output file \\
\hline RECHT & $\mathrm{R} * 4$ & SCENARIO & Receptor (intake) height above grade (m) \\
\hline
\end{tabular}




\begin{tabular}{|c|c|c|c|}
\hline VARIABLE & TYPE & $\begin{array}{l}\text { INCLUDE } \\
\text { BLOCK }\end{array}$ & DEFINITION \\
\hline RHT & $\mathrm{R} * 4$ & SCENARIO & Release height above grade $(m)$ \\
\hline RTYPE & $I^{*} 2$ & SCENARIO & Release type; 1 = ground, $2=$ vent, $3=$ stack \\
\hline SAMAX & $\mathrm{R} * 4$ & $\mathrm{XOQ}$ & Maximum one-hour, sector-average X/Q $\left(\mathrm{m} / \mathrm{s}^{3}\right)$ \\
\hline SAMIN & $\mathrm{R} * 4$ & XOQ & Minimum one-hour, sector-average X/Q $\left(\mathrm{m} / \mathrm{s}^{3}\right)$ \\
\hline SAXOQ & $\mathrm{R} * 4$ & & $\begin{array}{l}\text { One-hour sector-average } \mathrm{X} / \mathrm{Q}\left(\mathrm{s} / \mathrm{m}^{3}\right) \text { in subroutine } \\
\text { WINDYXOQ }\end{array}$ \\
\hline SAXOQ(MAXHOURS) & $\mathrm{R} * 4$ & XOQ & $\begin{array}{l}\text { Vector containing the one-hour, sector-average } \\
\mathrm{X} / \mathrm{Qs}\left(\mathrm{s} / \mathrm{m}^{3}\right)\end{array}$ \\
\hline SCENFILE & $A * 40$ & UNITS & Run specification file name and path \\
\hline SCENUNIT & $\mathrm{I} * 1$ & UNITS & Logical unit assigned to the run specification file \\
\hline SIGMAY & $\mathrm{R} * 4$ & & $\sigma_{y}$ in subroutine NSIGMA \\
\hline SIGMAZ & $\mathrm{R} * 4$ & & $\sigma_{z}$ in subroutine NSIGMA \\
\hline SIGY & $\mathrm{R} * 4$ & & $\begin{array}{l}\sigma_{y} \text { from subroutine NSIGMA in subroutine } \\
\text { WINDYXOQ }\end{array}$ \\
\hline SIGZ & $\mathrm{R} * 4$ & & $\begin{array}{l}\sigma_{Z} \text { from subroutine NSIGMA in subroutine } \\
\text { WINDYXOQ }\end{array}$ \\
\hline SPDL(MAXHOURS) & $I * 2$ & MET & $\begin{array}{l}\text { Vector containing the hourly, lower-level wind } \\
\text { speeds (original measurement units) }\end{array}$ \\
\hline SPDU(MAXHOURS) & $\mathrm{I} * 2$ & MET & $\begin{array}{l}\text { Vector containing the hourly, upper-level wind } \\
\text { speeds (original measurement units) }\end{array}$ \\
\hline SPD_TYPE & $I * 4$ & MET & $\begin{array}{l}\text { Wind speed measurement units; } 1=\mathrm{m} / \mathrm{s}, 2= \\
\mathrm{mph}, 3=\text { knots }\end{array}$ \\
\hline SRAD & $\mathrm{R} * 4$ & SCENARIO & Inside radius of vent or stack (m) \\
\hline STAB(MAXHOURS) & $I * 4$ & MET & Vector containing the hourly stability classes \\
\hline $\operatorname{SUM}(10)$ & $R * 4$ & XOQ & $\begin{array}{l}\text { Vector containing the running sum of hourly } X / Q s \\
\left(s / \mathrm{m}^{3}\right)\end{array}$ \\
\hline SW_CONST & $\mathrm{R} * 4$ & SCENARIO & Sector-width averaging constant \\
\hline $\mathrm{T} 2(10)$ & $\mathrm{R} * 4$ & & $\begin{array}{l}\text { Total number of } X / Q \text { averages considered in } \\
\text { subroutine SUMMARY }\end{array}$ \\
\hline TEST_FLG & $\mathrm{L} * 1$ & UNITS & Logical flag used to control expanded output \\
\hline
\end{tabular}




\begin{tabular}{|c|c|c|c|}
\hline VARIABLE & TYPE & $\begin{array}{l}\text { INCLUDE } \\
\text { BLOCK }\end{array}$ & DEFINITION \\
\hline TOT_MET & $I * 4$ & MET & $\begin{array}{l}\text { Total number of hours of meteorological data read } \\
\text { by subroutine METREAD }\end{array}$ \\
\hline TOT_XOQ & $1 * 4$ & $\mathrm{XOQ}$ & $\begin{array}{l}\text { Total number of hours considered in X/Q } \\
\text { calculations... includes hours of missing data }\end{array}$ \\
\hline TSIGY & $\mathrm{R} * 4$ & MET & $\begin{array}{l}\text { Horizontal diffusion coefficient following } \\
\text { adjustments to account for low wind speed and } \\
\text { building wake }\end{array}$ \\
\hline TSIGZ & $\mathrm{R} * 4$ & MET & $\begin{array}{l}\text { Vertical diffusion coefficient following } \\
\text { adjustments to account for low wind speed and } \\
\text { building wake }\end{array}$ \\
\hline T_DIFF & $\mathrm{R} * 4$ & SCENARIO & $\begin{array}{l}\text { Difference in grade elevation between release } \\
\text { point and receptor (T_DIFF = Grade } \text { RHT }^{-} \\
\text {Grade }_{\text {RECHT }} \text { ) }\end{array}$ \\
\hline UBAR & $\mathrm{R} * 4$ & & $\begin{array}{l}\text { Release height wind speed used in subroutines } \\
\text { WINDYXOQ, CURVEFIX, and WAKECORR }\end{array}$ \\
\hline UMIN & $\mathrm{R} * 4$ & MET & $\begin{array}{l}\text { Nominal minimum wind speed }(\mathrm{m} / \mathrm{s}) \text { below which } \\
\text { wind is assumed to carry effluent from release } \\
\text { point to receptor regardless of reported direction }\end{array}$ \\
\hline UPLIM(10) & $\mathrm{R} * 4$ & $\mathrm{XOQ}$ & Upper limit of the X/Q bins $\left(\mathrm{s} / \mathrm{m}^{3}\right)$ \\
\hline USTAR & $\mathrm{R} * 4$ & MET & $\begin{array}{l}\text { Scaling velocity for wind speed in the boundary } \\
\text { layer }(\mathrm{m} / \mathrm{s})\end{array}$ \\
\hline VAL95(10) & $\mathrm{R} * 4$ & & Vector containing the 95 th percentile $X / Q$ values \\
\hline wo & $\mathrm{R} * 4$ & SCENARIO & Vent or stack effluent vertical velocity $(\mathrm{m} / \mathrm{s})$ \\
\hline WIND_DIR & $I * 2$ & SCENARIO & $\begin{array}{l}\text { Wind direction carrying effluent from release } \\
\text { point directly to receptor (direction of the release } \\
\text { point from the receptor) }\end{array}$ \\
\hline WINDOW & $I * 2$ & SCENARIO & $\begin{array}{l}\text { Nominal width of the wind direction window for } \\
\text { which effluent is carried to receptor (degrees) }\end{array}$ \\
\hline zo & $\mathrm{R} * 4$ & SCENARIO & Surface roughness length (m) \\
\hline ZOL(7) & $\mathrm{R} * 4$ & MET & $\begin{array}{l}\text { Normalized height in the atmospheric boundary } \\
\text { layer }\end{array}$ \\
\hline ZERO(10) & $\mathrm{R} * 4$ & XOQ & $\begin{array}{l}\text { Vector containing the number of periods with } X / Q \\
=0 \text { for each averaging interval }\end{array}$ \\
\hline
\end{tabular}


Distribution

\section{DISTRIBUTION}

\section{Offsite}

38

Division of Radiation Safety and Safeguards

Office of Nuclear Reactor Regulation

U.S. Nuclear Regulatory Commission

Washington, D.C. 20555

R. L. Emch

J. Y. Lee (32)

J. J. Hayes (5)

1 Division of Reactor Accident Analysis Office of Nuclear Regulatory Research U.S. Nuclear Regulatory Commission Washington, D.C. 20555

J. H. Schaperow

1 Division of Regulatory Applications

Office of Nuclear Regulatory Research U.S. Nuclear Regulatory Commission Washington, D.C. 20555
A. K. Roecklein

Onsite

30 Pacific Northwest Laboratory

J. G. Droppo

K6-55

C. J. Fosmire

K9-30

P. C. Hays

K6-62

J. V. Ramsdell (18)

K9-30

S. A. Stage

K9-30

Records Center (2)

K3-70

Publishing Coordination

K1-06

Technical Library (5) 


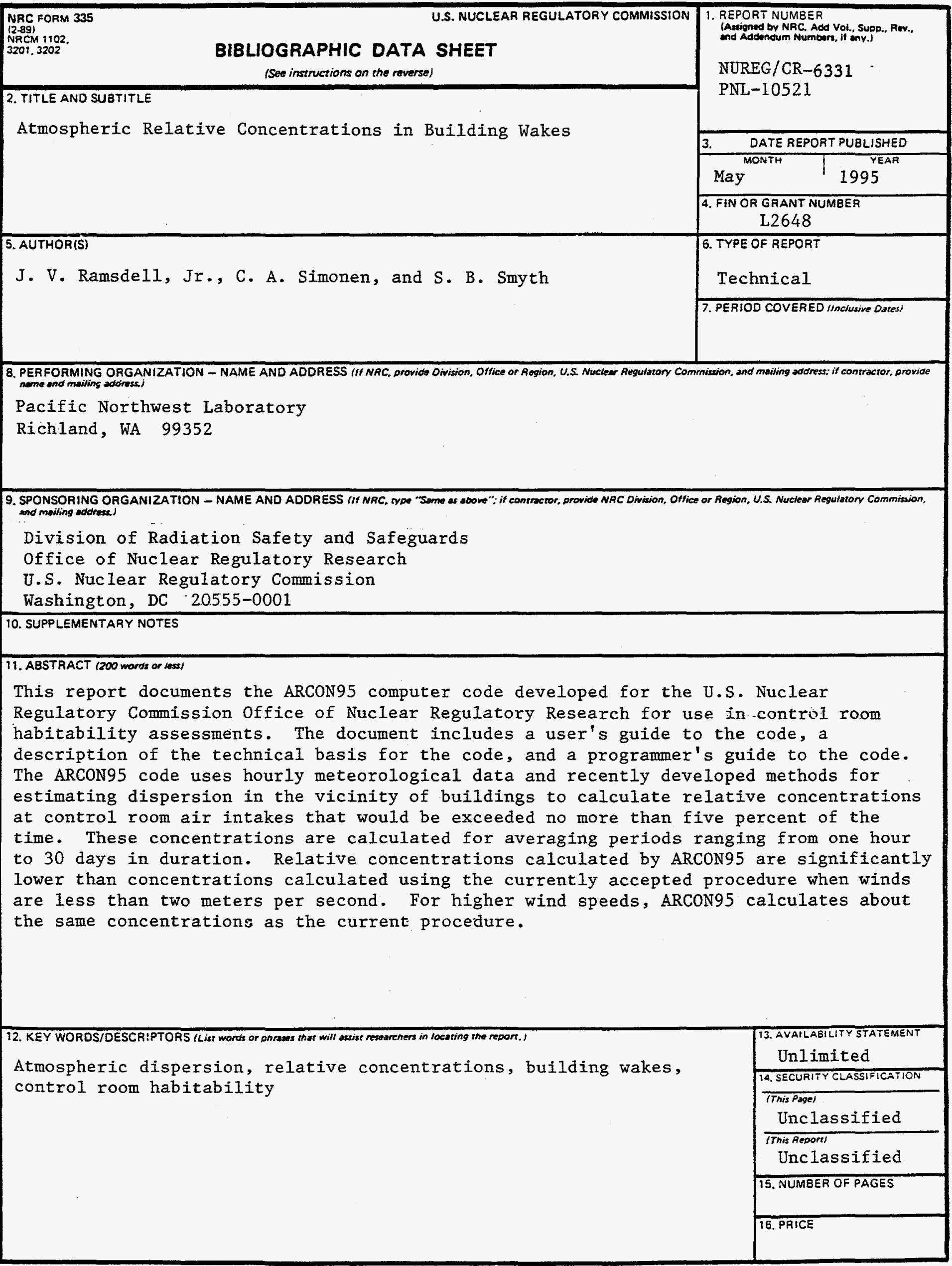

